Florida International University FIU Digital Commons

$10-27-2017$

\title{
Methods for Utilizing Connected Vehicle Data in Support of Traffic Bottleneck Management
}

Samaneh Khazraeian

Florida International University, skhaz001@fiu.edu

DOI: $10.25148 /$ etd.FIDC004061

Follow this and additional works at: https://digitalcommons.fiu.edu/etd

Part of the Transportation Engineering Commons

\section{Recommended Citation}

Khazraeian, Samaneh, "Methods for Utilizing Connected Vehicle Data in Support of Traffic Bottleneck Management" (2017). FIU Electronic Theses and Dissertations. 3496.

https://digitalcommons.fiu.edu/etd/3496 


\title{
FLORIDA INTERNATIONAL UNIVERSITY
}

Miami, Florida

METHODS FOR UTILIZING CONNECTED VEHICLE DATA IN SUPPORT OF TRAFFIC BOTTLENECK MANAGEMENT

\author{
A dissertation submitted in partial fulfillment of \\ the requirments for the degree of \\ DOCTOR OF PHILOSOPHY
}

in

CIVIL ENGINEERING

by

Samaneh Khazraeian 
To: $\quad$ Dean John L. Volakis

College of Engineering and Computing

This dissertation, written by Samaneh Khazraeian, and entitled Methods for Utilizing Connected Vehicle Data in Support of Traffic Bottleneck Management, having been approved in respect to style and intellectual content, is referred to you for judgment. We have read this dissertation and recommend that it be approved.

$\begin{array}{r}\hline \text { Albert Gan } \\ \hline \text { L. David Shen } \\ \hline \text { Xia Jin } \\ \hline \text { Yan Xiao } \\ \hline \text { Zhenmin Chen } \\ \hline \text { Mohammed Hadi, Major Professor }\end{array}$

Date of Defense: October 27, 2017

The dissertation of Samaneh Khazraeian is approved.

Dean John L.Volakis
College of Engineering and Computing

Andrés G. Gil

Vice President for Research and Economic Development and Dean of the University Graduate School

Florida International University, 2017 
(C) Copyright 2017 by Samaneh Khazraeian

All Rights Reserved. 


\section{DEDICATION}

To my dear parents, Tahereh \& Abbas

and

my beloved husband, Farshad 


\section{ACKNOWLEDGMENTS}

I would like to express the most sincere gratitude for my major professor, Dr. Mohammed Hadi, for his guidance, patience and support in navigating the research process. I genuinely believe that he is the best advisor ever. Words cannot express my gratitude for him. He brought me to United States and walked me through a Ph.D. in a fatherly manner. I did not feel the difficulty of the Ph.D. studies for a single moment. I will keep him in my thoughts forever.

I also would like to recognize my professor, Dr. Albert Gan, whose constant support during these four years was warmhearted. I learned much from him in the classroom and can attest that he was one of my best teachers. I am especially grateful to Dr. Yan Xiao for her limitless kindness in sharing her knowledge. I need to thank my dissertation committee members, Dr. Shen, Dr. Jin and Dr. Chen, for taking the time to read my dissertation and provide me with valuable comments.

This dissertation was supported by the National Cooperative Highway Research Program (NCHRP) of the National Academies of Sciences, Engineering, and Medicine, and the Florida International University Graduate School Dissertation Year Fellowship. I would like to thank the NCHRP and FIU graduate school staff for their support.

I will be always thankful to my dear friends, Nishat Zaman, Seyedmirsajad Mokhtarimousavi, Niousha Mesbah, Shirin Noei and Zahra Nafar. Their friendship made my Ph.D. journey more colorful!

Over the last few years, I have been fortunate to be supported by the following

LCTR researchers: Md Shahadat Iqbal, Dr. Tao Wang, Dr. Jianmin Jia, Dr. Aidin Massahi, Md Asif Rayhan and Dr. Kollol Shams. I need to also thank the FIU Civil and 
Environmental Engineering Department Chair, Dr. Atorod Azizinamini and staff, Carlton $\mathrm{Ng}$ and Jessica Teran. I am also thankful to my mentors Mark Plass and Jochen Lohmiller of the PTV group for their encouragement and support.

Last but not least, I would like to thank the smartest husband ever, Farshad. I am so blessed to have him in my life. His support and encouragement has made me who I am today. I would like to express my deepest gratitude to my parents, sisters and brothers. I am also extremely thankful to my father-in-law, Reza, for his limitless support and encouragement. 


\title{
ABSTRACT OF THE DISSERTATION
}

\section{METHODS FOR UTILIZING CONNECTED VEHICLE DATA IN SUPPORT OF TRAFFIC BOTTLENECK MANAGEMENT}

\author{
by \\ Samaneh Khazraeian \\ Florida International University, 2017 \\ Miami, Florida \\ Professor Mohammed Hadi, Major Professor
}

The decision to select the best Intelligent Transportation System (ITS) technologies from available options has always been a challenging task. The availability of connected vehicle/automated vehicle (CV/AV) technologies in the near future is expected to add to the complexity of the ITS investment decision-making process. The goal of this research is to develop a multi-criteria decision-making analysis (MCDA) framework to support traffic agencies' decision-making process with consideration of CV/AV technologies. The decision to select between technology alternatives is based on identified performance measures and criteria, and constraints associated with each technology.

Methods inspired by the literature were developed for incident/bottleneck detection and back-of-queue (BOQ) estimation and warning based on connected vehicle (CV) technologies. The mobility benefits of incident/bottleneck detection with different technologies were assessed using microscopic simulation. The performance of technology alternatives was assessed using simulated CV and traffic detector data in a 
microscopic simulation environment to be used in the proposed MCDA method for the purpose of alternative selection.

In addition to assessing performance measures, there are a number of constraints and risks that need to be assessed in the alternative selection process. Traditional alternative analyses based on deterministic return on investment analysis are unable to capture the risks and uncertainties associated with the investment problem. This research utilizes a combination of a stochastic return on investment and a multi-criteria decision analysis method referred to as the Analytical Hierarchy Process (AHP) to select between ITS deployment alternatives considering emerging technologies. The approach is applied to an ITS investment case study to support freeway bottleneck management.

The results of this dissertation indicate that utilizing $\mathrm{CV}$ data for freeway segments is significantly more cost-effective than using point detectors in detecting incidents and providing travel time estimates one year after $\mathrm{CV}$ technology becomes mandatory for all new vehicles and for corridors with moderate to heavy traffic. However, for corridors with light, there is a probability of $\mathrm{CV}$ deployment not being effective in the first few years due to low measurement reliability of travel times and high latency of incident detection, associated with smaller sample sizes of the collected data. 


\section{TABLE OF CONTENTS}

CHAPTER

PAGE

CHAPTER I : INTRODUCTION ...................................................................... 1

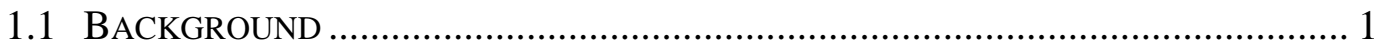

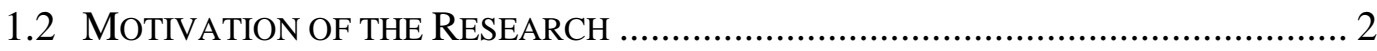

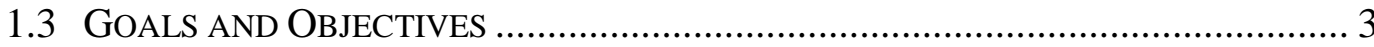

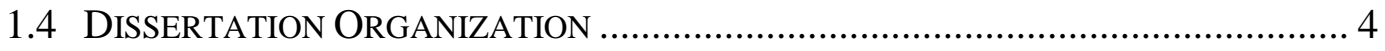

CHAPTER II: LITERATURE REVIEW ….......................................................... 5

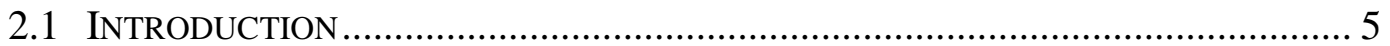

2.2 ConNECTED VEHICLE DATA AND APPLICATIONS............................................. 5

2.2.1 Connected Vehicle Data Elements ................................................. 5

2.2.2 DSRC versus Cellular-Based Technologies..................................... 6

2.2.3 Real-World Connected Vehicle Data Currently Available in the USDOT Research Data Environment (RDE) ................................... 7

2.2.4 Connected Vehicle Applications ................................................ 10

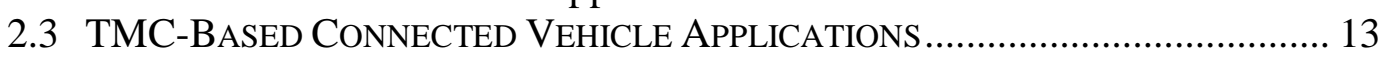

2.3.1 Incident/Bottleneck Detection ................................................. 13

2.3.2 Queue Warning and Back-of-queue Estimation............................. 31

2.4 Multi-CRITERIA DECISION ANALYSIS (MCDA) ...................................... 43

2.4.1 Simple Additive Weighting (SAW) ........................................... 44

2.4.2 Analytic Hierarchy Process (AHP) ............................................. 46

2.4.3 Technique for Order Preference Similarity to Ideal Solution (TOPSIS) .................................................................................. 49

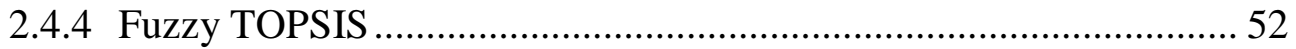

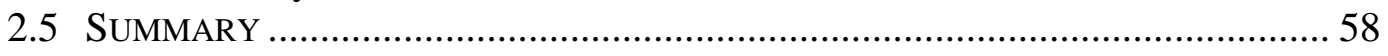

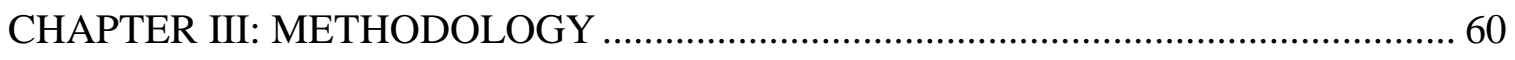

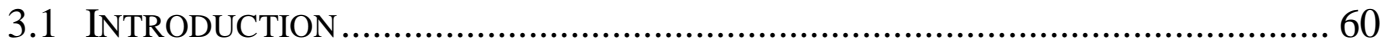

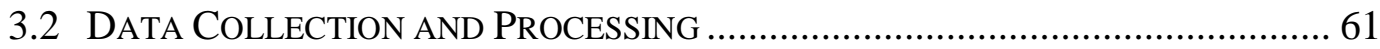

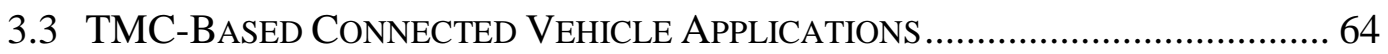

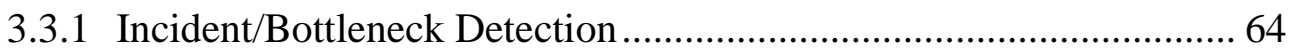

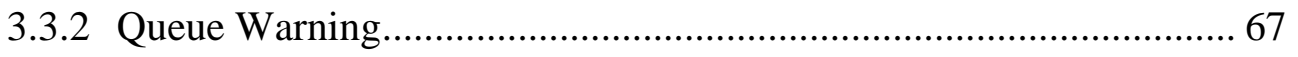

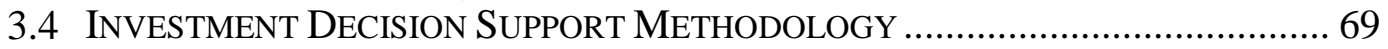

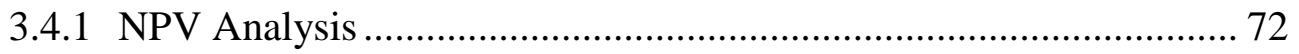

3.4.2 Analytical Hierarchy Process Application ..................................... 79

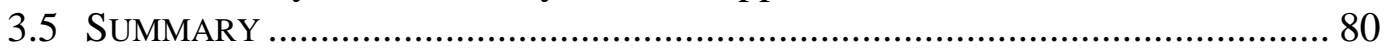

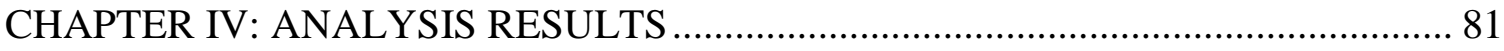

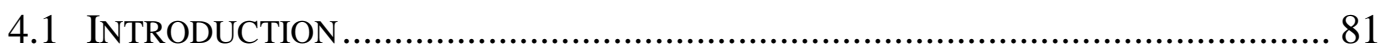

4.2 INCIDENT/BOTTLENECK DETECTION RESULTS ......................................... 81

4.3 QUEUE ESTIMATION AND WARNING RESULTS .......................................... 83

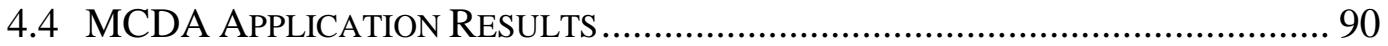


4.4.1 Monte Carlo Simulation Results ................................................ 92

4.4.2 AHP Application Results ............................................................ 93

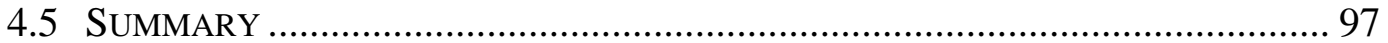

CHAPTER VI: CONCLUSIONS AND RECOMMENDATIONS ............................. 101

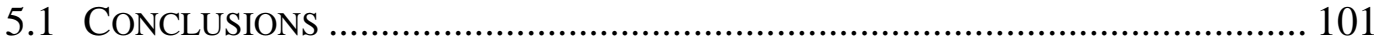

5.2 RECOMMENDATIONS FOR FUTURE WORKS ................................................. 104

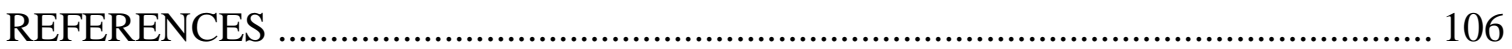

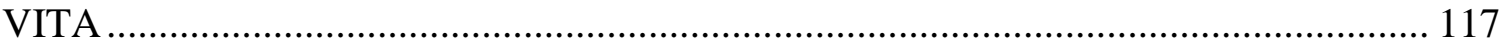




\section{LIST OF TABLES}

TABLE

PAGE

Table 2-1 SAE J2735 Messages and Communication Modes (AASHTO 2013) ............ 6

Table 2-2 A Brief Description of Data Sets in RDE.................................................. 7

Table 2-3 Connected Vehicle Applications (ITERIS 2016) …………………….......... 11

Table 2-4 Summary of Point Detector-Based Algorithm Performances ........................ 22

Table 2-5 Summary of Probe Vehicle-Based Incident Detection Algorithm

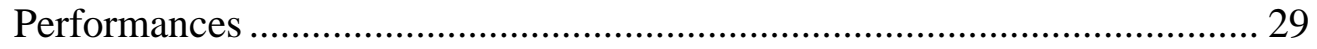

Table 2-6 Detection and False Alarm Rates (\%) ………............................................. 30

Table 2-7 Estimated Detection Time for Minor and Major Incidents ............................. 31

Table 2-8 Summary of Queue Warning Techniques in the United States..................... 34

Table 2-9 Decision Table in MCDM Methods (Venkata Rao 2006)............................... 45

Table 2-10 Value of Attributes (Venkata 2006) ............................................................ 50

Table 3-1 Criteria for Selection between Emerging and Existing Traffic Monitoring and Data Collection Technologies...............................................................72

Table 3-2 CV Deployment Unit Costs...................................................................79

Table 4-1 Mean Time to Detect (MTTD) for Different CV Market Penetrations and

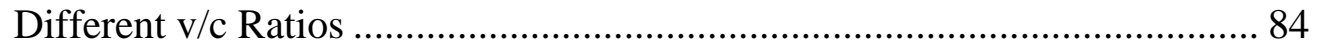

Table 4-2 Derived Equations for MTTD for Different CV Proportions and Different

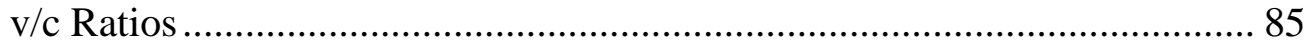

Table 4-3 Error Percentage for Each Market Penetration Rate .................................... 87 
Table 4-4 Statistical Analyses of the Impacts of QWS on the Number of Rear-End Conflicts Utilizing SSAM Model Results .................................................. 91

Table 4-5 Alternatives Performance Measures based on Monte Carlo Runs ............... 92

Table 4-6 Decision Objectives Pairwise Comparison by the Decision Makers ............ 95

Table 4-7 Decision Sub-Criteria Pairwise Comparison by the First Decision Maker ... 98

Table 4-8 AHP Results Based on Decision Maker 1 Ratings................................... 99

Table 4-9 AHP Results Based on Decision Maker 2 Ratings...................................... 99 


\section{LIST OF FIGURES}

FIGURE

PAGE

Figure 2-1 Volume-Occupancy Template Used in the McMaster Algorithm 20

Figure 2-2 Basic Principal of UCB Probed-Based Algorithm 25

Figure 2-3 Comparison of The Posted And Actual Distance To The Back-of-Queue on I-94 in Minnesota-June 14, 2013 (Paterson et al. 2013)..................35

Figure 2-4 The TME Queue Warning Algorithm Proposed by Balke et al. (2014) ........ 37

Figure 2-5 Cloud Based Queue Warning Algorithm Proposed by Balke et al. (2014) ... 39

Figure 2-6 V2V Based Queue Warning System Proposed by Balke et al. (2014)

Figure 2-7 Queue Warning Display Depending on the Vehicle Distance from BOQ Recommended by Balke et al. (2014) ........................................................ 41

Figure 2-8 Triangular Fuzzy Number a (Awasthi et al. 2011) .................................... 53

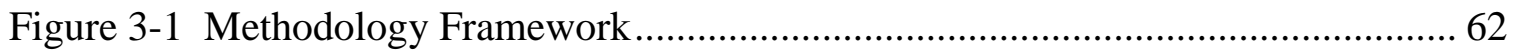

Figure 3-2 Process of Providing Input for the Incident Detection Method .................... 65

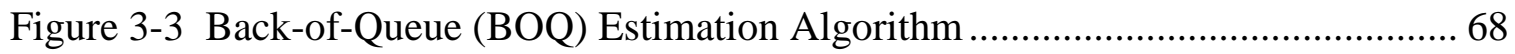

Figure 4-1 Average Error Percentages for Each Run ............................................ 86

Figure 4-2 Estimated Queue Lengths by Connected Vehicle Data vs Detector-Based and Ground Truth-Results Associated with (a) Worst TCA Run (b) Median TCA Run 88

Figure 4-3 Incremental NPV Distributions Based on the CV Deployment vs. Point Detector for Each Year of Starting Utilizing CV Data after CV Technology Becomes Mandated. 


\section{ABBREVIATIONS AND ACRONYMS}

\begin{tabular}{|c|c|}
\hline ASD & Aftermarket Safety Device \\
\hline AHP & Analytic Hierarchy Process \\
\hline AI & Artificial Intelligence \\
\hline AID & Automatic Incident Detection \\
\hline ARIMA & Autoregressive Moving-Average \\
\hline BSM & Basic Safety Message \\
\hline BOQ & Back-of-Queue \\
\hline CAD & Computer Aided Dispatch \\
\hline CAM & Cooperative Awareness Message \\
\hline CCTV & Closed-Circuit Television \\
\hline CDPD & Cellular Digital Packet Data \\
\hline $\mathrm{CHP}$ & California Highway Patrol \\
\hline CVRIA & Connected Vehicle Reference Implementation Architecture \\
\hline DAS & Data Acquisition System \\
\hline $\mathrm{DCF}$ & Discounted Cash Flow \\
\hline DELOS & Detector Logic with Smoothing \\
\hline DR & Detection Rate \\
\hline EOQ & End-Of-Queue \\
\hline FAR & False Alarm Rate \\
\hline FOQ & Front-of-Queue \\
\hline FSP & Freeway Service Patrol \\
\hline GPS & Global Positioning System \\
\hline
\end{tabular}




\begin{tabular}{|c|c|}
\hline INFLO & Intelligent Network Flow Optimization \\
\hline ISD & Integrated Safety Device \\
\hline ITS & Intelligent Transportation System \\
\hline IWZ & Intelligent Work Zone \\
\hline LPF & Low-Pass Filter \\
\hline LV & Low-Volume \\
\hline MAC & Media Access Control \\
\hline MDT & Mobile Data Terminals \\
\hline MM & Mile Marker \\
\hline MTTD & Mean Time to Detect \\
\hline NPV & Net Present Value \\
\hline OBU & On Board Unit \\
\hline PDM & Probe Data Message \\
\hline PET & Post Encroachment Time \\
\hline Q-WARN & Queue Warning \\
\hline QWS & Queue Warning System \\
\hline SAW & Simple Additive Weighting \\
\hline SND & Standard Normal Deviate \\
\hline SPD-HARM & Speed Harmonization \\
\hline SSAM & Surrogate Safety Assessment Model \\
\hline RSD & Retrofit Safety Device \\
\hline RSE & Road Side Unit \\
\hline TCA & Trajectory Conversion Algorithm \\
\hline
\end{tabular}




$\begin{array}{ll}\text { TMC } & \text { Transportation (Traffic) Management Center } \\ \text { TME } & \text { Traffic Management Entity } \\ \text { TRANSCOM } & \text { Transportation Operations Coordinating Committee } \\ \text { TTC } & \text { Time to Collision } \\ \text { TTI } & \text { Texas Transportation Institute } \\ \text { UMTRI } & \text { University of Michigan Transportation Research Institute } \\ \text { USDOT } & \text { United States Department of Transportation } \\ \text { VAD } & \text { Vehicle Awareness Device } \\ \text { V2I } & \text { Vehicle to Infrastructure } \\ \text { V2V } & \text { Vehicle to Vehicle } \\ \text { VTI } & \text { Virginia Tech Transportation Institute } \\ \text { WRTM } & \text { Weather Responsive Traffic Management } \\ \text { WSDOT } & \text { Washington State Department of Transportation }\end{array}$




\section{CHAPTER I}

\section{INTRODUCTION}

\subsection{BACKGROUND}

Traffic Management Centers (TMCs) are increasingly investing in advanced strategies and associated technologies with consideration of the costs and benefits of these implementations. These centers are the hubs for operating and managing traffic and incidents and disseminating information to travelers. The central software, utilized at these centers, enables TMC functionalities, and supports the management and operation of equipment, data source integration, and incident detection and response automation. An important function of these centers is the management of recurrent and non-recurrent bottlenecks. The detection of these bottleneck occurrences and their attributes, including the extent and duration, is an important component of future TMC operations.

Data quality and quantity to support real-time traffic operations and off-line transportation planning, including bottleneck identification, are expected to be significantly affected and improved by emerging connected vehicle technologies. Thus, transportation agencies need to start preparing for the next generation of advanced traffic management strategies that utilize connected vehicle (CV) data. As part of this preparation, the TMC central software needs to be enhanced to be able to capture and process the $\mathrm{CV}$ data to detect and determine the bottleneck characteristics.

Decisions to invest in alternative ITS technologies to support transportation system management and operations (TSMO) are expected to increase in complexity, particularly with the introduction of connected vehicles (CV) and automated vehicles (AV) in the coming years. A survey done as a part of the United States Department of 
Transportation (USDOT) ITS Deployment Tracking Project (Wright et al. 2014) identified safety and mobility benefits, integration with existing technologies, availability of funding, and equipment price as the major factors in the decision-making process for investing in ITS technologies (Gordon et al. 2014). The National CV Field Infrastructure Footprint Analysis document produced by the American Association of State Highway and Transportation Officials (AASHTO) (Wright et al. 2014) pointed out that public agencies will need to assess the use of connected vehicle probe data versus existing methods of data collection when making investment decisions.

\subsection{Motivation OF THE RESEARCH}

Investing in ITS strategies is becoming a challenge for transportation agencies with the introduction of connected and automated vehicle (CV/AV) technologies. Methods are needed to assess the impact of CV/AV on the TMC functionalities such as bottleneck management.

Currently, the available sources of data for TMCs to determine the state of managed systems, including bottleneck occurrence and characteristics, are: traffic sensors, cameras, automatic vehicle re-identification technologies (such as Bluetooth and Wi-Fi readers), and data collected from third-party feeds from HERE, INRIX, and WAZE. Connected vehicle data is a potential alternative for collecting and disseminating data. The collected traffic data provides the required inputs to different ATDM strategies such as incident management and queue warning. However, new algorithms need to be developed to utilize connected vehicle data to support bottleneck detection and characteristics determination as part of the next generation of active traffic and demand management (ATDM). The performance of existing and emerging technologies in 
bottleneck identification can be assessed with the use of new algorithms and used as a basis for the alternative selection process.

The decision to select among various technology alternatives, as proposed in this dissertation, is based on the functions, performance metrics and criteria, and constraints and risks associated with each technology. The decision reached based on these decision elements could be different for different agencies, based on agency objectives and local needs and conditions. Therefore, there is a need to develop a multi-criteria decisionmaking framework that support agencies in their decisions to invest in ITS technologies, with consideration of different criteria, as well as the uncertainties involved in the decision-making process.

\subsection{GOALS AND OBJECTIVES}

This dissertation aims to develop methods to assess the use of connected vehicle data, combined with developed algorithms for use as part of a framework to support agencies in the ITS investment decisions related to traffic bottleneck management. The specific objectives of this dissertation are:

Objective 1: Explore the potential use of connected vehicle data as a source of traffic bottleneck and back-of-queue identification.

Objective 2: Develop a framework that utilizes the results of the abovementioned assessment in the decision-making process and support traffic agencies in ITS investment decisions related to traffic bottleneck management. 


\subsection{Dissertation Organization}

The remainder of this dissertation includes four chapters and is organized as following. Chapter II presents a review of past studies related to the objectives of this research. First, a summary of available real-world CV data and CV applications is presented. Second, a review is presented on two CV applications that help TMCs manage freeway bottlenecks: incident/bottleneck occurrence detection and queue warning. Chapter II also presents a review of multi-criteria decision analysis (MCDA) methods widely used in the transportation field. Chapter III examines the methodology and elaborates on the algorithms developed as a part of this dissertation. Developed methods inspired by the literature are presented for incident/bottleneck detection and queue estimation and warning based on connected vehicle data. The performance of the use of $\mathrm{CV}$ and traffic detector data to support bottleneck management is assessed for use as a part of the proposed MCDA process. A novel MCDA framework (a combination of return on investment and AHP method) is proposed as a part of this dissertation and applied to an ITS investment case study to support the investment decision-making process. The Chapter IV discusses the analysis results of the developed methodology. Chapter V expands on the results presented in Chapter IV and summarizes the findings of this research. 


\section{CHAPTER II}

\section{LITERATURE REVIEW}

\subsection{INTRODUCTION}

This chapter includes three main parts that present reviews of past studies on CV data and its applications, as well as MCDA methods. The first part, CV data and applications, includes the review of studies on bottleneck/incident detection and queue warning and estimation algorithms, as well as a summary of available real-world CV data. The second part discusses some of the main MCDA methods used in the transportation field.

\subsection{CONNECTED VEHICLE DATA AND APPLICATIONS}

This section provides an introduction to the connected vehicle data elements, the communication technologies associated with connected vehicles, available real-world connected vehicle data, and connected vehicle applications.

\subsubsection{Connected Vehicle Data Elements}

The Society of Automotive Engineers (SAE) J2735 (2009) specifies the connected vehicle message types and components. One of the messages specified in the SAE J2735 standard is the basic safety message (BSM), which contains safety-related information and has two parts: BSM Parts I and II. BSM Part I is broadcasted each 10th of a second and contains core data elements, including vehicle position, heading, speed, acceleration, steering wheel angle, and vehicle size. BSM Part II contains optional data elements such as precipitation, air temperature, wiper status, light status, road coefficient of friction, Antilock Brake System (ABS) activation, Traction Control System (TCS) 
activation, and vehicle type. However, not all of these data will be available and mandated by the USDOT. There other types of CV messages specified in the J2735 standards in addition to BSM, as shown in Table 2-1. The data sets used in this study are BSM, Parts I and II.

Table 2-1 SAE J2735 Messages and Communication Modes (AASHTO 2013)

\begin{tabular}{|l|c|c|c|}
\hline \multicolumn{1}{|c|}{ Messages } & V2V & V2I & I2V \\
\hline Basic Safety Message Part 1 & $\checkmark$ & $\checkmark$ & \\
\hline Basic Safety Message Part 2 & $\checkmark$ & $\checkmark$ & \\
\hline Emergency Vehicle Alert & $\checkmark$ & & \\
\hline Common Safety Request & $\checkmark$ & & \\
\hline Probe Data Messages & & $\checkmark$ & \\
\hline Signal Request Message & & $\checkmark$ & \\
\hline Roadside Alert & & & $\checkmark$ \\
\hline Traveler Information & & & $\checkmark$ \\
\hline MAP Data & & & $\checkmark$ \\
\hline
\end{tabular}

\subsubsection{DSRC versus Cellular-Based Technologies}

The messages discussed above are transmitted either via dedicated short range communication (DSRC) or non-DSRC technologies (e.g., cellular, Wi-Fi), or the combination of the two. According to the AASHTO CV Infrastructure Footprint Analysis (Wright et al. 2014), around 80\% $(250,000)$ of the nation's traffic signal locations and 25,000 other roadside locations will be V2I enabled by the year 2040. Based on the aforementioned study, $50 \%$ of the existing ITS sites on freeways, such as vehicle detection stations, DMS, CCTV, and environmental sensor stations will be equipped with DSRC by that time. Many mobility applications do not require the information frequency of $1 / 10$ seconds. The information needs to be repeatedly sent to the infrastructure at a lower, updated rate. 


\subsubsection{Real-World Connected Vehicle Data Currently Available in the USDOT Research Data Environment (RDE)}

One of the options in performing the tasks of this project is to use real-world data collected in previous CV demonstrations. Such data are available from the Research Data Exchange (RDE). RDE is a transportation data sharing system that provides data from different sources to support ITS researchers and developers. The data currently available in the RDE are summarized in Table 2-2.

Table 2-2 A Brief Description of Data Sets in RDE

\begin{tabular}{|c|c|c|c|c|}
\hline $\begin{array}{c}\text { Data Set } \\
\text { Name }\end{array}$ & Location & Time Period & Sample Size & Purpose \\
\hline $\begin{array}{l}\text { Safety Pilot } \\
\text { Model } \\
\text { Deployment } \\
\text { Data }\end{array}$ & $\begin{array}{l}\text { Ann Arbor, } \\
\text { MI }\end{array}$ & $\begin{array}{l}\text { 10/1/2012 - } \\
4 / 30 / 2013 \\
\text { (The data in } \\
\text { October } 2012 \text { and } \\
\text { April } 2013 \text { are } \\
\text { provided in RDE) }\end{array}$ & $\begin{array}{l}\text { Over } 2,700 \\
\text { vehicles }\end{array}$ & $\begin{array}{l}\text {-Explores the real-world } \\
\text { effectiveness of connected } \\
\text { vehicle safety applications in } \\
\text { multi-modal driving conditions } \\
\text {-Evaluates how drivers adapt to } \\
\text { the use of connected vehicle } \\
\text { technology } \\
\text {-Identifies potential safety } \\
\text { benefits as a result of connected } \\
\text { vehicle technology. }\end{array}$ \\
\hline $\begin{array}{l}\text { ITS World } \\
\text { Congress } \\
\text { Connected } \\
\text { Vehicle }\end{array}$ & $\begin{array}{l}\text { The City of } \\
\text { Detroit }\end{array}$ & $\begin{array}{l}9 / 8 / 2014- \\
9 / 10 / 2014\end{array}$ & 9 vehicles & $\begin{array}{l}\text {-Supports a queue estimation } \\
\text { algorithm } \\
\text {-Demonstrates a real-world } \\
\text { implementation of a connected } \\
\text { vehicle environment } \\
\text {-Showcases the operation of the } \\
\text { associated Data Warehouse and } \\
\text { Data Clearinghouse with an } \\
\text { intention to support connected } \\
\text { vehicle research. }\end{array}$ \\
\hline $\begin{array}{l}\text { Road Weather } \\
\text { Demonstration }\end{array}$ & $\begin{array}{l}\text { A short } \\
\text { loop on } \\
\text { Belle Isle, } \\
\text { Detroit, MI }\end{array}$ & $\begin{array}{l}9 / 5 / 2014- \\
9 / 11 / 2014\end{array}$ & & $\begin{array}{l}\text {-For the public demonstration in } \\
\text { September } 2014 \text {. } \\
\text {-Showcases the ability of } \\
\text { instrumented vehicles to collect } \\
\text { vehicle sensor data under the } \\
\text { simulated road weather } \\
\text { conditions and trig advisories or } \\
\text { warnings to travelers. }\end{array}$ \\
\hline $\begin{array}{l}\text { FDOT Orlando } \\
\text { ITS World } \\
\text { Congress }\end{array}$ & Orlando FL & $\begin{array}{l}\text { 9/1/2010- } \\
10 / 22 / 2010\end{array}$ & $\begin{array}{l}\text { A set of Lynx } \\
\text { transit buses }\end{array}$ & $\begin{array}{l}\text {-Tests the capability of Vehicle } \\
\text { Awareness Devices (VADs) to } \\
\text { capture and store data in the } \\
\text { format of the J2735 Basic Safety } \\
\text { Message (BSM) on a large scale. }\end{array}$ \\
\hline NCAR 2010 & $\begin{array}{l}\text { Michigan } \\
\text { Test Bed }\end{array}$ & $\begin{array}{l}1 / 28 / 2010- \\
3 / 29 / 2010 \\
\text { (Only the best }\end{array}$ & $\begin{array}{l}\text { A small set of } \\
\text { vehicles }\end{array}$ & $\begin{array}{l}\text {-Focuses on comparing } \\
\text { atmospheric data from vehicle- } \\
\text { mounted sensors to data from a }\end{array}$ \\
\hline
\end{tabular}




\begin{tabular}{|c|c|c|c|c|}
\hline $\begin{array}{c}\text { Data Set } \\
\text { Name }\end{array}$ & Location & Time Period & Sample Size & Purpose \\
\hline & & $\begin{array}{l}\text { road side unit } \\
\text { (RSE) and on- } \\
\text { board equipment } \\
\text { (OBE) data in six } \\
\text { days are included } \\
\text { in this dataset.) } \\
\end{array}$ & & $\begin{array}{l}\text { nearby fixed weather observing } \\
\text { station. }\end{array}$ \\
\hline NCAR 2009 & $\begin{array}{l}\text { Michigan } \\
\text { Test Bed }\end{array}$ & $\begin{array}{l}/ 6 / 2009- \\
4 / 22 / 2009 \\
\text { (Nine-day RSE } \\
\text { data in April } \\
2009 \text { and six-day } \\
\text { good RSE and } \\
\text { OBE data are } \\
\text { available in the } \\
\text { data set.) }\end{array}$ & $\begin{array}{l}\text { A small set of } \\
\text { vehicles }\end{array}$ & $\begin{array}{l}\text {-Concentrates on collecting data } \\
\text { during periods of rainy or snowy } \\
\text { weather. }\end{array}$ \\
\hline San Diego & $\begin{array}{l}\text { I-5 in San } \\
\text { Diego }\end{array}$ & $\begin{array}{l}1 / 1 / 2010- \\
12 / 31 / 2010\end{array}$ & 10,000 trips & $\begin{array}{l}\text {-Provides multi-modal data and } \\
\text { contextual information (weather } \\
\text { and incidents) that can be used } \\
\text { to research and develop } \\
\text { applications for the USDOT } \\
\text { Dynamic Mobility Applications } \\
\text { (DMA) program. } \\
\text {-One of the four test data sets } \\
\text { acquired by the USDOT Data } \\
\text { Capture and Management } \\
\text { program. }\end{array}$ \\
\hline Pasadena & $\begin{array}{l}\text { Diverse } \\
\text { roadway } \\
\text { network in } \\
\text { and around } \\
\text { the City of } \\
\text { Pasadena, } \\
\text { California }\end{array}$ & $\begin{array}{l}9 / 1 / 2011- \\
10 / 31 / 2011\end{array}$ & & $\begin{array}{l}\text {-Provide multi-modal data and } \\
\text { contextual information (weather } \\
\text { and incidents) that can be used } \\
\text { to research and develop } \\
\text { applications for the USDOT } \\
\text { Dynamic Mobility Applications } \\
\text { (DMA) program. } \\
\text {-One of the four test data sets } \\
\text { acquired by the USDOT Data } \\
\text { Capture and Management } \\
\text { program. }\end{array}$ \\
\hline Portland & $\begin{array}{l}\text { Portland } \\
\text { (including } \\
\text { freeways } \\
\text { and } \\
\text { arterials) }\end{array}$ & $\begin{array}{l}9 / 15 / 2011- \\
11 / 15 / 2011\end{array}$ & & $\begin{array}{l}\text {-Provide multi-modal data and } \\
\text { contextual information (weather } \\
\text { and incidents) that can be used } \\
\text { to research and develop } \\
\text { applications for the USDOT } \\
\text { Dynamic Mobility Applications } \\
\text { (DMA) program. } \\
\text {-One of the four test data sets } \\
\text { acquired by the USDOT Data } \\
\text { Capture and Management } \\
\text { program. }\end{array}$ \\
\hline Seattle & Seattle & $\begin{array}{l}5 / 1 / 2011- \\
10 / 31 / 2011\end{array}$ & & $\begin{array}{l}\text {-Provide multi-modal data and } \\
\text { contextual information (weather } \\
\text { and incidents) that can be used } \\
\text { to research and develop } \\
\text { applications for the USDOT }\end{array}$ \\
\hline
\end{tabular}




\begin{tabular}{|c|c|c|c|c|}
\hline $\begin{array}{c}\text { Data Set } \\
\text { Name }\end{array}$ & Location & Time Period & Sample Size & Purpose \\
\hline & & & & $\begin{array}{l}\text { Dynamic Mobility Applications } \\
\text { (DMA) program. } \\
\text {-One of the four test data sets } \\
\text { acquired by the USDOT Data } \\
\text { Capture and Management } \\
\text { program. }\end{array}$ \\
\hline $\begin{array}{l}\text { Safety Pilot } \\
\text { Model } \\
\text { Deployment - } \\
\text { One Day } \\
\text { Sample }\end{array}$ & $\begin{array}{l}\text { Ann Arbor, } \\
\text { MI }\end{array}$ & $4 / 11 / 2013$ & $\begin{array}{l}\text { Over } 2,700 \\
\text { vehicles }\end{array}$ & $\begin{array}{l}\text {-Serve as the preview of the } \\
\text { larger Safety Pilot Model } \\
\text { Deployment data. } \\
\text {-Intend to help prepare } \\
\text { researchers and application } \\
\text { developers to understand these } \\
\text { data to assist their research and } \\
\text { development activities. }\end{array}$ \\
\hline $\begin{array}{l}\text { Vehicle } \\
\text { Infrastructure } \\
\text { Initiative Proof } \\
\text { of Concept }\end{array}$ & $\begin{array}{l}\text { Michigan } \\
\text { Test Bed }\end{array}$ & $\begin{array}{l}\text { 8/21/2008- } \\
8 / 29 / 2008 \text { (RSE } \\
\text { data for the } \\
\text { public application } \\
\text { tests were } \\
\text { available for } \\
\text { eight days in } \\
\text { August 2008. The } \\
\text { data in this data } \\
\text { set consists of } \\
\text { RSE and OBE } \\
\text { data for the } \\
\text { middle six of } \\
\text { these days.) }\end{array}$ & $\begin{array}{l}52 \text { RSEs } \\
\text { within } 45 \\
\text { square miles } \\
\text { and } 27 \\
\text { vehicles } \\
\text { configured } \\
\text { with OBEs }\end{array}$ & $\begin{array}{l}\text {-Proof of Concept (POC) trials. } \\
\text {-Three major phases were } \\
\text { included in this testing program: } \\
\text { subsystem test, system } \\
\text { integration and test, and public } \\
\text { and private applications test. }\end{array}$ \\
\hline $\begin{array}{l}\text { Leesburg VA } \\
\text { Vehicle } \\
\text { Awareness } \\
\text { Device }\end{array}$ & $\begin{array}{l}\text { Trips in } \\
\text { and around } \\
\text { Leesburg, } \\
\text { VA and } \\
\text { one long } \\
\text { road trip } \\
\text { from Ann } \\
\text { Arbor, MI } \\
\text { to } \\
\text { Leesburg, } \\
\text { VA by way } \\
\text { of eastern } \\
\text { Indiana. }\end{array}$ & $\begin{array}{l}10 / 18 / 2012- \\
12 / 19 / 2012\end{array}$ & $\begin{array}{l}\text { One test } \\
\text { vehicle }\end{array}$ & $\begin{array}{l}\text {-The data set was produced to } \\
\text { give researchers an early sample } \\
\text { of the large data set being } \\
\text { collected as part of the Safety } \\
\text { Pilot Model Deployment } \\
\text { (SPMD). }\end{array}$ \\
\hline $\begin{array}{l}\text { Minnesota } \\
\text { DOT Mobile } \\
\text { Observation } \\
\text { data }\end{array}$ & Minnesota & $\begin{array}{l}6 / 26 / 2013- \\
12 / 21 / 2015\end{array}$ & $\begin{array}{l}310 \\
\text { instrumented } \\
\text { snowplows } \\
\text { and } 19 \\
\text { instrumented } \\
\text { light duty } \\
\text { trucks as of } \\
\text { May } 2013 \text {. }\end{array}$ & $\begin{array}{l}\text {-Provides sample weather and } \\
\text { vehicle engine status data } \\
\text { transmitted in near-real time } \\
\text { from vehicles to MnDOT over } \\
\text { cellular media. (Vehicle-to- } \\
\text { Infrastructure) }\end{array}$ \\
\hline
\end{tabular}


As shown in Table 2-2, 10 out of the 14 datasets are connected vehicle-related data. The Safety Pilot Model Deployment is one of the largest real-world applications of connected vehicles. The Safety Pilot Model was deployed in Ann Arbor, Michigan between October 1, 2012 and April 30, 2013 (Hamilton 2015). Approximately 3,000 vehicles participated in this deployment, including passenger cars, commercial trucks, and buses. Four types of devices were installed in these vehicles, including Integrated Safety Device (ISD), Aftermarket Safety Device (ASD), Retrofit Safety Device (RSD), and Vehicle Awareness Device (VAD). Twenty-six roadside units (RSUs) were installed at signalized intersections and strategic freeway locations.

The dataset of the Safety Pilot Model consists of eight components, including two driving datasets (DAS1 and DAS2), basic safety message (BSM), RSE, and three types of contextual data (weather, network, and schedule). DAS1 is the data collected by the Data Acquisition System developed by the University of Michigan Transportation Research Institute (UMTRI), while DAS2 represents the data collected by the system developed by the Virginia Tech Transportation Institute (VTI). BSM is the basic safety message transmitted to and from an equipped vehicle. RSE is the data received and transmitted by roadside equipment. The contextual data of weather, network configuration and performance, and transit and special event schedule show the conditions that the data were collected.

\subsubsection{Connected Vehicle Applications}

The connected vehicle program of the United States Department of Transportation (USDOT) has defined a set of applications for connected vehicles, as discussed in this section. The Connected Vehicle Reference Implementation Architecture (CVRIA) is a 
connected vehicle architecture developed by the ITS joint program office of the USDOT and is composed of four viewpoints: Physical, Functional, Communication and Enterprise. These viewpoints are modeled in the forms of diagrams, tables, and associated databases (ITERIS 2016). Four types of connected vehicle applications are defined in the CVRIA: Environmental, Mobility, Safety, and Support. There are several applications under each type, as shown in Table 2-3. Table 2-3 displays the applicability of each application to TMC functions.

Table 2-3 Connected Vehicle Applications (ITERIS 2016)

\begin{tabular}{|c|c|c|c|}
\hline Type & Group & Application Name & $\begin{array}{c}\text { Potential } \\
\text { Application to } \\
\text { TMC }\end{array}$ \\
\hline \multirow{13}{*}{ Environmental } & \multirow{8}{*}{$\begin{array}{l}\text { AERIS/Sustainable } \\
\text { Travel }\end{array}$} & $\begin{array}{l}\text { Eco-Multimodal Real-Time Traveler } \\
\text { Information }\end{array}$ & $\square$ \\
\hline & & Eco-Ramp Metering & $\square$ \\
\hline & & Eco-Smart Parking & \\
\hline & & Eco-Speed Harmonization & $\square$ \\
\hline & & Eco-Traffic Signal Timing & $\square$ \\
\hline & & Eco-Transit Signal Priority & $\square$ \\
\hline & & Electric Charging Stations Management & \\
\hline & & Low Emissions Zone Management & \\
\hline & \multirow{5}{*}{ Road Weather } & $\begin{array}{l}\text { Road Weather Information and Routing } \\
\text { Support for Emergency Responders }\end{array}$ & $\square$ \\
\hline & & $\begin{array}{l}\text { Road Weather Information for Freight } \\
\text { Carriers }\end{array}$ & \\
\hline & & $\begin{array}{l}\text { Road Weather Information for } \\
\text { Maintenance and Fleet Management } \\
\text { Systems }\end{array}$ & $\square$ \\
\hline & & $\begin{array}{l}\text { Road Weather Motorist Alert and } \\
\text { Warning }\end{array}$ & $\square$ \\
\hline & & $\begin{array}{l}\text { Variable Speed Limits for Weather- } \\
\text { Responsive Traffic Management }\end{array}$ & $\square$ \\
\hline \multirow{5}{*}{ Mobility } & \multirow{4}{*}{ Public Safety } & $\begin{array}{l}\text { Advanced Automatic Crash Notification } \\
\text { Relay }\end{array}$ & $\square$ \\
\hline & & $\begin{array}{l}\text { Emergency Communications and } \\
\text { Evacuation }\end{array}$ & $\square$ \\
\hline & & $\begin{array}{l}\text { Incident Scene Pre-Arrival Staging } \\
\text { Guidance for Emergency Responders }\end{array}$ & $\square$ \\
\hline & & $\begin{array}{l}\text { Incident Scene Work Zone Alerts for } \\
\text { Drivers and Workers }\end{array}$ & $\square$ \\
\hline & Traffic Network & Cooperative Adaptive Cruise Control & \\
\hline
\end{tabular}




\begin{tabular}{|c|c|c|c|}
\hline Type & Group & Application Name & $\begin{array}{c}\text { Potential } \\
\text { Application to } \\
\text { TMC } \\
\end{array}$ \\
\hline & & Queue Warning & $\nabla$ \\
\hline & & Speed Harmonization & $\nabla$ \\
\hline & & Vehicle Data for Traffic Operations & $\nabla$ \\
\hline & \multirow{5}{*}{ Traffic signals } & Emergency Vehicle Preemption & \\
\hline & & Freight Signal Priority & $\square$ \\
\hline & & Intelligent Traffic Signal System & $\nabla$ \\
\hline & & Pedestrian Mobility & $\nabla$ \\
\hline & & Transit Signal Priority & $\square$ \\
\hline & \multirow{2}{*}{ Traveler Information } & Advanced Traveler Information Systems & $\nabla$ \\
\hline & & Traveler Information- Smart Parking & $\nabla$ \\
\hline \multirow{23}{*}{ Safety } & \multirow{3}{*}{ Transit Safety } & Transit Pedestrian Indication & \\
\hline & & Transit Vehicle at Station/Stop Warnings & \\
\hline & & $\begin{array}{l}\text { Vehicle Turning Right in Front of a } \\
\text { Transit Vehicle }\end{array}$ & \\
\hline & & Curve Speed Warning & $\nabla$ \\
\hline & & In-Vehicle Signage & \\
\hline & & Oversize Vehicle Warning & $\nabla$ \\
\hline & & $\begin{array}{l}\text { Pedestrian in Signalized Crosswalk } \\
\text { Warning }\end{array}$ & $\square$ \\
\hline & & Railroad Crossing Violation Warning & $\nabla$ \\
\hline & & Red Light Violation Warning & $\nabla$ \\
\hline & V2I Safety & $\begin{array}{l}\text { Reduced Speed Zone Warning / Lane } \\
\text { Closure }\end{array}$ & $\nabla$ \\
\hline & & Restricted Lane Warnings & $\nabla$ \\
\hline & & Spot Weather Impact Warning & $\nabla$ \\
\hline & & Stop Sign Gap Assist & \\
\hline & & Stop Sign Violation Warning & \\
\hline & & Warnings about Hazards in a Work Zone & $\nabla$ \\
\hline & & Warnings about Upcoming Work Zone & $\nabla$ \\
\hline & & $\begin{array}{l}\text { Blind Spot Warning + Lane Change } \\
\text { Warning }\end{array}$ & \\
\hline & & Control Loss Warning & \\
\hline & & Do Not Pass Warning & \\
\hline & V2V Safety & Emergency Electronic Brake Light & \\
\hline & & Emergency Vehicle Alert & \\
\hline & & Forward Collision Warning & \\
\hline & & Intersection Movement Assist & \\
\hline
\end{tabular}




\begin{tabular}{|c|c|c|c|}
\hline Type & Group & Application Name & $\begin{array}{c}\text { Potential } \\
\text { Application to } \\
\text { TMC } \\
\end{array}$ \\
\hline & & Motorcycle Approaching Indication & \\
\hline & & Pre-crash Actions & $\square$ \\
\hline & & Situational Awareness & \\
\hline & & Slow Vehicle Warning & \\
\hline & & Stationary Vehicle Warning & \\
\hline & & Tailgating Advisory & \\
\hline & & Vehicle Emergency Response & \\
\hline \multirow{9}{*}{ Support } & \multirow{8}{*}{ Core Services } & Core Authorization & $\nabla$ \\
\hline & & Data Distribution & $\square$ \\
\hline & & Infrastructure Management & $\nabla$ \\
\hline & & Location and Time & $\square$ \\
\hline & & Map Management & $\square$ \\
\hline & & Object Registration and Discovery & $\nabla$ \\
\hline & & Privacy Protection & $\nabla$ \\
\hline & & System Monitoring & $\nabla$ \\
\hline & Security & Security and Credentials Management & $\square$ \\
\hline
\end{tabular}

The description of each application and the subset of CVRIA that belongs to that application, including physical and enterprise diagrams, processes, requirements and security, are available online (ITERIS 2016). A subset of the applications that support TMC operations will be investigated in this study, including incident detection as a special case of bottleneck identification and queue warning.

\subsection{TMC-Based CONNECTEd Vehicle ApPlications}

As stated in the previous section, this study explores the use of CV data to support two TMC operation applications: incident/bottleneck detection and queue warning.

\subsubsection{Incident/Bottleneck Detection}

An Automatic Incident Detection (AID) system aims to detect incident occurrence automatically utilizing traffic data such as speed, volume and occupancy. An AID system 
has two components: a data collection system and an incident detection algorithm. The data collection system provides real-time traffic data such as speed, occupancy, and flow using data collection devices (e.g., point detectors, CCTV cameras, tag readers, Bluetooth, etc.). The collected data is analyzed through incident detection algorithms to declare the incident occurrence. The performance of incident detection algorithms is normally evaluated using three commonly used performance measures: detection rate (DR), false alarm rate (FAR) and mean time to detect (MTTD) (Parkany et al. 2005, Mahmassani et al. 2005). DR is the ratio of number of correct detections by the total number of actual incidents occurring in a time period and is shown in the following equation:

$$
D R=\frac{\text { Number of correct detections }}{\text { Total Number of incidents }} * 100 \%
$$

Different researchers have defined FARs differently for different purposes. $\mathrm{FAR}_{\text {online }}$ and $\mathrm{FAR}_{\text {off-line }}$ are the two main definitions found in the literature. $\mathrm{FAR}_{\text {online }}$ is the percentage of the number of incorrect decisions relative to the total number of algorithm decisions (all the declared alarms), while FAR $_{\text {off-line }}$ is the ratio of algorithm incorrect decisions by the number of algorithm applications (Wu et al. 2013). The two FAR definitions are shown in the following equations:

$$
\begin{aligned}
& F A R_{\text {online }}=\frac{\text { Number of incorrect detections }}{\text { Total number of algorithm decisions }} * 100 \% \\
& F A R_{\text {off-line }}=\frac{\text { Number of incorrect detections }}{\text { Total number of algorithm decisions }} * 100 \%
\end{aligned}
$$


MTTD is the difference between the estimated incident time by the algorithm and the detected incident time, which is shown below.

$$
\text { MTTD = Estimated incident time }- \text { detected incident time }
$$

The following section presents an extensive literature review on the existing incident/bottleneck detection algorithms. The classification of AID can be based on the underlying algorithm or the data collection system, as described below.

Generally, the AID methods are categorized into six groups and are based on the underlying algorithm:

- comparative algorithms

- $\quad$ statistical algorithms

- time-series algorithms

- filtering based algorithms

- traffic modeling algorithms

- artificial intelligence algorithms

Each of these algorithm categories is described below.

The logic behind comparative algorithms is comparing traffic flow characteristics such as speed and occupancy upstream and downstream of the incident location. These algorithms are based on the fact that these characteristics upstream of the incident are different from the ones downstream of the incident. An alarm is declared when the difference between the downstream and upstream measurements exceeds a predefined threshold.

The California series algorithms initially proposed by Payne et al. (1976) are the most known comparative algorithms. These algorithms use occupancy measurements 
obtained from point detectors and compare the upstream and downstream occupancies of two adjacent detectors. This difference passes through three conditions with three different thresholds: 1) the absolute difference between downstream and upstream occupancy; 2) the relative difference between downstream and upstream occupancy compared to the upstream occupancy; and 3) the relative difference between downstream and upstream occupancy compared to the downstream occupancy. Ten versions of the California algorithms were developed based on the initial logic. These algorithms were implemented in Los Angeles and Minneapolis. The offline test results show that Algorithm \#7 and Algorithm \#8 (Payne et al. 1978) had the best performance among the tested versions. The California algorithms are popular due to their ease of implementation and simple logic.

Statistical algorithms detect incidents using statistical techniques. The two main statistical incident detection algorithms are the standard normal deviate (SND) algorithm and the Bayesian algorithm.

The SND was developed in 1970 by Dudek et al. (1974) at the Texas Transportation Institute (TTI) and used in Houston, Texas. The standard normal deviation of a traffic flow parameter is calculated by the algorithm and then compared with a threshold. If the SND is bigger than the threshold, the incident alarm is triggered. Based on the results of the SND algorithm evaluation from the Gulf Freeway in Houston, the algorithm was able to detect the incident in 1.1 minutes, with a 1.3\% FAR and 92\% DR. Aggregated point detector occupancy data at a one-minute interval was used as input to the algorithm. 
The Bayesian algorithm was proposed by Levin and Krause (1978). The algorithm uses the frequency distributions of the difference between downstream and upstream occupancy under incident and no-incident conditions. Having the distributions, the probability of a set of data that belong to incident and no-incident conditions is calculated. If the ratio of the probabilities is more than a threshold, the incident alarm is triggered. The offline version of the algorithm was tested in the J.F. Kennedy Expressway in Texas. The study concluded that the Bayesian algorithm has better performance than the California algorithm in terms of DR and FAR, but has a higher MTTD with $100 \%$ DR, 0\% FAR and a 4-minute MTTD.

Time-series algorithms are based on the principle that traffic flow follows a predictable pattern. The short-term traffic condition is predicted by these algorithms, and if the measured traffic parameters deviate significantly from the predicted values, the incident occurrence is declared.

One of the well-known time series algorithms is the autoregressive movingaverage (ARIMA) method developed by Ahmed and Cook (1977). Occupancy is used as the input to the controller. The algorithm is based on the principle that the difference between occupancy at time step $\mathrm{t}$ and time $\mathrm{t}-1$ can be forecasted by averaging the errors between the observed and predicted values in the past three time steps. The errors are supposed to follow a normal pattern in an incident-free condition, while the abnormal errors indicate the incident presence. The ARIMA algorithm was tested offline, and the results were compared with the California and the double exponential smoothing algorithm. The paper concluded that the ARIMA outperformed the other two algorithms by having $100 \%$ DR, 1.4\% FAR and less than a 1.5-minute MTTD. 
Smoothing/filtering-based algorithms remove the short-term noise that causes false alarms from raw detector data and makes the changes in traffic patterns more visible. The technique for calculating the weighted average of a traffic variable is called "smoothing." Filtering algorithms use a linear filter to remove undesirable high frequency components of the data and pass through the low-frequency ones. The double exponential smoothing (DES) algorithms, low-pass filter (LPF) algorithms, and the discrete wavelet transform and linear discriminant analysis (DWT-LDA) algorithms belong to the smoothing/ filtering-based algorithms category.

The DES algorithm calculates a weighted average of the past and present values of traffic variables to predict short-term traffic conditions. A tracking signal, which is the sum of all of the previous errors between the forecasted and observed traffic variable, is calculated. If the tracking signal deviates from zero and reaches a predefined threshold, the incident alarm is triggered. This algorithm was tested by Cook and Cleveland (1974), who used occupancy and flow as control variables. The study results show that the DES algorithm outperforms the California algorithm in terms of MTTD, but has a higher FAR.

The low-pass filter (LPF) algorithm, which is also called the Minnesota algorithm or the DELOS (detector logic with smoothing), was proposed by Stephanedes and Chassiakos (1993). The LPF algorithm removes high frequency components (noise) and passes low frequency fluctuations. The spatial difference between downstream and upstream occupancies is used as the control variable. The method employs two different filters (with a 3-minute and 5-minute moving average of occupancies) and three smoothing methods: statistical median, moving average and exponential smoothing. The data from the I-35W Freeway in the Twin Cities was used to evaluate the LPF method 
performance. The study concluded that the algorithm outperforms the California \#7 and time series algorithm proposed by Ahmed and Cook (1977) by having a 0.15\% FAR.

The DWT algorithms were originally developed for the purpose of signal and image processing. It has been widely used by researchers to detect incidents. It uses the wavelet transform to extract the traffic features under incident and no-incident conditions. It has been shown that the extracted traffic features under incident conditions differ significantly from normal conditions. Teng and Qi (2003) used the DWT algorithm for incident detection. The occupancy difference between two consecutive detectors was used as the input to the wavelet transform algorithm. Based on the study's findings, the DWT algorithm was found to have a superior performance, compared to the California algorithm and the low-pass filter algorithms, based on examining the detection rate versus the false alarm rate curves.

Traffic modeling algorithms use traffic flow-based models to predict traffic behaviors under incident conditions and detect the incidents by comparing the observed traffic measurements and the predicted values by the model. Two representative traffic modeling algorithms are the catastrophe theory model (MacMaster algorithm) and the low-volume (LV) incident detection algorithm.

The MacMaster algorithm is the most well-known traffic modeling-based incident detection algorithm that utilizes volume and occupancy obtained from point detectors to detect abrupt changes to regular traffic patterns. This method utilizes a volumeoccupancy template composed of four regions, as shown in Figure 2-1 (the uncongested traffic, low-occupancy congestion, high-occupancy congestion, and downstream bottleneck regions). This template needs to be developed for each location by using 
historical data. The MacMaster algorithm has been modified by other researchers (Forbes et al. 1990, Hall et al. 1993, Gall et al. 1989). Hall et al. (1993) evaluated the MacMaster algorithm using field data from the Burlington Skyway in Ontario, Canada and Queen Elizabeth Way in Mississauga, Canada. The results showed a good performance of the algorithm.

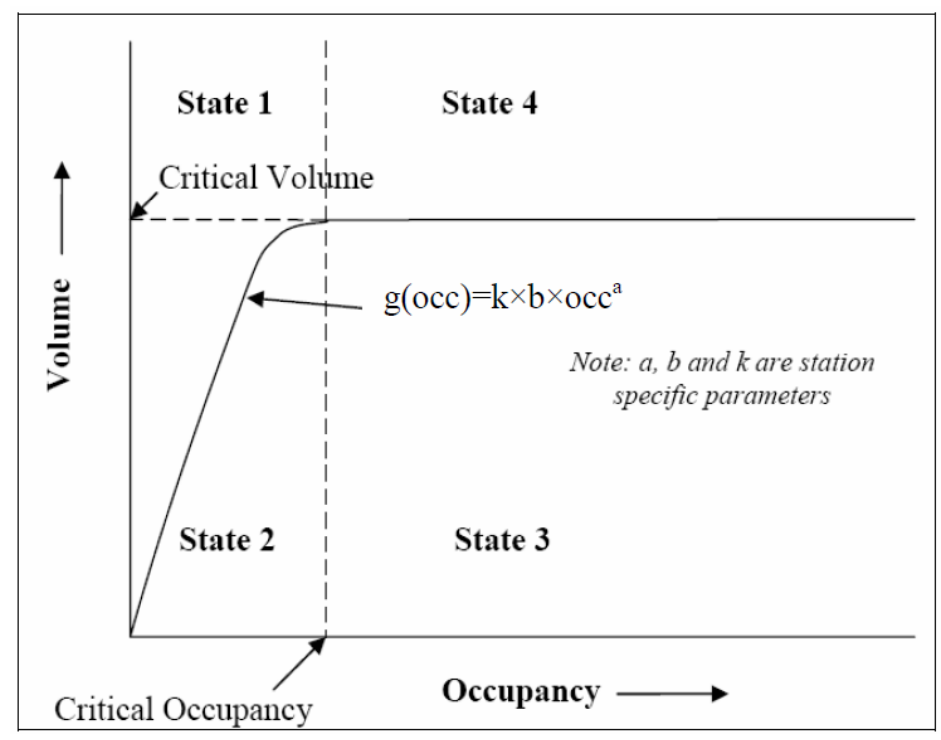

Figure 2-1 Volume-Occupancy Template Used in the McMaster Algorithm (Forbes et al. 1990)

The low-volume (LV) algorithm (Fambro et al. 1979) is designed to detect incidents in non-congested conditions when the incident does not lead to severe congestion. Unlike the aforementioned algorithms, the LV algorithm relies on individual vehicle data entering the roadway network. The vehicles' exiting times are predicted based on vehicle speeds and entering times. Then, the predicted exiting time is compared with the observed existing time, and the decision about the incident occurrence is made.

Artificial intelligence (AI) algorithms detect the incidents using either a rulebased technique or a training-based technique. Examples of the utilized methods are 
neural networks (Stephanedes et al. 1995), fuzzy logic (Ching-Ping Chang et al. 1994) or combinations of the two.

Fuzzy logic was first used by Chang et al. (1994) to supplement the California \#8 algorithm in order to improve it. The fuzzy algorithm does not generate an incident alarm. Rather, it provides the probability of an incident, given a set of traffic data (occupancy). Fuzzy logic aims to remove sharp crisp thresholds and use fuzzy sets instead. The decision tree in the California algorithm was also replaced by the fuzzy rules.

Neural network algorithms are designed based on the human brain neural system. Neural-based automatic incident detection algorithms usually have three layers: the input layer that processes the traffic sensor data, the intermediate layer, which analyzes the data, and the output layer, which generates the incident or no-incident alarm. The network is trained to generate appropriate weights to the inputs and to process them to generate the alarms. The early attempt to use neural network for incident detection was conducted by the University of California, Irvine (Ritchie et al. 1993) and University of Minnesota (Dia et al. 1997) in the 1990s. Based on the results, the neural-based algorithm outperformed the California algorithm by achieving an $85 \%$ detection rate, $0.075 \%$ false alarm rate, and a 3-minute MTTD. According to the University of Minnesota's results, the performance was not as good as the University of California study, yet it was promising. Table 2-4 presents a summary of the algorithms presented in the previous section.

The AID methods can also be grouped based on the corresponding data collection system, as follows: 
- detector-based detection

- probe-based detection

- driver-based detection

Table 2-4 Summary of Point Detector-Based Algorithm Performances

\begin{tabular}{|l|c|c|c|l|}
\hline \multicolumn{1}{|c|}{ Algorithm Name } & $\begin{array}{c}\text { DR } \\
(\%)\end{array}$ & $\begin{array}{c}\text { MTTD } \\
(\mathbf{m i n})\end{array}$ & FAR (\%) & \multicolumn{1}{c|}{ Location } \\
\hline California & 82 & 0.85 & 1.73 & $\begin{array}{l}\text { California, Chicago, } \\
\text { Texas }\end{array}$ \\
\hline SND & 92 & 1.1 & 1.3 & Huston \\
\hline Bayesian & 100 & 4 & 0 & Texas \\
\hline McMaster & 68 & 2.2 & 0.0018 & Minnesota \\
\hline ARIMA & 100 & 1.5 & 1.4 & - \\
\hline $\begin{array}{l}\text { DES (Double Exponential } \\
\text { Smoothing) }\end{array}$ & - & $\begin{array}{l}\text { Better } \\
\text { than } \\
\text { California }\end{array}$ & $\begin{array}{l}\text { Higher } \\
\text { Than } \\
\text { California }\end{array}$ & - \\
\hline LPF (Low-Pass Filter) & - & - & 0.15 & Twin Cities \\
\hline Neural Networks & 85 & 3 & 0.075 & - \\
\hline $\begin{array}{l}\text { Neural Networks (Martin, et al., } \\
\text { 2009) }\end{array}$ & 89 & 0.96 & 0.012 & $\begin{array}{l}\text { Modeling, Simulation } \\
\text { and Analysis (MSA) }\end{array}$ \\
\hline LPF (Stephanedes, et al., 1991) & 80 & 4 & 0.3 & Modeling \\
\hline DES (Cook, 1974) & 92 & 0.7 & 1.87 & Toronto \\
\hline Bayesian (Levin, et al., 1979) & 100 & 4 & 0 & Modeling \\
\hline
\end{tabular}

The three groups are described in the following subsections.

Detector-based algorithms that use point-detector data were covered in the previous section and summarized in Table 2-4.

As mentioned earlier, most of the traditional automatic incident detection algorithms use point detector data to detect incidents. However, there are some disadvantages of using point detector data. The main drawback of the point detectorbased methods is that they cannot detect the incident until the queue caused by the incident reaches the upstream detector (Chue et al. 2002), which may take a long time or may never happen if the queues due to incidents are short or do not exist. These algorithms were also found to produce large numbers of false alarms (Stephanedes et al. 
1992, Mahmassani et al. 1998, Petty et al. 1997). Furthermore, these sensors cannot be deployed all over the network, as they are expensive and cannot cover the entire network. It is also difficult to realize the true traffic conditions, as sensors collect spot traffic data. Incidents may be detected more efficiently using travel time measurements collected by probes (e.g., Bluetooth, Wi-Fi, electronic toll tag readers and global positioning system (GPS)), as they have a wider roadway coverage. A study by TTI examined the feasibility of using probe vehicles in freeway incident detection (Balke et al. 1996). Two hundred trained commuters were asked to report their position as they passed reference points using cellular phone calls. The vehicles were tracked using their probe identification number by operators in the center, and their travel times were estimated between two adjacent reference points. Reference points were located evenly spaced, approximately 5 miles apart at key interchanges. The algorithm was developed based on the standard normal deviates (SND) principal. If the probes travel time is longer than a threshold calculated according to this principal, the incident alarm is triggered. The threshold is calculated as shown in the following equation:

$$
\text { Threshold }=\bar{t}_{i}+S N D * s_{i}
$$

where,

$\bar{t}_{i}=$ historical average travel time for a given time of day interval, $S N D=\mathrm{z}$ value for a normally distributed population, and

$s_{i} \quad=$ standard deviation of the average travel time in the same interval.

Based on the preliminary results, the TTI algorithm is worse than most of the common loop detector algorithms. It should be noted that this is most likely due to the low market penetration of probe vehicles. 
The Upper Confidence Bound (UCB) algorithm was developed by Petty et al. (1997) and utilizes information from vehicles equipped with radio transponders on the I880 Freeway in Hayward, California. The radio transponder can communicate with the existing cellular phone stations via the cellular digital packet data (CDPD) protocol. The probed data is transmitted to the station, and then from the station to the TMC for further analysis. The probe vehicle's headway was calculated as 6-8 minutes, which indicates an approximately $0.08-0.1 \%$ market penetration. The algorithm works based on the principal that vehicles change their speed and acceleration when passing the incident location. Hence, the location of the incident is detected by observing the probe vehicle's speed and acceleration profile, and if the acceleration falls above a threshold $(\alpha)$ with a certain speed $\left(v_{t}\right)$, incident occurrence is declared (Figure 2-2). The reason for including $\left(v_{t}\right)$ is to eliminate the large accelerations occurring in the stop-and-go traffic. The paper concluded that the probe-based algorithm is feasible and does not have some of the infrastructure-based problems that loop-based algorithms experience.

Mouskos et al. (1998) conducted a study to evaluate the performance of the Transportation Operations Coordinating Committee (TRANSCOM) System for Managing Incidents and Traffic (TRANSMIT). The TRANSMIT algorithm uses travel times estimated from probe vehicles equipped with electronic toll tags for traffic surveillance and incident detection. The system was installed on a 22-mile section of the Garden State Parkway in New Jersey and the New York State Thruway, where more than 1.5 million vehicles were equipped with tags as part of the system. 

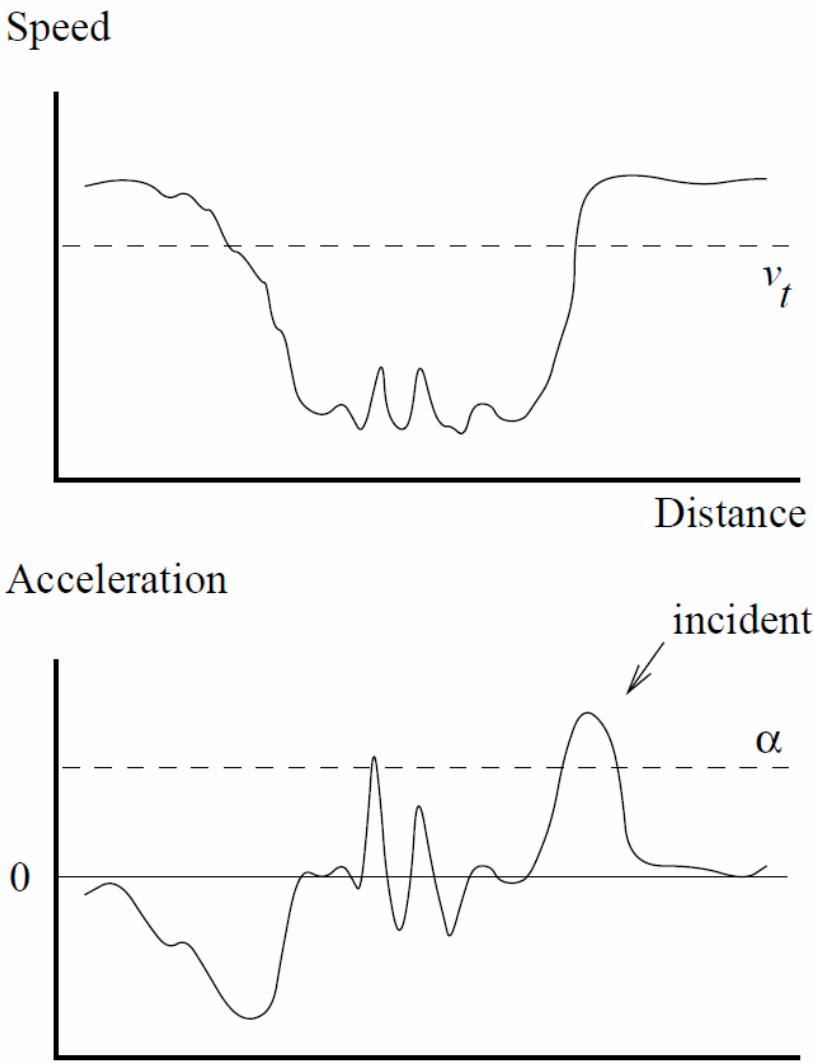

Distance

Figure 2-2 Basic Principal of UCB Probed-Based Algorithm (Petty et al. 1997)

Roadside readers were placed at distance intervals of 0.5-2.1 miles along the corridor, which related the tag identification number, location, lane position and time information to the TMC when an equipped vehicle passed the readers. The TRANSMIT algorithm is similar to the TTI algorithm mentioned above and assumes that a vehicle's travel time is normally distributed, and the incident alarm is declared when multiple successive probe vehicles arrive later than expected to the downstream reader. The threshold for declaring the incident occurrence is shown in the following equation.

$$
T H_{i}=H T_{i}+M S D * H S D_{i}
$$

where,

$H T_{i} \quad=$ historical average travel time for time interval $i$, 
$H S D_{i}=$ standard deviation of historical travel time, and

MSD $=$ a multiplier that was set to 3 in the TRANSMIT algorithm.

The probability of a false alarm for vehicle $\mathrm{j}$ during the time interval $\mathrm{i}$ is calculated using the equation below:

$$
P\left(F A_{i, j}\right)=P\left(E_{i}\right)+P\left(N E_{i}\right) * P\left(L T_{i}\right)
$$

where,

$$
\begin{aligned}
P\left(E_{i}\right)= & \text { probability of exiting the probe vehicle from the corridor before } \\
& \text { reaching the downstream reader, } \\
P\left(N E_{i}\right)= & \text { probability that a vehicle does not exit, and } \\
P\left(L T_{i}\right)= & \text { probability of the probe vehicle arriving at the downstream reader } \\
& \text { later than expected for a non-incident reason. }
\end{aligned}
$$

Findings of the study show that the algorithm is comparable to the common loopbased algorithms. The detection rate for most of the roadside terminals (RST) was $100 \%$, and was 28 to $61 \%$ for the fewer terminals due to anomalies in the reader transmission rate.

Crabtree et al. (2007) examined the use of connected vehicle data communicated using DSRC to detect freeway incidents. The CORSIM microsimulation tool was used to simulate the incidents, and an output post-processing was conducted to generate connected vehicle probe data. The algorithm was based on the comparison between measured travel time and "normal" travel time estimated based on no-incident conditions data. The travel time threshold used in the study was set to one-third of the travel time standard deviation with a minimum of 20 seconds, and a maximum of 60 seconds. The results showed that the proposed algorithm can rapidly and reliably detect incidents. The 
study concluded that for a market penetration of $30 \%$ (25\% trucks, $5 \%$ cars) the MTTD ranges from 2 to 4 minutes for a reader spacing of 2 miles and 2.5 to 14 minutes for a reader spacing of 10 miles.

In 2015, Asakura et al. (2015) proposed two incident detection algorithms based on data collected from probe vehicles equipped with on-board GPS equipment. The AIMSUN microsimulation tool was used as the traffic simulator to assess the algorithms. One of the algorithms was based on the comparison of probe vehicle travel time on two consecutive links. If the average vehicle's travel time on the upstream link is more than the downstream link, a bottleneck is detected in the upstream link. The second algorithm is based on backward congestion shockwave detection using three GPS-equipped consecutive vehicles. The paper concluded that the first algorithm (Algorithm I) produced a DR, FAR and MTTD of 55\%, $0.041 \%$, and 14.8 minutes at $1 \%$ market penetration, all of which indicate a higher detection rate and false alarm compared to the second algorithm (Algorithm II), which produced a DR, FAR and MMTD of 19.1\%, 0.0021\%, and 7.9 minutes at $1 \%$ probe market penetration. Different market penetrations were tested, and when the market penetration was more than $0.5 \%$, the Algorithm I results were satisfactory. Algorithm II had its best performance when the market penetration reached 5\% with a DR, FAR, and MTTD of 50\%, 0.00022 and 6.4 minutes, respectively (Asakura et al. 2015).

A Bluetooth-based arterial incident detection method was proposed by $\mathrm{Yu}$ et al. in 2015. The incident detection algorithm uses travel time and Media Access Control (MAC) address counts based on Bluetooth device measurements. A moving average over time was used to detect the traffic patterns resulting from incidents. The paper concluded 
that the DR and FAR that could be obtained using this method are $75 \%$ and $0 \%$, respectively, at $6 \%$ market penetration. There is no information about the MTTD performance in the paper.

Chue et al. (2002) proposed a mobile sensor and sample-based algorithm (MOSES) that detects the incident based on the statistical difference in the mean travel time of two sets of probe vehicle samples before and during incidents. The Paramics microsimulation tool was used to model the network. The paper concluded that freeway incident detection time varies from 12 minutes at 5\% market penetration to 3-4 minutes at $50 \%$ market penetration. The DR was found to range from $50 \%$ to $90 \%$, and the FAR was found to range between $0.5 \%$ to $2 \%$ when the market penetration varies between $20 \%$ and 50\%. A summary of the probe-based algorithm performances reviewed above and other algorithms are shown in Table 2-5.

In driver-based algorithms, incidents are detected directly by road users using cellular phones (call to 911 or TMC), service patrol vehicles, police cruises, roadside call boxes, and calls by public entity personnel (roadway maintenance crews, transit operators, fire departments, etc.). One of the advantages of driver-based detection is that the location, severity, and type of incident can be described easily. The methods can provide broader monitoring coverage than the other existing surveillance systems and has the ability to cover both minor and major roads (Parkany et al. 2005).

Skabardonis et al. (1998) evaluated the cellular phone-based incident detection on a 9-mile section of I-880 in the San Francisco Bay Area and compared it with the following diver-based methods: 
- California Highway Patrol (CHP) calls: calls from CHP officers patrolling about 50 freeway segments (each segment 10 miles in length);

- Call boxes: calls from the roadside call boxes used by motorists to report the incidents;

Table 2-5 Summary of Probe Vehicle-Based Incident Detection Algorithm Performances

\begin{tabular}{|c|c|c|c|c|c|}
\hline $\begin{array}{l}\text { Algorithm } \\
\text { Name }\end{array}$ & $\begin{array}{c}\text { Probe } \\
\text { Technology }\end{array}$ & $\begin{array}{c}\text { Penetration } \\
\text { Rate }\end{array}$ & $\begin{array}{c}\text { Environment } \\
\text { Type }\end{array}$ & $\begin{array}{c}\text { Data } \\
\text { Requirement }\end{array}$ & MMTD \\
\hline $\begin{array}{l}\text { MIT } \\
\text { (Parkany et } \\
\text { al. 1995) }\end{array}$ & AVI/ETC & $50 \%$ & $\begin{array}{l}\text { MITSIM-Based } \\
\text { Simulation }\end{array}$ & $\begin{array}{l}\text { Travel time and } \\
\text { headway by } \\
\text { lane, Lane } \\
\text { switches, } \\
\text { Volume by lane }\end{array}$ & $0.8 \mathrm{~min}$ \\
\hline $\begin{array}{l}\text { TTI (Balke et } \\
\text { al. 1996) }\end{array}$ & Cellular & $\begin{array}{c}\text { 5-min } \\
\text { headway }\end{array}$ & $\begin{array}{l}\text { Field in } \\
\text { Houston, TX }\end{array}$ & Travel time & $15 \mathrm{~min}$ \\
\hline $\begin{array}{l}\text { TRANSMIT } \\
\text { (Mouskos et } \\
\text { al. 1998) }\end{array}$ & AVI/ETC & $\begin{array}{c}1-\min \\
\text { headway }\end{array}$ & $\begin{array}{l}\text { Field in } \\
\text { Metropolitan } \\
\text { NYC }\end{array}$ & Travel time & $15 \mathrm{~min}$ \\
\hline $\begin{array}{l}\text { Waterloo } \\
\text { (Hellinga et } \\
\text { al. 2000) }\end{array}$ & AVI/ETC & $10 \%$ & $\begin{array}{l}\text { INTEGRATION } \\
\text { - Based } \\
\text { Simulation }\end{array}$ & Travel time & $0.3 \mathrm{~min}$ \\
\hline $\begin{array}{l}\text { MOSES } \\
\text { (Chue et al. } \\
2002)\end{array}$ & $\begin{array}{l}\text { Mobile } \\
\text { Sensor }\end{array}$ & 5 to $50 \%$ & $\begin{array}{l}\text { Paramics Micro- } \\
\text { Simulation }\end{array}$ & Travel time & $\begin{array}{l}12 \text { to } 4 \\
\min \end{array}$ \\
\hline $\begin{array}{l}\text { DSRC - } \\
\text { based } \\
\text { method } \\
\text { (Crabtree et } \\
\text { al. 2007) }\end{array}$ & DSRC & $30 \%$ & $\begin{array}{l}\text { CORSIM } \\
\text { Micro- } \\
\text { Simulation }\end{array}$ & Travel time & $\begin{array}{l}\text { Reader } \\
\text { spacing } 2 \\
\text { miles: } 2 \\
\text { to } 4 \text { min } \\
\text { Reader } \\
\text { spacing } \\
10 \text { miles: } \\
2.5 \text { to } 14 \\
\text { min }\end{array}$ \\
\hline \begin{tabular}{|l|} 
Bluetooth- \\
based \\
method (Yu \\
et al. 2015) \\
\end{tabular} & Bluetooth & $6 \%$ & Field in Oregon & $\begin{array}{l}\text { Travel time and } \\
\text { volume }\end{array}$ & $\begin{array}{l}\text { Not } \\
\text { reported }\end{array}$ \\
\hline $\begin{array}{l}\text { GPS-based } \\
\text { method } \\
\text { (Asakura et } \\
\text { al. 2005) } \\
\end{array}$ & GPS & $1 \%$ & $\begin{array}{l}\text { AIMSUN } \\
\text { Micro- } \\
\text { Simulation }\end{array}$ & Travel time & $14.8 \mathrm{~min}$ \\
\hline
\end{tabular}


- Cellular 911 calls: calls from motorists using their cellular phone, which is directly routed to the Computer Aided Dispatch (CAD) center;

- Public Entities' calls: calls from public organizations (e.g., fire departments, local police departments, etc.) personnel; and

- Freeway Service Patrol (FSP) calls: 52 FSP trucks monitoring 218 miles of the Bay Area that communicate with the CAD center via two-way radios and onboard Mobile Data Terminals (MDTs).

Incidents reported by cellular phone calls and other sources were obtained from the CHP computer-aided dispatch center. Incidents observed by probe vehicle drivers passing the same freeway with an average headway of 7 minutes are also included in the evaluation.

The detection rates and false alarms for each of the abovementioned methods are shown in Table 2-6. The reported events that cannot be verified by the CHP officers dispatched to the scene are considered false alarms.

Table 2-6 Detection and False Alarm Rates (\%)

\begin{tabular}{|l|c|c|}
\hline \multicolumn{1}{|c|}{ Detection Source } & Detection Rate & False Alarm Rate \\
\hline Cellular Phone & 37.9 & 7.4 \\
\hline CHP & 25 & 0 \\
\hline FSP & 17.1 & 0 \\
\hline Public Entity & 13.3 & 5.4 \\
\hline Call Box & 4.5 & 0 \\
\hline
\end{tabular}

The study also concluded that the fastest detection method is cellular phone calls. On average, cellular phone motorists report the incident 3 minutes sooner than the probe vehicles, while CHP officers detect the incident 2 minutes slower than the probe vehicles.

Christenson (1995) conducted a survey of the existing cellular call-in programs in the United States, which have a dedicated line for drivers to report the incident. Table 2-7 
shows the average detection time for minor and major incidents. Minor and major incidents can be incidents whose responses are or are not sufficient from motorist, assistant patrol, or police officer.

Table 2-7 Estimated Detection Time for Minor and Major Incidents

\begin{tabular}{|l|c|c|}
\hline \multicolumn{1}{|c|}{ Detection Method } & $\begin{array}{c}\text { Detection Time (minute) for } \\
\text { Minor Incidents }\end{array}$ & $\begin{array}{c}\text { Detection Time (minute) } \\
\text { for Major Incidents }\end{array}$ \\
\hline Cellular Telephone & 2 & 2 \\
\hline Motorists Assistant Patrol & 5 & 5 \\
\hline Police or Highway Patrol & 10 & 10 \\
\hline Closed-Circuit Television & 5 & 5 \\
\hline Roadside Call Boxes & 10 & 10 \\
\hline Roadside Telephones & 10 & 10 \\
\hline Loop Detectors & 5 & 5 \\
\hline
\end{tabular}

Mussa (1997) developed an analytical model to evaluate the performance of driver-based incident detection. The probability of incident detection was assumed to have a binomial distribution. The detection time is the time that a driver with a communication medium arrives within a 100-foot visible zone. The FRESIM microscopic simulation (currently a component of CORSIM) was used to evaluate the performance of river-based incident detection. The paper concluded that all of the incidents are detected in one minute, regardless of the incident type if the cellphone market penetration is $10 \%$.

\subsubsection{Queue Warning and Back-of-Queue Estimation}

Rear-end collisions are a main safety concern on freeways and are caused by slow/stopped traffic. One-third of all collisions have been reported to be rear-end incidents (NTSF 2001). Recurrent congestion (bottlenecks), incidents, and work zones are three main causes of slow/stopped traffic and can lead to queued traffic conditions and consequently, rear-end collisions. Queue warning systems are designed to inform 
drivers about the queued traffic ahead so that they can react in a timely manner. Based on the results of one study by Daimler-Benz (NTSF 2001), 60\% of rear-end collisions could be prevented if drivers had an extra half of a second of warning. The study also indicated that $90 \%$ of rear-end collisions could be prevented if an additional second of warning would be given to drivers. Findings from the queue warning system (QWS) evaluation in Amsterdam showed that the system reduced the overall crash frequency by $23 \%$ and secondary crash frequency by $46 \%$. An evaluation of queue warning systems and freeway lane control found a $20 \%$ reduction in crash rates (FHWA 1999). A queue warning system in Madison County, Illinois showed a 13.8\% reduction in incidents (Enterprise 2014). A new, innovative end-of-queue warning system implemented on I-35 along 96 miles in central Texas reduced crashes by $45 \%$, and fewer rear-end collisions were observed (ARTBA Work Zone Safety Consortium 2015). Different queue detection techniques have been tested so far. A video-based queue detection was implemented on the E313 Freeway in a Belgian city. The detection algorithm reads the speed and occupancy measured by the video detection camera, and if the occupancy is more than $50 \%$ and the speed is less than $50 \mathrm{~km} / \mathrm{h}(31 \mathrm{mph})$, a warning message is sent to the dynamic message signs (DMS) upstream of the incident (FLIR 1998). The QWS implemented in Toronto, Canada on Queen Elizabeth Way in the town of St. Catharines uses microwave sensor stations data to warn drivers about slow/stopped traffic. If the differential speed between two microwave stations is high, drivers are advised through arterial DMS (Alexander et al. 2002). In Jutland, a city in Denmark, the QWS is activated when the speed obtained from traffic sensors is below $50 \mathrm{~km} / \mathrm{h}(31 \mathrm{mph})$. After the system activation speed limits of 90,70 and $50 \mathrm{~km} / \mathrm{h}(56,44$ and $31 \mathrm{mph})$ are shown on 
the successive DMS upstream of the queue tail (Wiles et al. 2003). The queue QWS in Oslo, Norway utilizes video detectors to detect the back-of-queue. If speeds are below 30 $\mathrm{km} / \mathrm{h}$ (19 mph), occupancy is higher than 30\%, and if the limits for speed and occupancy exceed more than 15 seconds, a warning is sent to drivers through DMSs. Reference 62 concluded that the queue warning system has a positive effect on driver speed and braking characteristics, which means that the video detectors detected the queue fairly well (Engan et al. 2001). The smart work zone in Illinois (Nemsky 2014), which is composed of Doppler speed detectors, Bluetooth readers, and portable DMSs, were found to reduce the number of rear-end crashes by $14 \%$. This reduction occurred despite the increase in traffic volume and the higher number of temporarily closed lanes during the project. There are queue warning systems implemented all over the U.S., as summarized in Table 2-8.

Ulman et al. (2016) investigated the safety effects of portable end-of-queue (EOQ) warning system implementation at Texas work zones along 96 miles of I-35 that were being widened. The EOQ system consists of portable radar speed sensors connected to one or more portable DMSs.

A portable travel rumble strip was also deployed upstream of the nighttime lane closures where the queue was expected to grow. The EOQ was implemented on more than 200 nighttime lane closures along the corridor. The number of expected crashes for each lane closure was estimated with and without EOQ. The results indicate that the EOQ system had a positive impact on reducing crashes. The EOQ system reduced the number of crashes by 44 percent, and reduced crash costs by $\$ 1.36$ million over the study period. 
The crash cost savings were estimated to offset the cost of the EOQ system deployment after 95 to 190 nights of use.

Table 2-8 Summary of Queue Warning Techniques in the United States

\begin{tabular}{|l|l|l|}
\hline \multicolumn{1}{|c|}{ State/City } & \multicolumn{1}{|c|}{ Problem Type } & \multicolumn{1}{|c|}{$\begin{array}{c}\text { Queue Detection } \\
\text { Technique }\end{array}$} \\
\hline $\begin{array}{l}\text { Florida/Palm Beach county IH 95 } \\
\text { (Wiles et al. 2003) }\end{array}$ & Construction Zone Queues & $\begin{array}{l}\text { Video Detection } \\
\text { Radar (ADDCO) }\end{array}$ \\
\hline Illinois/IH 55 (Wiles et al. 2003) & Construction Zone Queues & Radar Detection \\
\hline $\begin{array}{l}\text { Indiana/IH 65 @ State Rd 131 } \\
\text { (INDOT 2000) }\end{array}$ & Exit Ramp Spillback & Embedded Loops \\
\hline $\begin{array}{l}\text { Central Minnesota (Iowa State } \\
\text { University 2002) }\end{array}$ & $\begin{array}{l}\text { Recurrent Congestion (at } \\
\text { Freeway Lane Drop) } \\
\text { Rear-End Collisions }\end{array}$ & Optical Detectors \\
\hline $\begin{array}{l}\text { Pennsylvania/US 22 (FHWA 1998) } \\
\text { Construction Zone Queues } \\
\text { Sight Distance Limitations } \\
\text { Rear-End Collisions }\end{array}$ & $\begin{array}{l}\text { Queue Length } \\
\text { Detectors } \\
\text { using Infrared Beams }\end{array}$ \\
\hline $\begin{array}{l}\text { Pennsylvania/ Turnpike (Paturnpike } \\
\text { 1999) }\end{array}$ & $\begin{array}{l}\text { Construction Zone Queues } \\
\text { Rear-End Collisions }\end{array}$ & $\begin{array}{l}\text { Radar Detector Speed } \\
\text { Devices }\end{array}$ \\
\hline $\begin{array}{l}\text { Texas/San Antonio TransGuide (Trans } \\
\text { Guide 2002) }\end{array}$ & $\begin{array}{l}\text { Recurrent Congestion } \\
\text { Rear-End Collisions }\end{array}$ & Embedded Loops \\
\hline
\end{tabular}

Paterson et al. (2013) investigated the accuracy and latency of the queue warning and travel time estimation systems for the Minnesota I-94 Intelligent Work Zone (IWZ) project. The results showed that the accuracy of the back-of-queue estimation were within one mile across different queue lengths (note that detectors were spaced at onemile intervals). The comparison of the posted and actual distance to the back-of-queue is shown in Figure 2-3.

Most of the existing queue estimation methods are point detector-based and use either speed or cumulative volume to estimate the queue length. In the speed-based methods, downstream and upstream speed measurements are compared with a threshold. 


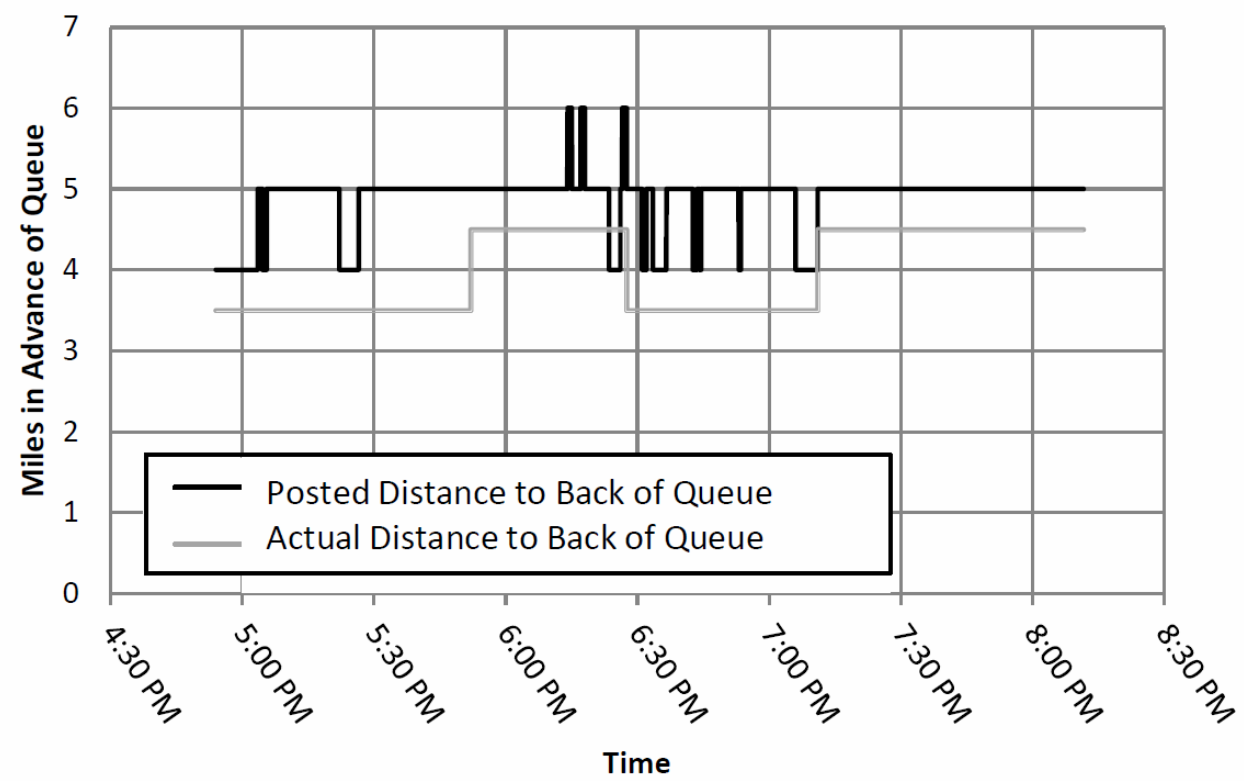

Figure 2-3 Comparison of the Posted and Actual Distance to the Back-of-Queue on I-94 in Minnesota-June 14, 2013 (Peterson et al. 2013)

If both are less than a threshold, the queue length is assumed to be equal to the length of the segment, and if only downstream measurements are less than the threshold, the queue length is assumed to be half of the segment length. The cumulative, volumebased methods use volume measurements instead of speed. The cumulative downstream detector arrival volume count is compared with the cumulative departure volume count, and the difference between these two is estimated as the number of vehicles in queue (Nam et al. 1999, Zhang 2006, Vanajakshi et al. 2009). The cumulative volume method, however, requires detection of ramps, as well as mainline segments.

Pesti et al. (2013) proposed a point detector-speed-based queue estimation algorithm and used VISSIM microsimulation to evaluate the algorithm. Different design parameters such as speed thresholds, aggregation interval, detector spacing and portable DMS locations were examined. A speed threshold of $35 \mathrm{mph}$, aggregation interval of 5 minutes and DMS message update interval of 1 or 5 minutes were recommended by the 
study (Pesti et al. 2013). All of the aforementioned QWS rely on fixed traffic sensors or cameras to detect the back-of-queue. Hence, the location of back-of-queue cannot be detected exactly. If the transmitted messages from the connected vehicles are utilized, the detection has the potential to be faster and more accurate. A recent study by Elfar et al. (2016) attempted to examine the queue warning system in a connected environment using a microsimulation platform. However, the results of the study have not been published yet.

Balke et al. (2014) developed speed harmonization and queue warning algorithms to generate recommended speeds and queue warning information to drivers as a part of the United States Department of Transportation Intelligent Network Flow Optimization (INFLO) prototype. The study also addressed how the prototype uses the recommended speed and queue warnings generated by algorithms to produce both infrastructure and vehicle-based warning messages. Three types of queue warning algorithms were included in the prototype: Traffic Management Entity (TME)-based, Cloud-based, and vehicle based. The TME queue warning algorithm fuses the data obtained from the traffic sensors and connected vehicles to detect the back-of-queue (BOQ) and generate queue warning messages through both infrastructure signs and connected vehicles. It is assumed that the front-of-queue (FOQ) is known. The process of detecting the BOQ is shown in Figure 24. 


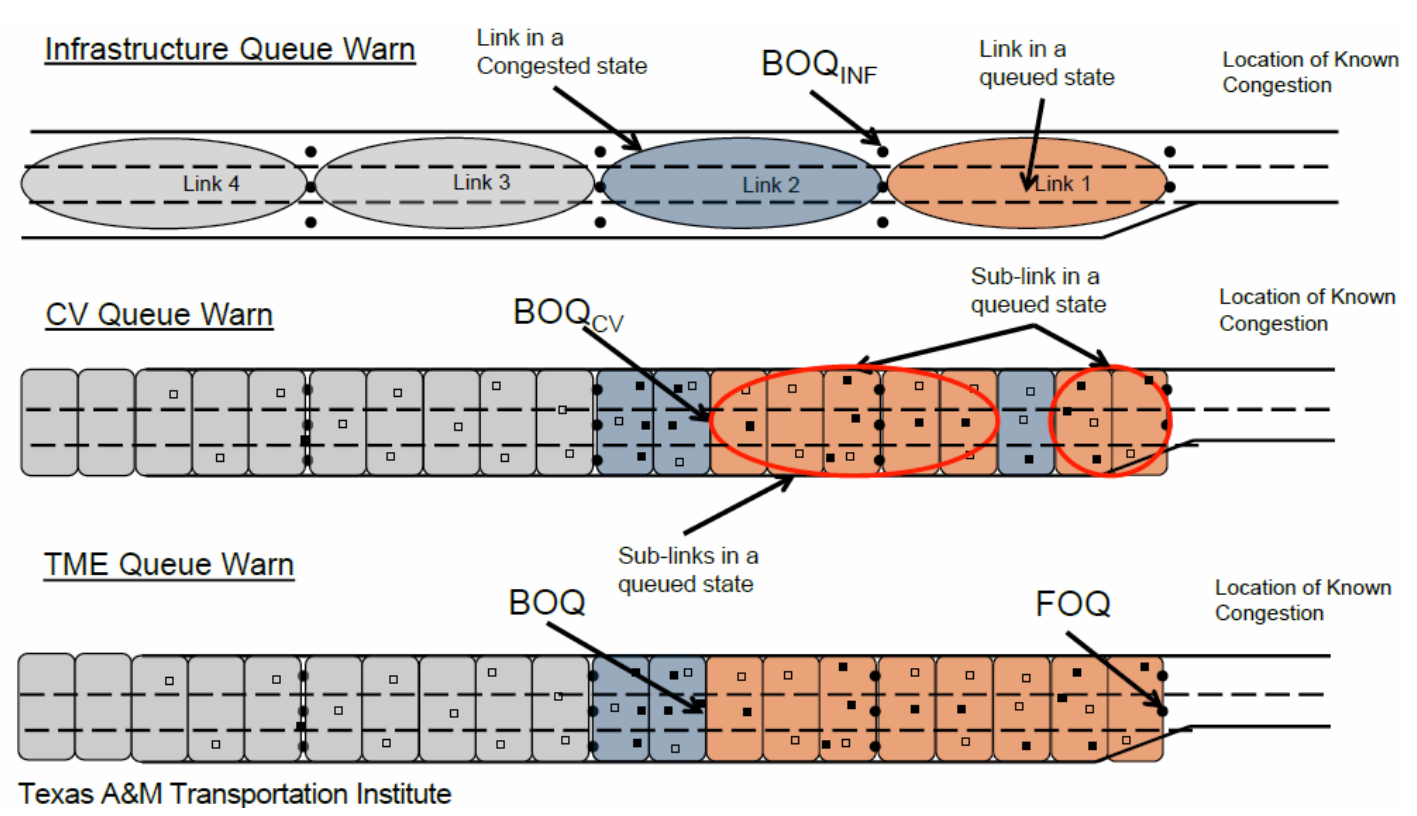

Figure 2-4 The TME Queue Warning Algorithm Proposed by Balke et al. (2014)

In the cloud-based queue warning algorithm, connected vehicles send BSM messages, queued state ( $\mathrm{Y}$ or $\mathrm{N})$, and mile marker (MM) location of the vehicle to the cloud using cellular communication. The information is analyzed in the cloud, and BSM messages are assigned to sublinks based on the vehicle's location. Then, the queued state of the sublink is determined, and the BOQ is defined as the mile marker of the most upstream sublink. Based on the BOQ, the queue growth rate, length of queue and speed in the queue are calculated. Finally, the generated queue warning messages are displayed in the connected vehicles. The process of determining the BOQ is repeated every 5 seconds. The cloud-based queue warning application is shown in Figure 2-5.

In the vehicle-to-vehicle-based (V2V) algorithm, each vehicle sends its mile marker location and queued state ( $\mathrm{Y}$ or $\mathrm{N}$ ), along with other $\mathrm{V} 2 \mathrm{~V}$ message data elements each $1 / 10^{\text {th }}$ of a second to the surrounding vehicles using DSRC communication. Vehicle queued status is determined using vehicle speed and separation (gap) from the immediate 
downstream vehicle. A non-queued connected vehicle can identify the BOQ that has the information from the downstream vehicles. Then, the BOQ information is transmitted by all of the non-queued vehicles. A warning message is displayed in the upstream vehicles regarding the BOQ. If the vehicle location is further than a user-defined threshold from the BOQ (10 miles for the prototype testing), the warning message will not be displayed. The V2V queue warning system is shown in Figure 2-6.

The queue warning message display is also discussed in reference (Balke et al. 2014). The TME-based and cloud-based algorithms generate the FOQ and BOQ, location, speed in queue, and rate of queue growth, while the V2V-based algorithm generates only the location of the BOQ and sends it to the vehicles. Based on the location of the vehicle from the back-of-queue, the type of the displayed message varies. A vehicle can be in stopping sight distance, decision sight distance, or upstream of the decision sight distance from the BOQ, as shown in Figure 2-7. The displayed messages are set differently for each of these locations. 


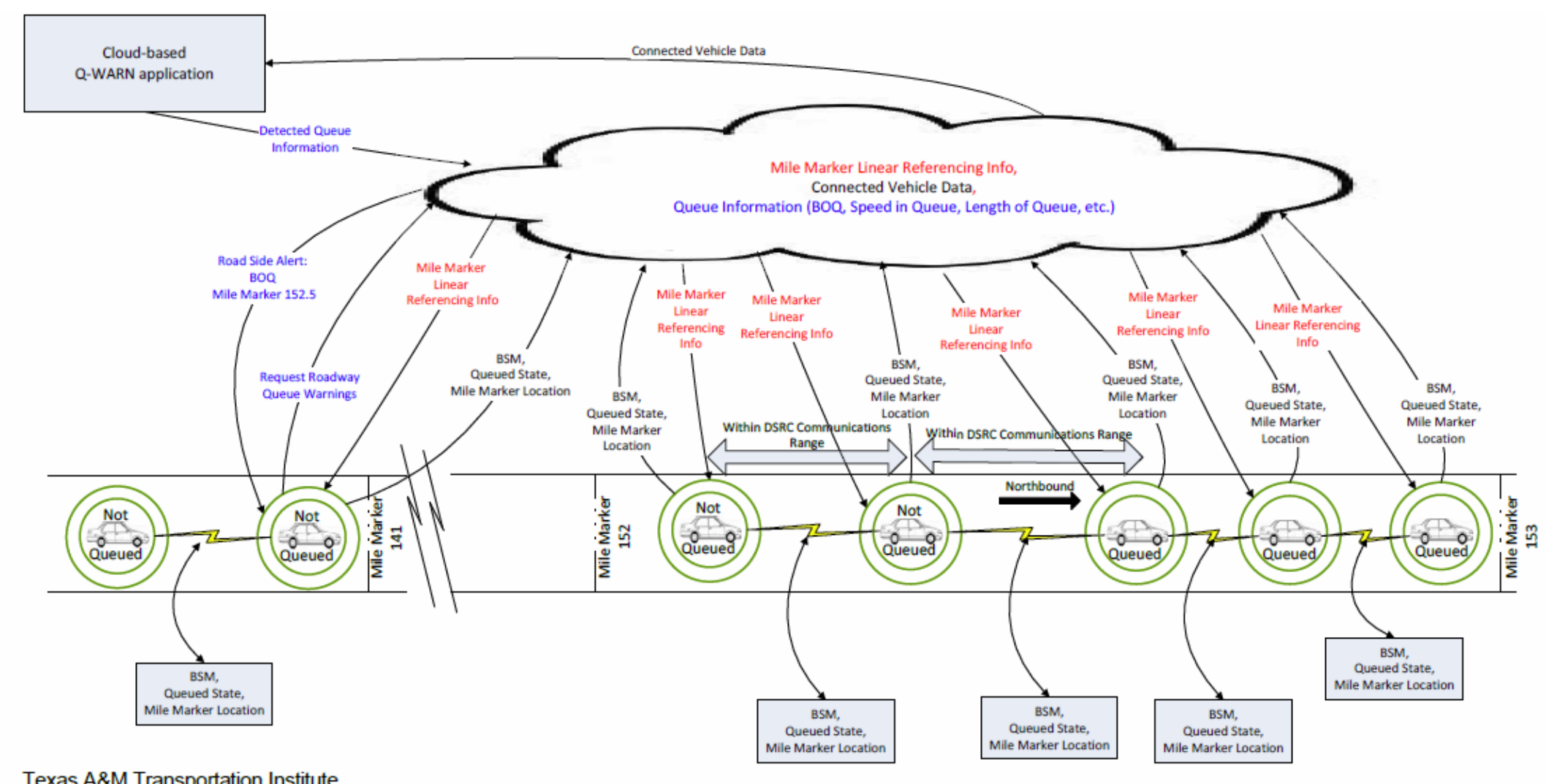

Figure 2-5 Cloud-Based Queue Warning Algorithm Proposed by Balke et al. (2014) 


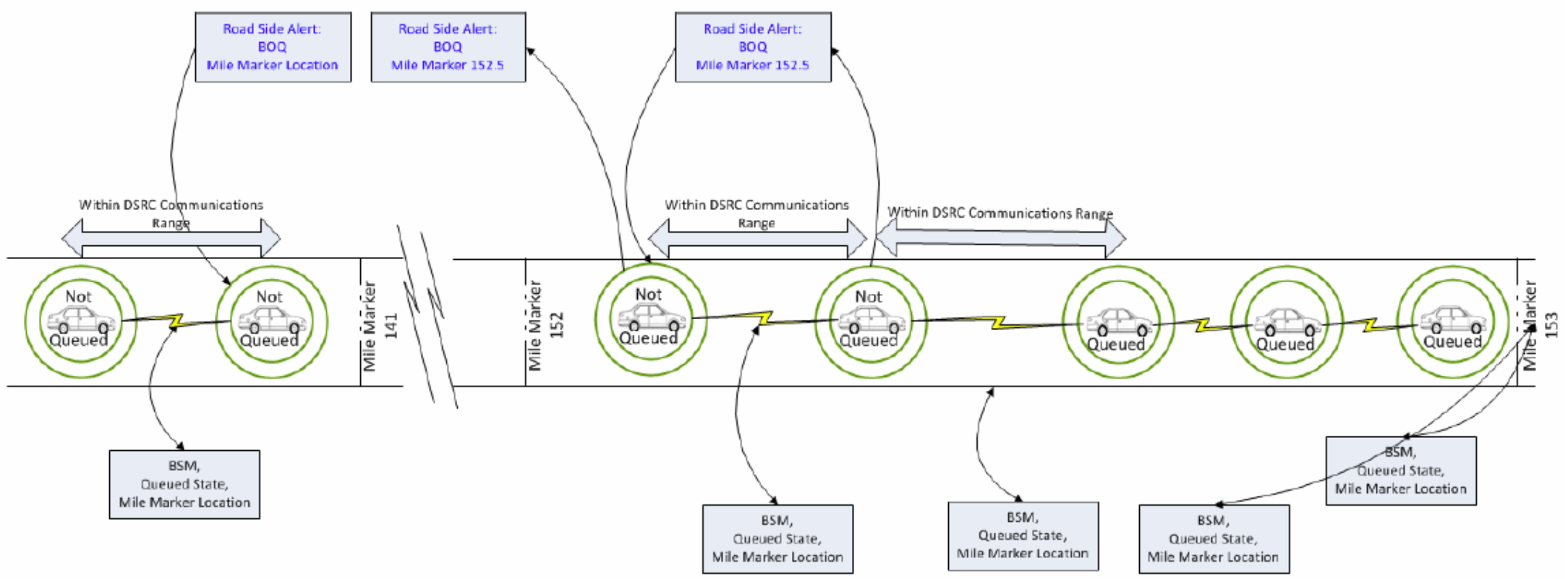

Texas A\&M Transportation Institute

Figure 2-6 V2V-Based Queue Warning System Proposed by Balke et al. (2014) 


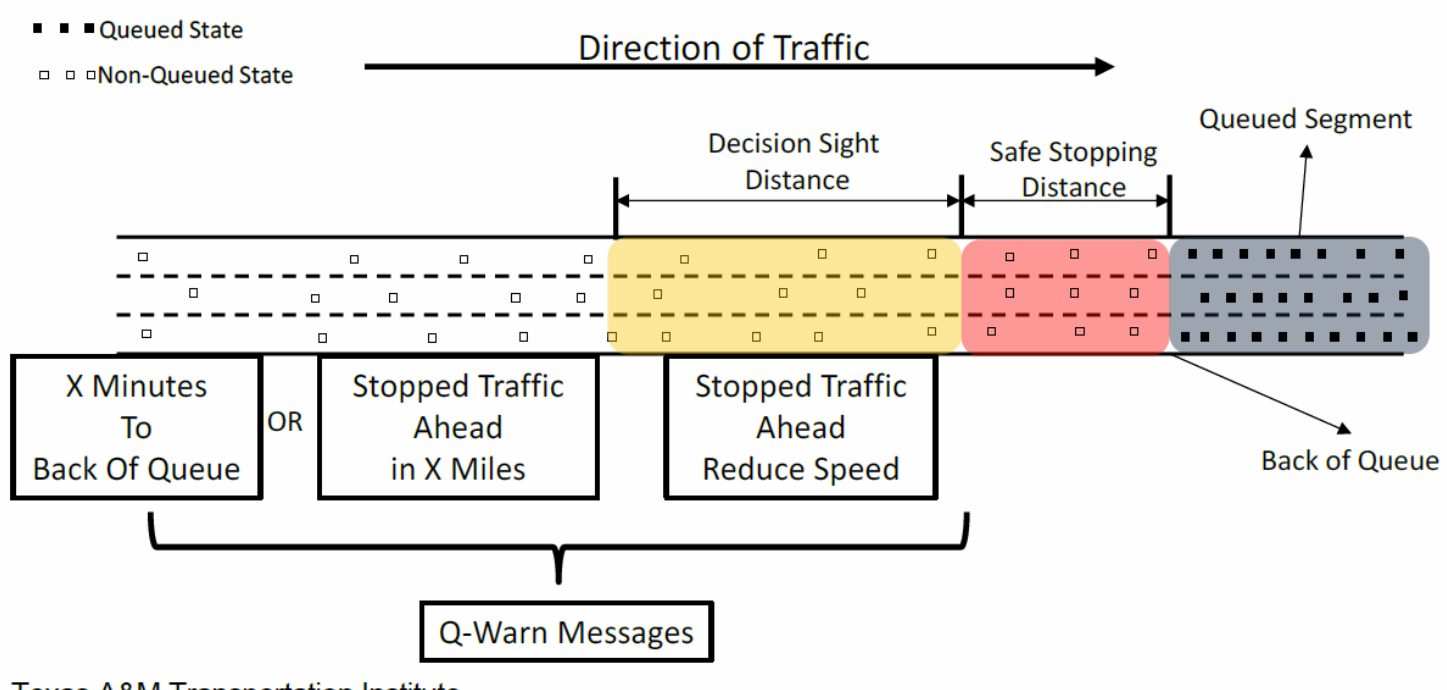

Texas A\&M Transportation Institute

Figure 2-7 Queue Warning Display Depending on the Vehicle Distance from BOQ Recommended by Balke et al. (2014)

Dowling et al. (2015) evaluated the impacts of the developed prototype of Speed Harmonization (SPD-HARM) by Balke et al. (2014). The VISSIM microsimulation was used to model 8.5 miles of the U.S. 101 Freeway in San Mateo, California. The SPDHARM /Q-WARN (queue warning) prototype was written in the VISSIM COM interface. However, researchers pointed out that the Q-WARN application could not be assessed in the microsimulation due to the lack of information on how drivers would react to the queue warning messages. Therefore, only the performance of the SPDHARM was tested in the microsimulation. It was assumed that $100 \%$ of drivers comply with the recommended speed generated by the SPD-HARM algorithm. The study concluded that the prototype reduced the magnitude of shockwaves (speed drops between vehicles) at a $10 \%$ market penetration level. It also showed a rapid increase in the benefits for the first $20 \%$ of vehicles that were both connected and complying with the SPD-HARM recommendations. After the $20 \%$, the rate of increase in the benefits is lower, but still increasing. 
A small-scale demonstration was conducted by TTI, Battelle and the Washington State Department of Transportation (WSDOT) (Stephens et al. 2015) involving equipping 21 vehicles with connected vehicle systems traveling in a 23 -mile corridor of I-5 from Tukwila to Edmonds through downtown Seattle during the week of January 12, 2015. The connected vehicle data was transmitted and gathered using bot cellular phone and DSRC communication. The purpose of the small-scale demonstration was to implement the INFLO prototype and test its functionality and performance in a real traffic environment. The TME-based queue warning and TME-based speed harmonization described earlier, combined with Weather Responsive Traffic Management (WRTM), were implemented. Speed data were collected from both the WSDOT infrastructurebased detectors and the connected vehicles. The collected data were analyzed in real time as the Q-WARN and SPD-HARM messages were delivered to drivers. The study concluded that no loss of BSM data was observed and there was no disruption in the algorithm due to any loss of BSM data. The data capture, processing, and delivery of messages to the drivers took less than 10 seconds. This guaranteed that drivers receive the queue warning message 1 mile in advance of the back-of-queue. The Q-WARN was found to detect the back-of-queue 3 minutes sooner and could locate the back-of-queue more accurately ( 0.5 to 1.5 miles farther upstream) than road loop detectors. Since the INFLO algorithms capture the speed data each 0.1-mile interval, they can provide a better estimation of vehicle speed in the queue than the infrastructure-based sensors that capture speed every 0.5 miles. 


\subsection{Multi-Criteria Decision AnAlysis (MCDA)}

For most of the cases, the decision-making process involves many objective and constraints that conflict with each other. The MCDA is a branch of operation research that tries to find a compromise solution among different alternative considering multiple objectives (criteria). In other words, there is no solution that optimizes all of the criteria. MCDA helps decision makers select the best alternative with regards to the conflicting objectives. There are several MCDA methods used in the literature. The simplest MCDA approach is the Simple Multi-Attribute Rating Technique (SMART) approach, also known as the Simple Additive Weighting (SAW) method, described by Fishburn (1967). This approach involves identifying decision criteria, criterion weights, assessment of the values associated with each criteria, normalizing the values to a common scale, and obtaining "scores" based on the values. The result is a weighted score for each of the compared alternatives. When there are a large number of evaluation criteria and the priorities of multiple stakeholders are to be considered, the SAW method cannot sufficiently capture the weights of different criteria (Annette et al. 2016). More advanced MCDA methods, compared to the SAW method, have been proposed and successfully used. These methods include the Analytic Hierarchy Process (AHP), Technique for Order Preference Similarity to Ideal Solution (TOPSIS) (Hwang et al. 1981), Preference Ranking Organization Method for Enrichment of Evaluations (PROMETHEE) (Brans et al. 1985, San Cristobal. 2013), Elimination Et Choix Traduisant la Realité (ELECTRE) (Roy 1968, Benayoun et al. 1966, Hokkanen et al. 1997) and others (Jato-Espino et al. 2014). All of these methods require stakeholder inputs regarding their preferences and priorities, with respect to various decision criteria and an assessment of each alternative 
to meet each criterion. Among these MCDA methods, the AHP method developed by Saaty (1980) has been the most widely used in various disciplines, including transportation engineering. According to the Macharis et al. (2015) study, 33\% of the reviewed publications on utilizing MCDA in the transportation field used AHP or a variant of AHP in their analysis. In the following section, some of the highly used MCDA methods such as AHP are elaborated.

\subsubsection{Simple Additive Weighting (SAW)}

The Simple Additive Weighting (SAW), described by Fishburn (1967), determines a weighted score for each of the alternatives to be compared. If the units of different inputs (attributes) vary, the input values are normalized using linear or vector normalization. The overall score of an alternative is calculated using the following equation:

$$
P_{i}=\sum_{j=1}^{M} w_{j}\left(m_{i j}\right)
$$

where,

$$
\begin{aligned}
& \mathrm{P}_{\mathrm{i}} \quad=\text { the } \mathrm{i}^{\text {th }} \text { alternative score, } \\
& \mathrm{w}_{\mathrm{j}} \quad=\text { the } \mathrm{j}^{\text {th }} \text { attribute (criterion) weight, and } \\
& \mathrm{m}_{\mathrm{ij}} \quad=\text { value of the } \mathrm{j}^{\text {th }} \text { attribute, in a non-normalized form, for the } \mathrm{i}^{\text {th }} \text { alternative. } \\
& \text { In this method, each attribute has a weight and the sum of all weights should be } 1 . \\
& \text { The decision table is shown in Table 2-9. This table is applicable to all of the MCDA }
\end{aligned}
$$
methods. 
Table 2-9 Decision Table in MCDM Methods (Venkata Rao 2006)

\begin{tabular}{|c|c|c|c|c|c|c|}
\hline Alternatives & \multicolumn{7}{|c|}{ Attributes } \\
\hline & $\begin{array}{c}\mathrm{B}_{1} \\
\left(\mathrm{~W}_{1}\right)\end{array}$ & $\begin{array}{c}\mathrm{B}_{2} \\
\left(\mathrm{~W}_{2}\right)\end{array}$ & $\begin{array}{c}\mathrm{B}_{3} \\
\left(\mathrm{~W}_{3}\right)\end{array}$ & $\begin{array}{c}(-) \\
(-)\end{array}$ & $\begin{array}{c}\mathrm{B}_{\mathrm{M}} \\
\left(\mathrm{W}_{\mathrm{M}}\right)\end{array}$ \\
\hline $\mathrm{A}_{1}$ & $\mathrm{~m}_{11}$ & $\mathrm{~m}_{12}$ & $\mathrm{~m}_{13}$ & - & - & $\mathrm{m}_{1 \mathrm{M}}$ \\
\hline $\mathrm{A}_{2}$ & $\mathrm{~m}_{21}$ & $\mathrm{~m}_{22}$ & $\mathrm{~m}_{23}$ & - & - & $\mathrm{m}_{2 \mathrm{M}}$ \\
\hline $\mathrm{A}_{3}$ & $\mathrm{~m}_{31}$ & $\mathrm{~m}_{32}$ & $\mathrm{~m}_{33}$ & - & - & $\mathrm{m}_{3 \mathrm{M}}$ \\
\hline- & - & - & - & - & - & - \\
\hline- & - & - & - & - & - & - \\
\hline $\mathrm{A}_{\mathrm{N}}$ & $\mathrm{m}_{\mathrm{N} 1}$ & $\mathrm{~m}_{\mathrm{N} 2}$ & $\mathrm{~m}_{\mathrm{N} 3}$ & - & - & $\mathrm{m}_{\mathrm{NM}}$ \\
\hline
\end{tabular}

If the attribute units are different, the performance measures can be normalized and each alternative weight is calculated, as shown below:

$$
P_{i}=\sum_{j=1}^{M} w_{j}\left(m_{i j}\right)_{n o r m a l}
$$

where $\left(\mathrm{m}_{\mathrm{ij}}\right)_{\text {normal }}$ is the normalized value of the $\mathrm{m}_{\mathrm{ij}}$.

When the attributes are beneficial, the normalized value is calculated by dividing the $\mathrm{m}_{\mathrm{ij}}$ by the maximum $\mathrm{m}_{\mathrm{ij}}$ among all of the alternatives (in the $\mathrm{jth}$ column). Beneficial attributes are the ones that yield more desirability as they increase (e.g., profit). For the non-beneficial attributes, the normalized value of $\mathrm{m}_{\mathrm{ij}}$ is obtained by dividing the maximum $\mathrm{m}_{\mathrm{ij}}$ by the $\mathrm{m}_{\mathrm{ij}}$.

If the condition of the equality of the sum to 1 is relaxed, then each alternative score is calculated using the following equation, and the method is called the simple multiple attribute rating technique (SMART) (Venkata Rao 2006).

$$
P_{i}=\frac{\sum_{j=1}^{M} w_{j}\left(m_{i j}\right)_{\text {normal }}}{\sum_{j=1}^{M} w_{j}}
$$

In a study by Medina et al. (2014), three MCDA methods were used to select the optimal traffic signal control considering different modes of transportation such as cars, buses, pedestrians and bicycles. One of the methods used was the SAW. The score of 
each alternative $\mathrm{j}$, which is a set of signal timing settings, was calculated using Equation 2-11. Each mode is a selection criterion i with a weight $\left(w_{i}\right)$. Lower scores indicate better alternatives, as delay is to be minimized.

$$
s_{j}=\sum_{i} d_{i j} v_{i} w_{i}
$$

where,

$$
\begin{aligned}
& d_{i j} \quad=\text { delay per unit of mode } \mathrm{i} \text { for alternative } \mathrm{j}, \\
& v_{i} \quad=\text { volume of mode } \mathrm{i}, \text { and } \\
& w_{i} \quad=\text { weight of mode } \mathrm{i} .
\end{aligned}
$$

\subsubsection{Analytic Hierarchy Process (AHP)}

The Analytic Hierarchy Process (AHP) developed by Thomas Saaty (1980) is one of the popular MCDA methods that help decision makers prioritize different alternatives and make the best decision. A weight is assigned to each evaluation criterion based on decision makers' pairwise comparisons of the criteria. Then, for a fixed criterion, a score is assigned to each alternative based on the decision maker's pairwise comparison of the alternatives based on that criterion. The higher the score, the better the alternative with respect to the corresponding criterion. Finally, the criteria weight and alternatives scores are combined and a global score is generated for each alternative using the AHP method. The global score of each alternative is a weighted sum of the scores with respect to all of the criteria. The AHP method has three steps:

- calculating the vector of criteria weights,

- calculating the matrix of alternatives scores, and

- ranking the alternatives. 
The first step is calculating the vector of criteria weights. In this step, a pairwise comparison matrix A $\left(\mathrm{m}^{*} \mathrm{~m}\right)$ is created, where $\mathrm{m}$ is the number of evaluation criteria. Each element $\mathrm{a}_{\mathrm{ij}}$ of the matrix indicates the importance of ith criterion relative to the jth criterion. If $a_{i j}>1$, criterion $i$ is more important than criterion $j$. The values used to measure the relative importance between the two criteria are selected from a numerical scale ranging from 1 to 9 , and the reciprocals are used when the second criterion (jth criterion) is more important $(1 / 2,1 / 3 \ldots 1 / 8,1 / 9)$. After creating the pairwise comparisons matrix, a normalized pairwise matrix $A_{\text {norm }}$ is created and each element of the matrix is calculated as shown in the following equation.

$$
\bar{a}_{i j}=\frac{a_{i j}}{\sum_{i=1}^{m} a_{i j}}
$$

where $\bar{a}_{i j}$ are elements of the normalized pairwise matrix $\left(\mathrm{A}_{\text {norm}}\right)$ indicating the importance of ith criterion relative to the jth criterion and $a_{i j}$ are elements of the pairwise comparison matrix A.

Finally, each criterion's weight $\left(w_{j}\right)$ is calculated by averaging the elements on each row of the normalized matrix using the equation below:

$$
w_{j}=\frac{\sum_{j=1}^{m} \bar{a}_{i j}}{m}
$$

where $w_{j}$ is criterion $\mathrm{j}$ weight and $\mathrm{m}$ is pairwise comparison matrix dimension.

In the second step, a matrix of alternative scores is calculated. The score matrix $\mathrm{S}$ is an $n^{*} m$ matrix, where $n$ is the number of alternatives and $m$ is the number of criteria. In order to derive the matrix $\mathrm{S}$, a pairwise matrix $\mathrm{B}^{(\mathrm{i})}$ needs to be created for each of the $\mathrm{m}$ criterion $(\mathrm{i}=1, \ldots, \mathrm{m})$. Matrix $\mathrm{B}^{(\mathrm{i})}$ is an $\mathrm{n}^{*} \mathrm{n}$ matrix, and each element $a_{k h}^{i}$ of the matrix $\mathrm{B}^{(\mathrm{i})}$ indicates the importance of the $\mathrm{k}^{\text {th }}$ alternative, compared to the $\mathrm{h}^{\text {th }}$ alternative, with 
respect to the $\mathrm{i}^{\text {th }}$ criterion. If $a_{k h}^{i}>1$, the $\mathrm{k}^{\text {th }}$ alternative is better than the $\mathrm{h}^{\text {th }}$ alternative, with respect to the $\mathrm{i}^{\text {th }}$ criterion. Then, the same procedure applied to matrix $\mathrm{A}$ is applied to each matrix $B^{(i)}$. Each element of the matrix is divided by the sum of entries in the same column, and then the elements of each row are averaged to calculate the score vectors $s^{(i)}$ $, i=1, \ldots, m$. In other words, $s^{(i)}$ is a vector composed of different alternative scores with respect to the $\mathrm{i}^{\text {th }}$ criterion. The score matrix $\mathrm{S}$ is defined as the following:

$$
S=\left[S^{(1)} \ldots S^{(m)}\right]
$$

where $S$ is the score matrix and $\mathrm{s}^{(\mathrm{i})}$ is the score vector with respect to the $\mathrm{i}^{\text {th }}$ criterion.

Finally, in the third step, having the weight vector $w$ and the score matrix $\mathrm{S}$, the global score for each alternative is calculated by multiplying $\mathrm{S}$ and w, as shown below:

$$
v=S . w
$$

where,

$$
\begin{array}{ll}
v & =\text { global score for each alternative, } \\
S & =\text { score matrix }, \text { and } \\
w & =\text { criteria weight vector. }
\end{array}
$$

The $i^{\text {th }}$ element of $\mathrm{v}$ is the global score for alternative $\mathrm{i}$. Finally, AHP ranks the alternatives by ordering the global scores in a descending order.

A consistency ratio (CR) needs to be calculated to make sure that the rankings given by different decision makers and used as inputs to the AHP application are consistent. CR is calculated using the following equation:

$$
C R=\frac{C I}{R I}
$$

where, 


$$
\begin{aligned}
& C R \quad=\text { consistency ratio, } \\
& C I \quad=\text { consistency index }, \text { and } \\
& R I \quad=\text { the random index } .
\end{aligned}
$$

$\mathrm{CI}$ is calculated using the following equation, and RI is obtained from reference (Saaty, 1980). If the consistency ration is less than 0.1, the rankings are consistent; otherwise, they have to be revised by the decision makers.

$$
C I=\frac{\lambda_{\max }-n}{n-1}
$$

where $\lambda_{\max }$ is the maximum Eigen value of the comparison matrix and $\mathrm{n}$ is the number of criteria being compared.

\subsubsection{Technique for Order Preference Similarity to Ideal Solution (TOPSIS)}

The technique for order preference by similarity to ideal solution (TOPSIS) method was introduced by Hwang and Yoon in 1981 (1981). The TOPSIS method defined two hypothetical alternatives using available attribute values: the positive ideal solution and the negative ideal solution. The positive ideal solution is composed of the best observed attribute values in the database (highest values for the beneficial attributes and lowest value for the non-beneficial attributes). On the other hand, the negative ideal solution is an option composed of the worst attribute values in the database. The best alternative is the one that has the shortest Euclidean distance from the ideal solution and the farthest from the negative ideal solution. The procedure to select the best alternative among others in the TOPSIS method is described below.

The first step is to create a matrix similar to the decision table (Table 2-9), in which each row belongs to one alternative and each column belongs to one attribute. 
Each element $m_{i j}$ of the decision table represents the original value of the $j^{\text {th }}$ attribute (non-normalized) for the $\mathrm{i}^{\text {th }}$ alternative. When the attribute values are subjective, Table 210 may be used to assign a ranked value to the attribute.

Table 2-10 Value of Attributes (Venkata 2006)

\begin{tabular}{|l|c|}
\hline Subjective Measure of Attribute & Assigned Value \\
\hline Exceptionally Low & 0.0 \\
\hline Extremely Low & 0.1 \\
\hline Very Low & 0.2 \\
\hline Low & 0.3 \\
\hline Below Average & 0.4 \\
\hline Average & 0.5 \\
\hline Above Average & 0.6 \\
\hline High & 0.7 \\
\hline Very High & 0.8 \\
\hline Extremely High & 0.9 \\
\hline Exceptionally High & 1.0 \\
\hline
\end{tabular}

Then, the normalized decision matrix, $\mathrm{R}$, is obtained using the following equation:

$$
R_{i j}=\frac{m_{i j}}{\left[\sum_{j=1}^{M} m_{i j}^{2}\right]^{1 / 2}}
$$

where,

$$
\begin{aligned}
& R_{i j}=\text { element of the normalized decision matrix that represents the value of } \\
& \text { the } \mathrm{j}^{\text {th }} \text { attribute for the } \mathrm{i}^{\text {th }} \text { alternative, and } \\
& m_{i j} \quad=\text { element of the decision table that represents the original value of the } \mathrm{j}^{\text {th }} \\
& \quad \text { attribute (non-normalized) for the } \mathrm{i}^{\text {th }} \text { alternative. }
\end{aligned}
$$

The next step is to calculate the attribute weight vector. A set of weights $w_{j}$ (for $\mathrm{j}=1,2, \ldots, \mathrm{M})$ such that $\sum w_{j}=1$ is obtained in this part. The weighted normalized matrix $\mathrm{V}$ is then calculated. Matrix $\mathrm{V}$ is obtained by the multiplication of each element of matrix $\mathrm{R}$ with the associated weight, as shown in the following equation.

$$
V_{i j}=w_{j} R_{i j}
$$


where,

$$
\begin{aligned}
& V_{i j}=\text { element of the weighted normalized matrix that represents the value of } \\
& \text { the } \mathrm{j}^{\text {th }} \text { attribute for the } \mathrm{i}^{\text {th }} \text { alternative, } \\
& w_{j} \quad=\text { weight of criterion } \mathrm{j} \text {, and } \\
& R_{i j} \quad=\text { element of the normalized decision matrix that represents the value of } \\
& \quad \text { the } \mathrm{j}^{\text {th }} \text { attribute for the } \mathrm{i}^{\text {th }} \text { alternative. }
\end{aligned}
$$

The positive ideal solution and negative ideal solution are generated in the next step, as expressed below.

$$
\begin{gathered}
V^{+}=\left\{\left(\max \left(V_{i j}\right) \text { if } j \in J\right),\left(\min \left(V_{i j}\right) \text { if } j \in J\right)\right\}=\left\{V_{1}^{+}, V_{2}^{+}, \ldots \ldots, V_{M}^{+}\right\} \\
V^{-}=\left\{\left(\min \left(V_{i j}\right) \text { if } j \in J\right),\left(\max \left(V_{i j}\right) \text { if } j \in J\right)\right\}=\left\{V_{1}^{-}, V_{2}^{-}, \ldots \ldots, V_{M}^{-}\right\} \\
\mathrm{i}=1,2, \ldots, \mathrm{N}
\end{gathered}
$$

where,

$$
\begin{array}{ll}
J & =\text { associated with beneficial attributes }(\mathrm{j}=1,2, \ldots, \mathrm{M}), \\
J & =\text { associated with the non-beneficial attributes }(\mathrm{j}=1,2, \ldots, \mathrm{M}), \\
V^{+} & =\text {positive ideal solution, and } \\
V^{-} & =\text {negative ideal solution. }
\end{array}
$$

Each alternative distance from the ideal solution and the negative ideal solution is calculated using the following equations:

$$
\begin{array}{cc}
S_{i}^{+}=\left\{\sum_{j=1}^{M}\left(V_{i j}-V_{j}^{+}\right)^{2}\right\}^{0.5} & i=1,2, \ldots, N \\
S_{i}^{-}=\left\{\sum_{j=1}^{M}\left(V_{i j}-V_{j}^{-}\right)^{2}\right\}^{0.5} & i=1,2, \ldots, N
\end{array}
$$

where,

$S_{i}^{+} \quad=$ alternative $\mathrm{i}$ distance from the ideal solution, and 
$S_{i}^{-} \quad=$ alternative $\mathrm{i}$ distance from the negative ideal solution.

The relative closeness of an alternative to the ideal solution, $P_{i}$, is obtained using the following equation:

$$
P_{i}=\frac{S_{i}}{\left(S_{i}^{+}+S_{i}\right)}
$$

where $P_{i}$ is the overall score of alternative i.

Finally, the alternatives are arranged in a descending order based on their $P_{i}$ value, and the best alternative is selected. The higher the score $P_{i}$, the better the alternative.

\subsubsection{Fuzzy TOPSIS}

In the following section, the fuzzy set theory is briefly introduced, and then the fuzzy TOPSIS method is discussed.

\subsubsection{Introduction to the Fuzzy Set Theory}

The fuzzy logic concept was proposed by Professor Lotfi Zade (1965) at the University of California, Berkeley, and uses linguistic knowledge and human expertise in the decision-making process. For example, the probability of the occurrence of an incident can be expressed in linguistic terms of very high, high, and low, etc. There are certain definitions and properties related to the fuzzy set theory that are explained as follows.

A fuzzy set $\tilde{a}$ is characterized by a membership function $\mu_{\tilde{a}}(x)$ that maps each crisp input $\mathrm{x}$ to a value between 0 and 1 . There are different types of membership functions such as triangular, trapezoidal, bell-shaped, etc., among which the triangular fuzzy set (Figure 2-8) has been popular and commonly used due to its simplicity (Yeh et 
al. 2004, Pedrycz 1994). A triangular fuzzy set $\tilde{a}$ is defined by three numbers: $\widetilde{a}=$ $\left(a_{1}, a_{2}, a_{3}\right)$. The membership function $\mu_{\tilde{a}}(x)$ of a triangular fuzzy set $\tilde{a}$ is shown in the equation below:

$$
\mu_{\tilde{a}}(x)=\left\{\begin{array}{lr}
0, & x \leq a_{1} \\
\frac{x-a_{1}}{a_{2}-a_{1}}, & a_{1} \leq x \leq a_{2} \\
\frac{a_{3}-x}{a_{3}-a_{2}}, & a_{2} \leq x<a_{3} \\
0, & x>a_{3}
\end{array}\right.
$$

where,

$$
\begin{array}{ll}
\mu_{\tilde{a}}(x) & =\text { membership function of a triangular fuzzy set } \tilde{a}, \\
\widetilde{a} & =\text { triangular fuzzy set }\left(a_{1}<a_{2}<a_{3}\right) \\
a_{1}, a_{2}, a_{3} & =\text { triangular fuzzy set parameters, and } \\
x & =\text { crisp input. }
\end{array}
$$

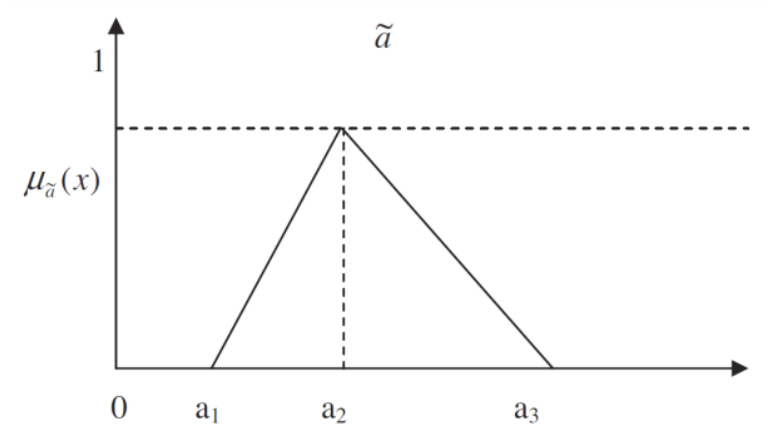

Figure 2-8 Triangular Fuzzy Number $\widetilde{a}$ (Awasthi et al. 2011)

Let $\widetilde{a}=\left(a_{1}, a_{2}, a_{3}\right)$ and $\widetilde{b}=\left(b_{1}, b_{2}, b_{3}\right)$ be two triangular fuzzy sets. The main operations on the two sets are shown below:

$$
\begin{array}{ll}
\tilde{a}(+) \tilde{b}=\left(a_{1}+b_{1}, a_{2}+b_{2}, a_{3}+b_{3}\right), & a_{1} \geq 0, b_{1} \geq 0 \\
\tilde{a}(\times) \tilde{b}=\left(a_{1} \times b_{1}, a_{2} \times b_{2}, a_{3} \times b_{3}\right), & a_{1} \geq 0, b_{1} \geq 0 \\
\tilde{a}(-) \tilde{b}=\left(a_{1}-b_{1}, a_{2}-b_{2}, a_{3}-b_{3}\right), & a_{1} \geq 0, b_{1} \geq 0
\end{array}
$$




$$
\begin{array}{lc}
\tilde{a}(/) \tilde{b}=\left(a_{1} / b_{1}, a_{2} / b_{2}, a_{3} / b_{3}\right), & a_{1} \geq 0, b_{1} \geq 0 \\
\tilde{a}^{-1}=\left(\frac{1}{a_{1}}, \frac{1}{a_{2}}, \frac{1}{a_{3}}\right) & a_{1} \geq 0 \\
k * \tilde{a}=\left(k a_{1}, k a_{2}, k a_{3}\right) & a_{1} \geq 0, k \geq 0 \\
k / \tilde{a}=\left(k / a_{1}, k / a_{2}, k / a_{3}\right) & a_{1} \geq 0, k \geq 0 \\
\tilde{a} / k=\left(a_{1} / k, a_{2} / k, a_{3} / k\right) & a_{1} \geq 0, k \geq 0 \\
\tilde{a}(+) \tilde{b}=\tilde{b}(+) \tilde{a} & \\
\tilde{a}(\times) \tilde{b}=\tilde{b}(\times) \tilde{a} & \\
\tilde{a}(-) \tilde{b}=\tilde{b}(-) \tilde{a} & \\
k * \tilde{a}=\tilde{a} * k &
\end{array}
$$

The distance between the two sets is obtained using the vertex method, as shown in the equation below.

$$
d(\tilde{a}, \tilde{b})=\sqrt{\frac{1}{3}\left[\left(a_{1}-b_{1}\right)^{2}+\left(a_{2}-b_{2}\right)^{2}+\left(a_{3}-b_{3}\right)^{2}\right]}
$$

where,

$$
\begin{array}{ll}
d(\tilde{a}, \tilde{b}) & =\text { distance between the two fuzzy sets } \tilde{a} \text { and } \tilde{b}, \\
a_{1}, a_{2}, a_{3} & =\text { triangular fuzzy set } \tilde{a} \text { parameters, and } \\
b_{1}, b_{2}, b_{3} & =\text { triangular fuzzy set } \tilde{b} \text { parameters. }
\end{array}
$$

\subsubsection{Fuzzy TOPSIS Steps}

The first step when using the fuzzy TOPSIS is computing the decision matrix. Let us assume there are $\mathrm{m}$ alternatives, $\mathrm{n}$ criteria and $\mathrm{k}$ decision makers to rate the criteria. The performance ratings of each decision maker $\mathrm{k}(\mathrm{k}=1,2, \ldots, \mathrm{K})$ for each alternative $\mathrm{A}_{\mathrm{j}}$ 
$(\mathrm{j}=1,2, \ldots, \mathrm{n})$, with respect to criteria $\mathrm{C}_{\mathrm{i}}(\mathrm{i}=1,2, \ldots, \mathrm{m})$, are defined as $\tilde{R}_{k}=\tilde{x}_{i j k}$ with a membership function of $\mu_{\tilde{R}_{k}}(x)$, as defined in the equation below, if the triangular fuzzy set is used:

$$
\tilde{x}_{i j k}=\left(a_{i j k}, b_{i j k}, c_{i j k}\right)
$$

where,

$$
\begin{aligned}
\tilde{x}_{i j k} & =\text { The performance ratings of each decision maker } \mathrm{k} \text { for each } \\
& \text { alternative } \mathrm{A}_{\mathrm{j}} \text { with respect to criteria } \mathrm{C}_{\mathrm{i}}, \\
a_{i j k}, b_{i j k}, c_{i j k}= & \text { triangular fuzzy set } \tilde{x} \text { parameters. }
\end{aligned}
$$

Therefore, each element of the decision matrix, which is denoted as $X_{i j}(\mathrm{i}=1,2, \ldots$, $\mathrm{m}$ and $\mathrm{j}=1,2, \ldots, \mathrm{n})$ is given by aggregating $\tilde{x}_{i j k}$, as shown below.

$$
\tilde{X}_{i j}=\left(a_{i j}, b_{i j}, c_{i j}\right)
$$

where,

$$
\begin{aligned}
a_{i j} & =\min \left(a_{i j k}\right), \\
b_{i j} & =\frac{\sum_{k=1}^{K} b_{i j k}}{k}, \text { and } \\
c_{i j} & =\max \left(c_{i j k}\right) .
\end{aligned}
$$

Finally, the fuzzy decision matrix is constructed, as shown below.

$$
\widetilde{D}=\left[\begin{array}{ccc}
\tilde{x}_{11} & \cdots & \tilde{x}_{1 n} \\
\vdots & \ddots & \vdots \\
\tilde{x}_{m 1} & \cdots & \tilde{x}_{m n}
\end{array}\right] \quad i=1,2, \ldots, m ; j=1,2, \ldots, n
$$

where $\widetilde{D}$ is the decision matrix.

The second step is computing the criteria weights. The aggregated fuzzy weights $\widetilde{w}_{i j}$ of each criterion are obtained using the following equation: 


$$
\widetilde{w}_{j}=\left(w_{j 1}, w_{j 2}, w_{j 3}\right)
$$

where,

$$
\begin{aligned}
& \widetilde{w}_{j}=\text { fuzzy weight for criterion } \mathrm{j}, \\
& w_{j 1}=\min \left(a_{j k 1}\right), \\
& w_{j 2}=\frac{\sum_{k=1}^{K} w_{j k 2}}{k}, \text { and } \\
& w_{j 3}=\max \left(w_{j k 3}\right) .
\end{aligned}
$$

In the third step, the decision matrix is normalized. The normalized fuzzy matrix $\widetilde{R}$ is calculated using the following equation:

$$
\tilde{R}=\left[\tilde{r}_{i j}\right]_{m \times n}, \quad i=1,2, \ldots, m ; j=1,2, \ldots, n
$$

where,

$$
\begin{array}{ll}
r_{i j}=\left(\frac{a_{i j}}{c_{j}^{*}}, \frac{b_{i j}}{c_{j}^{*}}, \frac{c_{i j}}{c_{j}^{*}}\right), & c_{j}^{*}=\operatorname{Max}\left(c_{i j}\right) \quad \text { (Beneficial criteria) } \\
r_{i j}=\left(\frac{a_{j}^{-}}{c_{i j}}, \frac{a_{j}^{-}}{b_{i j}}, \frac{a_{j}^{-}}{a_{i j}}\right), \quad a_{j}^{-}=\operatorname{Min}\left(a_{i j}\right) \quad \text { (Non-beneficial criteria) }
\end{array}
$$

The weighted normalized matrix is computed in the fourth step. The weighted normalized matrix $\tilde{V}$ is obtained by multiplying the weights $\left(\widetilde{w}_{j}\right)$ of criteria by the normalized fuzzy decision matrix $\tilde{r}_{i j}$, as shown below:

$$
\tilde{V}=\left[\tilde{v}_{i j}\right]_{m \times n}
$$

where,

$$
\begin{aligned}
& \tilde{V}=\text { weighted normalized matrix, and } \\
& v_{i j}=r_{i j} \times w_{j} .
\end{aligned}
$$


The fuzzy positive ideal solution (FPIS) and fuzzy negative ideal solution (FNIS) are computed in the fifth step. The FPIS and FNIS for each alternative are calculated using the following equations:

$$
A^{*}=\left(\tilde{v}_{1}^{*}, \tilde{v}_{2}^{*}, \ldots, \tilde{v}_{n}^{*}\right)
$$

where,

$$
\begin{aligned}
& A^{*}=\text { fuzzy positive ideal solution, } \\
& \begin{array}{r}
\tilde{v}_{j}^{*}=\max _{i}\left\{v_{i j 3}\right\}, i=1,2, \ldots, m ; j=1,2, \ldots, n . \\
A^{-}=\left(\tilde{v}_{1}^{-}, \tilde{v}_{2}^{-}, \ldots, \tilde{v}_{n}^{-}\right)
\end{array}
\end{aligned}
$$

where,

$$
\begin{aligned}
& A^{-}=\text {fuzzy negative ideal solution, } \\
& \tilde{v}_{j}^{-}=\min _{i}\left\{v_{i j 1}\right\}, i=1,2, \ldots, m ; j=1,2, \ldots, n .
\end{aligned}
$$

In the sixth step, the distance of each alternative from FPIS and FNIS is computed. Each alternative distance from the FPIS and the FNIS is calculated, as shown below:

$$
d_{i}^{*}=\sum_{j=1}^{n} d_{v}\left(\tilde{v}_{i j}, \tilde{v}_{j}^{*}\right), i=1,2, \ldots, m
$$

where,

$$
\begin{aligned}
& d_{i}^{*} \quad=\text { distance of alternative } \mathrm{i} \text { from the fuzzy positive ideal solution, and } \\
& d_{v}(\tilde{a}, \tilde{b})=\text { distance between fuzzy numbers } \tilde{a} \text { and } \tilde{b} \\
& \qquad d_{i}^{-}=\sum_{j=1}^{n} d_{v}\left(\tilde{v}_{i j}, \tilde{v}_{j}^{-}\right), i=1,2, \ldots, m
\end{aligned}
$$

where $d_{i}^{-}$is the distance of alternative i from the fuzzy negative ideal solution. 
Then, the closeness coefficient of each alternative is calculated. Each alternative's closeness coefficient, $C C_{i}$, is calculated, as shown below:

$$
C C_{i}=\frac{d_{i}^{-}}{d_{i}^{-}+d_{i}^{*}}, i=1,2, \ldots, m
$$

where $C C_{i}$ is alternative i closeness coefficient.

Finally, the alternatives are ranked based on this closeness coefficient in a descending order. The best alternative is closest to FPSI and farthest from FNIS (Awasthi et al. 2011).

\subsection{Summary}

Bottleneck management (recurrent and non-recurrent) is one of the crucial TMC functionalities that can help alleviate freeway congestion. Detection of bottlenecks and their attributes, including the identification of the extent (back-of-queue) is an important part of TMC's operation. Timely bottleneck/incident detection has been the topic of many research papers starting in the 1970s. Several advanced algorithms have been proposed for bottleneck/incident detection ever since. Point-detectors and probes have been the source of data for most of these algorithms. There is a lack of studies on utilizing the connected vehicle data as an alternative source of data for bottleneck identification. It is necessary to assess the performance of the existing and emerging technologies in bottleneck identification by the new algorithms and use it as a basis for the alternative selection process.

It is also necessary to identify a method to support the selection between legacy and emerging technologies for bottleneck management. Several MCDA methods have been developed to facilitate the decision-making process. The main MCDA methods

were elaborated in this chapter. The basis for most of the MCDA methods is the same 
and includes: (1) assigning a weight to each evaluation criterion based on decision makers' pairwise comparisons of the criteria; (2) assigning a score to each alternative based on the decision maker's pairwise comparison of the alternatives for each criterion. The higher the score, the better the alternative with respect to the corresponding criterion; and (3) combining the criteria weights and alternative scores and generating a global score for each alternative. Among the MCDA methods reviewed in this chapter, the AHP method is one of the most widely used methods in the transportation field. With the introduction of $\mathrm{CV}$ technology, there is a need to utilize the MCDA methodology for ITS investment decision problems, as will be done in this study. 


\section{CHAPTER III}

\section{METHODOLOGY}

\subsection{INTRODUCTION}

This chapter provides a detailed description of the methods developed and proposed as a part of this dissertation to achieve the defined objectives. The incident/bottleneck detection and queue estimation and warning methods were adopted from the literature and modified for the CV technology application. The performance of the adopted methods was tested using $\mathrm{CV}$ and point detector data and used in the proposed MCDA framework of this dissertation. The proposed MCDA method which is a combination of return on investment and AHP analysis was applied to an ITS investment case study for the purpose of alternative selection.

Figure 3-1 shows the general framework of the methodology used to accomplish the objectives of this research. The first part describes the data acquisition and processing. Multiple data sources were utilized to calibrate, develop, and test the models and methods used in this research work. As the focus of the study is on bottleneck management, two TMC-related CV applications that help manage bottlenecks were implemented as a part of the study framework to support agencies in the ITS investment decisions: incident/bottleneck detection and queue warning.

The second part of this chapter presents proposed algorithms for incident/bottleneck detection and queue estimation and warning utilizing CV data. To test the developed algorithms, a one-lane blockage incident was modeled in a microscopic simulation to generate a bottleneck location for the purpose of this study. The simulation model was calibrated for the incident condition using real-world data (explained in the 
data collection section). An incident/bottleneck detection algorithm inspired by the California method was developed and modified based on CV data to detect abnormalities in traffic behavior. The bottleneck and back-of-queue were detected based on the simulated connected vehicle data, and the queue warning message was disseminated dynamically at a specific location in the simulated corridor, upstream of the back-ofqueue using a DMS or connected vehicle on-board units (OBUs). The performance of the proposed algorithms, including the incident/bottleneck detection and back-of-queue estimation, was tested using simulated connected vehicle data, as well as simulated point detector data, to provide the basis for an alternative selection process utilizing MCDA.

In the third part, a novel MCDA method composed of a stochastic return on investment and the AHP method is proposed. The approach is applied to a case study of freeway bottleneck management service, which includes incident/bottleneck detection and travel time estimation to support the selection between $\mathrm{CV}$ deployment and legacy detection technology. It should be noted that the application of this MCDA methodology can be applied to any other ITS service.

\subsection{Data Collection and Processing}

As mentioned in the previous section, data sources and modeling tools were used in this study to develop, calibrate and test the developed methods, as listed below:

- The VISSIM micro-simulation was used to simulate traffic under normal and incident conditions. For both incident detection and queue warning applications, a virtual incident was created in the traffic simulation model. A real-world network was used to test the developed methods for incident detection, back-of-queue 
estimation, and queue warning. The network is a 15-mile segment of the I-95 southbound (SB) corridor in Broward County, Florida.

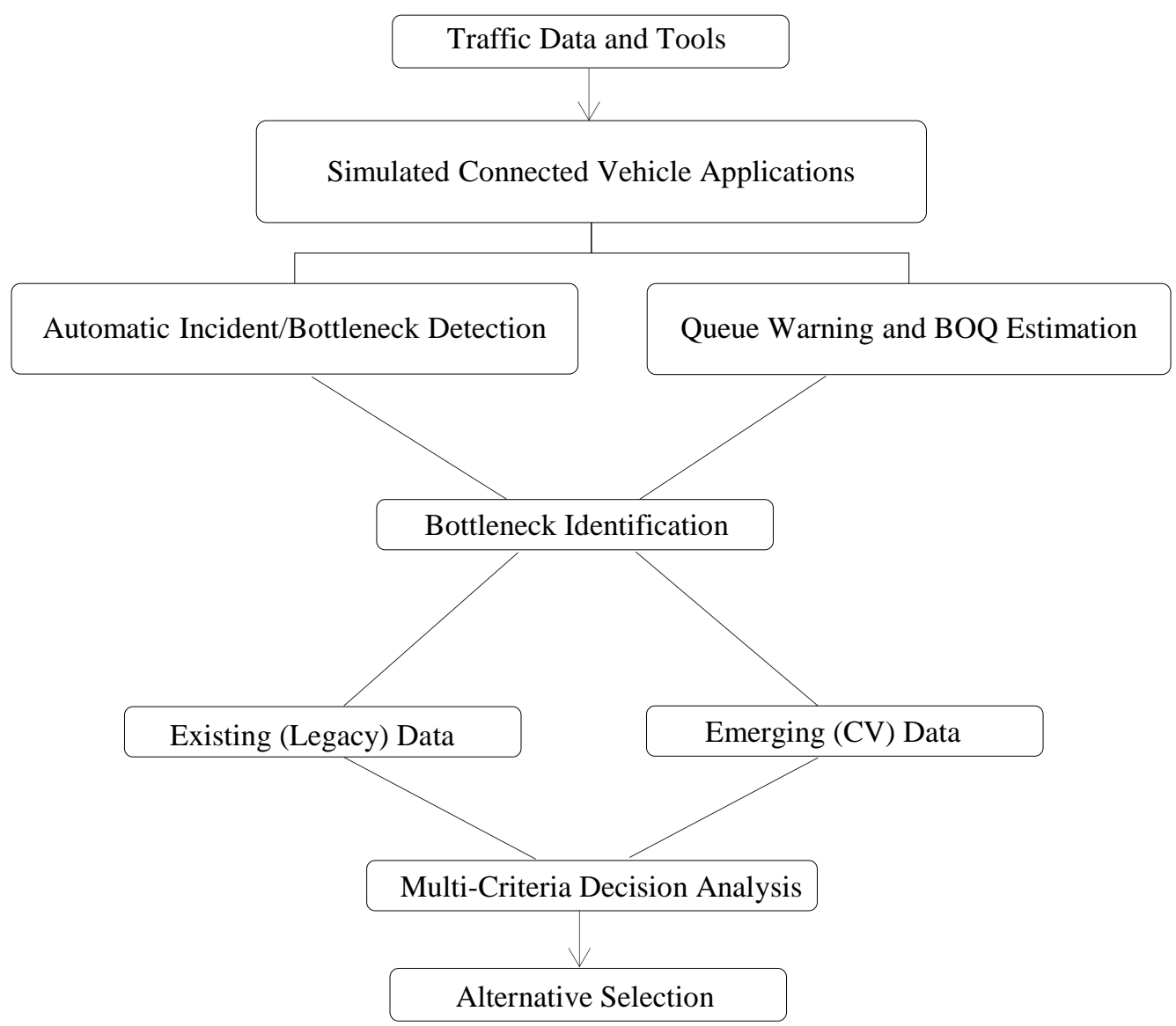

Figure 3-1 Methodology Framework

- Real-world data were used, which included speed and occupancy measurements from point detectors on I-95 SB and the associated incident database. In order to model an incident in VISSIM, a real-world incident on the I-95 SB facility was selected from the I-95 incident database. Then, using measurements from the point detectors, the traffic performance was calibrated for incident condition.

- The Trajectory Conversion Algorithm (TCA) produced by the FHWA (2014) was used to emulate the connected vehicle data based on vehicle trajectory data 
generated from simulation models. The TCA can read vehicle trajectories from simulations or real-world data and emulate the transmission of the Basic Safety Messages (BSM), Probe Data Messages (PDMs) and European Cooperative Awareness Messages (CAM). The method of the study assumes that the speed of the vehicles will be estimated based on data collected from connected vehicles using the BSM, as specified in the SAE J2735 standards (2009).

- The Surrogate Safety Assessment Model (SSAM) tool was used to evaluate the safety impacts of the tested queue warning system. SSAM is a tool developed by the FHWA for performing safety analysis of vehicle trajectory data generated by micro-simulation software to calculate the frequency of different types of conflicts, including crossing, lane-changing, and rear-end conflicts, and severity indicators such as time-to-collision (TTC) and post-encroachment time (PET). The tool computes safety surrogate measures for each conflict and then generates a summary of the surrogate measures, including the mean, maximum, minimum and variance. A conflict is a situation in which two vehicles approach each other so that there is a risk of collision if they continue their movements. TTC is estimated using the speed, position, and future trajectory of the two vehicles. If the estimated TTC is less than a threshold, the movement is identified as a conflict. The conflict type is another output of the SSAM tool that determines whether the conflict is related to rear-end, lane-change, or crossing movements (Gettman et al. 2008). 


\subsection{TMC-BASEd CONNECTED Vehicle APPLICATIONS}

Two TMC-based connected vehicle applications were implemented and assessed in this study: incident/bottleneck detection and queue warning. The detailed description of the proposed algorithms for each of the applications is provided below.

\subsubsection{Incident/Bottleneck Detection}

In this study, a freeway incident/bottleneck detection method based on a vehicle's speed estimated by connected vehicle data inspired by the literature was developed. The speed is expected to change due to most incident conditions, although the change is expected to be a function of the congestion level with and without incidents. Minor incidents that do not attract some attention from the drivers to cause them to change their speeds will not be detected by this method. The method of the study assumes that the speed of the vehicles will be estimated based on data collected from connected vehicles using the BSM of the SAE J2735 standards. It is assumed that the BSM messages will be communicated to the infrastructure using DSRC, cellular communication or other communication technologies.

The proposed method, which is referred to as the "Speed Difference Method," is a simplified version of the California algorithm. This method is based on hypothesis testing of the occurrence of the incident in a segment (the hypothesis test segment) and aims to detect the abnormality in traffic conditions using a predefined threshold based on the acceptable probability of false alarms. The network is decomposed to "m" segments and the average speed of each segment is calculated at each time step. This method simply takes the average of the measurements in each segment during a time period (45 seconds 
in this study), and if the difference between the downstream average speed and upstream average speed is more than a threshold, the location is identified as the incident location. The 99 percentile of speed difference distribution under the no-incident condition is selected as the threshold for testing the hypothesis for an incident on the subject segment. In other words, the probability of false alarm was set to $1 \%$ and the associated threshold was calculated. The process of providing inputs for the incident detection method is shown in Figure 3-2.

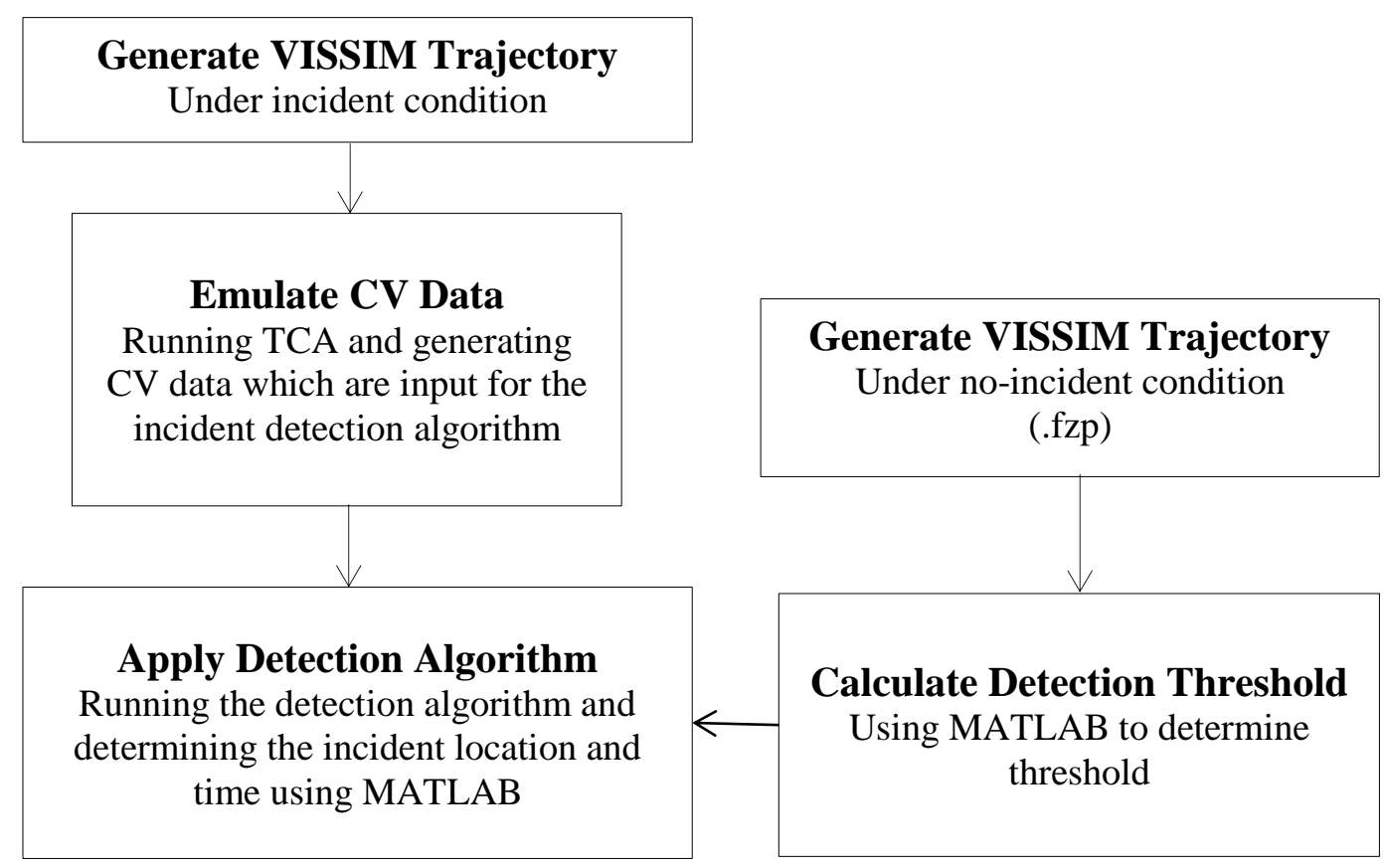

Figure 3-2 Process of Providing Input for the Incident Detection Method

The method was tested using the VISSIM microscopic simulation tool. VISSIM was used to emulate an incident occurring in a mixed connected vehicle and not connected vehicles in a traffic stream. The vehicle's trajectories produced by VISSIM was fed to the TCA tool (2014) to emulate BSM messages generating from the simulation. Then, the generated BSM messages were input into the incident detection method to investigate its performance. 


\subsubsection{VISSIM Calibration for Incident Condition}

A one-lane blockage incident was introduced into the traffic stream in the microscopic simulation model to emulate a non-recurrent bottleneck condition for the purpose of this study. Since VISSIM cannot model incidents directly, the incident was modeled by creating a signal head in one lane of the freeway, and the rubbernecking effect was modeled by changing the car-following factors upstream of the incident location through the VISSIM COM interface.

The values of the car-following factors for the incident link during the incident conditions were changed based on values recommended in the literature. Knoop et al. (1990) explored driver behaviors under incident conditions by looking at the vehicles' trajectories collected by a helicopter from two actual incidents. The results showed that the driver's reaction time, headway distribution, and capacity are affected by the presence of the incident. A bimodal headway distribution, an increase in reaction time, and a $30 \%$ decrease in capacity were observed in incident conditions. Some researchers found that the incident impacts can be modeled by changing VISSIM car-following factors. A detailed description of the VISSIM car modeling factors can be found in the VISSIM user manual (2012). A study of the VISSIM calibration parameters (Woody 2006) found that the $\mathrm{CC} 0, \mathrm{CC} 1, \mathrm{CC} 2, \mathrm{CC} 4$ and $\mathrm{CC} 5$ parameters have the most effect on the capacity of a freeway link. $\mathrm{CC} 0$ is the desired distance between stopped cars. $\mathrm{CC} 1$ is the desired time headway that the driver wants to keep from the leading vehicle. CC2 is the safety distance, which is the minimum distance a driver keeps from the leading vehicle. CC4 and CC5 are the parameters controlling the speed differences between a following and leading vehicle. Increasing $\mathrm{CC} 0, \mathrm{CC} 1$, and the absolute value of the $\mathrm{CC} 4 / \mathrm{CC} 5$ ratio result 
in capacity reduction. Gomes et al. (2004) modified the CC1, CC2, and CC4/CC5 parameters to model the capacity drops resulting from curvatures. The calibrated parameters for the studied freeway segment were $\mathrm{CC} 1, \mathrm{CC} 2$, and $\mathrm{CC} 4 / \mathrm{CC} 5$, with the values of 1.7, 0.9 and -2/2, respectively. Rahman et al. (2014) found that the carfollowing values proposed in prior studies for incident modeling produced better results in terms of macroscopic measures, compared to the default values. Rompis et al. (2014) developed a methodology for VISSIM calibration based on the kinematic queuing theory. In this study, incidents were modeled by coding a traffic signal in VISSIM. Based on the results from the reviewed studies, the $\mathrm{CC} 0, \mathrm{CC} 1$ and $\mathrm{CC} 2$ values were changed to replicate the actual freeway operation under incident conditions.

\subsubsection{Queue Warning}

In the previous section, the incident detection method based on $\mathrm{CV}$ data, as utilized in this study, was explained. Once the incident is detected, the back-of-queue estimation algorithm and queue warning are activated in the simulation model. To identify the back-of-queue, the segments are sorted based on their position, compared to the incident location. If a segment average speed is below a threshold, the segment is considered queued. The algorithm continues to test if the next upstream segment is queued and the first unqueued segment upstream of the incident is declared as the backof-queue. The BOQ estimation algorithm is shown in Figure 3-3. Lastly, the performance of the connected vehicle-based BOQ detection is compared with the ground truth queue based on VISSIM results and with the queue estimated based on point detection in the simulation. The point detector-based BOQ algorithm is taken from the Pesti et al. (2013) study, which estimates the location of queue using the following equation. 


$$
X=X_{D E T}(i)+\frac{1}{2} \Delta X_{D E T}
$$

where,

$$
\begin{aligned}
& X \quad=\text { back-of-queue location, } \\
& X_{D E T}(i)=\text { distance from the incident location to the speed detector } \mathrm{i}, \text { and } \\
& \Delta X_{D E T}=\text { detector spacing. }
\end{aligned}
$$

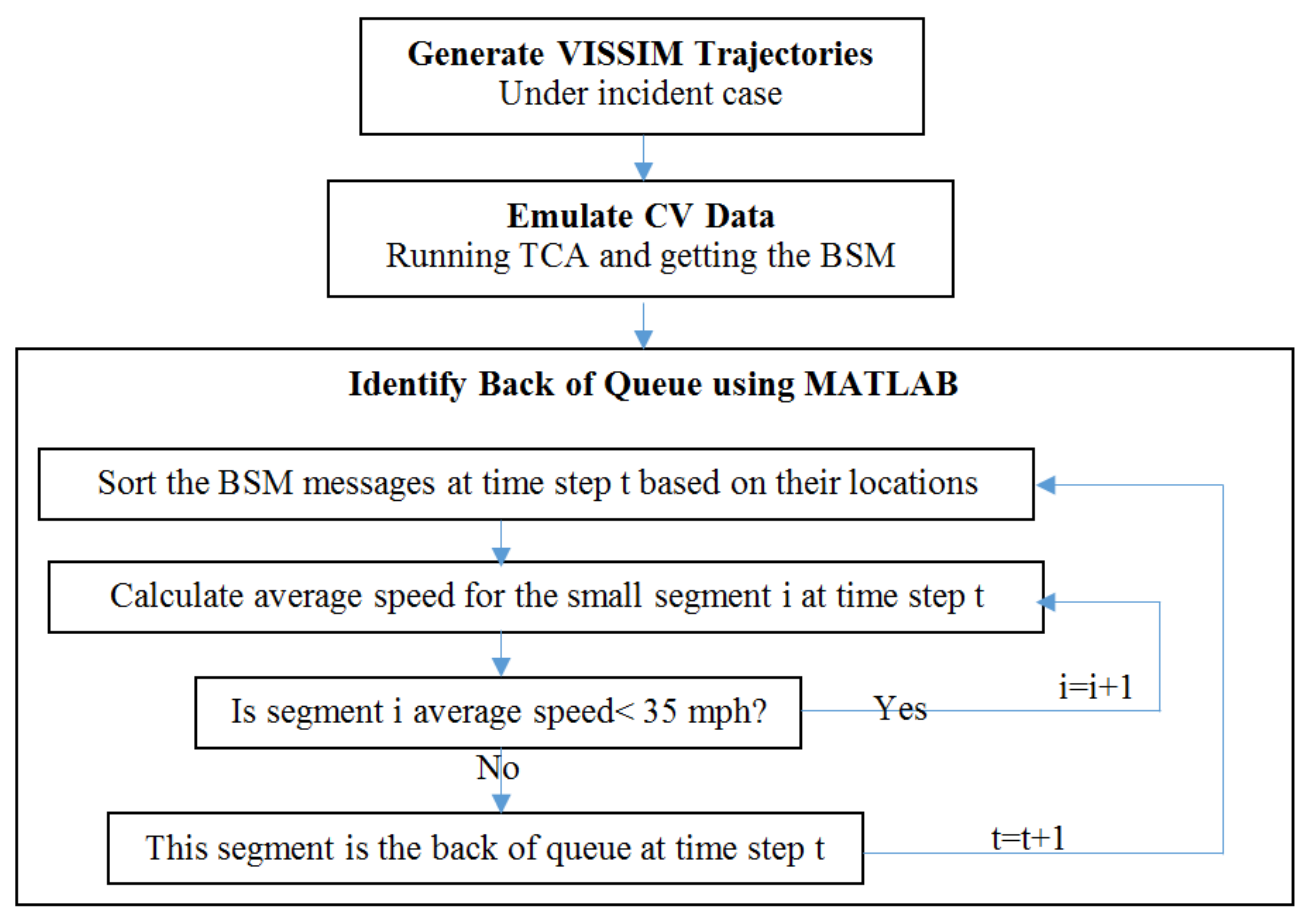

Figure 3-3 Back-of-Queue (BOQ) Estimation Algorithm

The queue warning system is activated when the incident (or recurrent bottleneck) is detected and the queue starts growing. In this study, the queue warning impact is modeled by changing a certain percentage of a vehicle's speed upstream of the queue using the VISSIM COM interface. It is assumed that the back-of-queue is detected by the connected vehicle data and the queue warning message is shown dynamically at a specific location upstream of the back-of-queue using a DMS or connected vehicle onboard units (OBUs). The proportions of vehicles changing speeds in response to OBU 
messages reflect the number of connected vehicles equipped with OBU and driver acceptance of the message advisory. In the future, with the introduction of connected automated vehicles, the response to queue warning messages will be set automatically by the vehicle, and the driver acceptance will become less of a factor.

The vehicle's trajectories produced by VISSIM are fed to the TCA tool to emulate BSM messages generating from the simulated vehicles. The generated BSM messages are input to the incident and BOQ detection algorithms utilized in this study to investigate their performances. The trajectories of the simulated vehicles are also input to the SSAM tool to obtain safety surrogate measures to analyze the safety benefits of the queue warning system.

\subsection{InVESTMENT DECISION SUPPORT METHOdology}

Decisions to invest in alternative ITS technologies to support transportation system management and operations (TSMO) are expected to increase in complexity, particularly with the introduction of $\mathrm{CV}$ and automated vehicles (AV) in the coming years.

Although the rate of deployment of new technologies is highly uncertain, $\mathrm{CV}$ and AV technologies promise significant potential savings and opportunities for TSMO applications. Traditionally, ITS technology and associated strategy alternatives have been assessed using return on investment analyses that utilize methods like deterministic Net Present Value (NPV) and Discounted Cash Flow (DCF). For example, the traditional NPV method involves deterministic estimates of the present values of the current and future benefits and costs over the project's life. Discount rates are used to calculate the present value of cash flows. These methods are unable to capture the risks and 
uncertainties associated with the investment problem (Wright et al. 2014). The Monte Carlo method (Boyle 1977) is capable of integrating multiple sources of uncertainty and has been used in various fields to account for uncertainty by expressing cost and benefit parameters as probability distributions rather than as fixed values (Yang et al. 2007, Neufville et al. 2011, Sullivan et al. 1982, Cox et al. 1999). Therefore, the Monte Carlo simulation method was selected for use to account for the uncertainty in traffic flow.

Measures that are difficult to be assessed in dollar values cannot be accounted for using the economic return on investment analysis methods. In addition, these methods cannot account for agency preferences and constraints that cannot be converted to dollar values. Thus, these methods are not fully adequate for use in assessing technology alternatives (Sullivan 1985). As described in the review of the literature section, MCDA methods have been proposed to account for both qualitative and quantitative factors in the decision-making process.

Among the MCDA methods reviewed in Chapter II, the AHP method developed by Saaty (1980) has been the most widely used in various disciplines, including transportation engineering. According to the Macharis et al. (2005) study, 33\% of the reviewed publications on utilizing MCDA in the transportation field used AHP or a variant of AHP in their analysis. Hence, the AHP method was selected for use in this study.

This study proposes a combination of a stochastic NPV and the AHP method to select between ITS deployment alternatives with consideration of emerging technologies. The approach is applied to the selection between CV deployment and legacy detection technology to support the freeway traffic data collection and monitoring service, which 
includes incident detection and travel time estimation. It should be noted that the application to the data collection and monitoring service is utilized as a case study, and the methodology can be applied to any other ITS services. The stochastic NPV analysis utilizes a Monte Carlo approach to account for uncertainty in the estimation of the benefits and costs of utilizing CV versus the legacy systems. The AHP method involves the consideration of various criteria and measures weighed by agency priorities and preferences. This approach considers these priorities and preferences, in addition to accounting for measures that cannot be converted to dollar values. Both of these considerations are not possible with the NPV analysis. The results from the NPV analysis are included as one of the four objectives defined in the AHP evaluation. The other three objectives are the provision of the required functions, achieving the required performance, and minimizing the risks and constraints. The results of the selection among the various alternatives are expected to be dependent on the input parameters, which are different for different agencies and locations.

A four-level decision-making hierarchy according to the AHP method is defined for the purpose of alternative selection in this study, as shown in Table 3-1. The top level of the decision hierarchy or the goal for the case study service is "To select between CV and existing detection technologies for providing traffic data collection and monitoring service." The two middle levels of the hierarchy include the overall objectives and the sub-criteria associated with each of the objectives, and the lower level is the alternative level. The monetizable measures are assessed in the stochastic NPV analysis using the Monte Carlo simulation, and the NPV results are included as a criterion in the AHP analysis. The non-monetizable measures are included as additional measures in the AHP 
analysis. The NPV and AHP analysis, as conducted in this study, are discussed in more details in the following subsections.

Table 3-1 Criteria for Selection between Emerging and Existing Traffic Monitoring and Data Collection Technologies

\begin{tabular}{|c|c|c|c|}
\hline Goal & Objectives & Sub-Criteria & Alternatives \\
\hline \multirow{15}{*}{$\begin{array}{l}\text { Selecting between } \mathrm{CV} \text { and } \\
\text { existing detection } \\
\text { technologies for providing } \\
\text { traffic data collection and } \\
\text { monitoring service }\end{array}$} & \multirow{3}{*}{$\begin{array}{l}\text { 1-Provision } \\
\text { of the } \\
\text { required } \\
\text { functions }\end{array}$} & $\begin{array}{l}\text { 1.1- Ability to measure travel } \\
\text { time }\end{array}$ & \multirow{15}{*}{$\begin{array}{l}\text { Alternative 1: } \\
\text { Point } \\
\text { detectors }\end{array}$} \\
\hline & & $\begin{array}{l}\text { 1.2- Ability to measure volume } \\
\text { and/or density }\end{array}$ & \\
\hline & & $\begin{array}{l}\text { 1.3- Ability to measure new } \\
\text { measures (acceleration noise, } \\
\text { stops, breaks, wiper on/off, light } \\
\text { on/off, emission, potential for } \\
\text { crashes etc.) }\end{array}$ & \\
\hline & \multirow{3}{*}{$\begin{array}{l}\text { 2-Achieving } \\
\text { the required } \\
\text { performance }\end{array}$} & $\begin{array}{l}\text { 2.1-Mean absolute error in } \\
\text { measurement }\end{array}$ & \\
\hline & & $\begin{array}{l}\text { 2.2-Stdandard deviation of error } \\
\text { of measurement }\end{array}$ & \\
\hline & & 2-3 Detection timeliness & \\
\hline & \multirow{7}{*}{$\begin{array}{l}\text { 3-Minimizing } \\
\text { the risks and } \\
\text { constraints }\end{array}$} & 3.1-Technology uncertainty & \\
\hline & & 3.2-Standard stability & \\
\hline & & $\begin{array}{l}\text { 3.3-Uncertainty in business } \\
\text { model }\end{array}$ & \\
\hline & & $\begin{array}{l}\text { 3.4-Data archiving and } \\
\text { processing and technical skill } \\
\text { concerns }\end{array}$ & \\
\hline & & $\begin{array}{l}3.5 \text {-Funding (initial and } \\
\text { recurring) }\end{array}$ & \\
\hline & & $\begin{array}{l}\text { 3.6-Data availability and sharing } \\
\text { concern }\end{array}$ & \\
\hline & & $\begin{array}{l}\text { 3.7-Security and privacy } \\
\text { concerns }\end{array}$ & \\
\hline & \multirow{2}{*}{$\begin{array}{l}\text { 4- } \\
\text { Maximizing } \\
\text { the return on } \\
\text { investment } \\
\text { based on } \\
\text { NPV }\end{array}$} & $\begin{array}{l}\text { 4.1-Median present worth (based } \\
\text { on Monte Carlo analysis) }\end{array}$ & \\
\hline & & $\begin{array}{l}\text { 4.2- } 15 \% \text { present worth (based } \\
\text { on Monte Carlo analysis) }\end{array}$ & \\
\hline
\end{tabular}

\subsubsection{NPV Analysis}

Maximizing the return on investment is one of the criteria included in this study's MCDA analysis, as indicated in Table 3-1. As stated earlier, this study utilizes a 
stochastic approach based on the Monte Carlo analysis to estimate the NPV. This section describes the assessment of the return on investment of utilizing connected vehicle data versus traditional point-detector data to detect freeway incidents, and collect travel time information using a case study of a 15-mile long freeway facility in Florida. Unlike the traditional return on investment analysis, which calculates deterministic point estimates of the NPV of the project's alternatives, the NPV analysis of this study employs a Monte Carlo simulation to account for the uncertainties involved in the assessment and generates a distribution for each alternative's NPV. To calculate the NPV, the alternative benefits and costs need to be calculated first, as discussed in the following subsections.

\subsubsection{Traffic Data Collection and Monitoring Benefits}

The incremental benefits of traffic monitoring technology alternatives are assumed to result from: 1) faster incident/bottleneck detection that results in lower delays; and 2) more accurate traveler time estimation that results in better diversion decisions.

The first part of the benefits is due to faster incident/bottleneck detection. To evaluate the two alternatives of this study ( $\mathrm{CV}$ versus point detectors), a base case was defined and the benefit, in terms of delay reduction, of each alternative was calculated relative to the base case, as shown in the following equation. The defined base case is "No detection technology," which involves detection utilizing service patrol, police calls, CCTV monitoring, and other "manual" methods, but no infrastructure-based incident detection.

$$
\text { Incident Detection Benefit }{ }_{i}=\left(T D_{\text {base }}-T D_{\text {alternative }}\right) \times V O T \times I F_{i}
$$

where, 
$T D_{\text {base }} \quad=$ total delay of the base alternative (veh-hr),

$T D_{\text {alternative }}=$ total delay of the alternative (veh-hr),

VOT = value of time (dollars), and

$I F_{i} \quad=$ total number of incidents for the $\mathrm{i}^{\text {th }}$ year.

The benefits of using CV data versus point detector data were calculated using the difference between the benefits in delay when utilizing $\mathrm{CV}$ data for detection $\left(T D_{C V}\right)$ in veh-hr and the benefits in delay when using detector data for detection $\left(T D_{\text {detector }}\right)$. The delay saving of incident detection is assessed using queuing theory equations (May 1990) that calculate the total delay (TD) based on demand, capacity, and incident duration, as follows:

$$
\begin{aligned}
& T D=t_{R} t_{Q}\left(\lambda-\mu_{R}\right) / 2 \\
& t_{Q}=t_{R}\left(\mu-\mu_{R}\right) /(\mu-\lambda)
\end{aligned}
$$

where,

$$
\begin{aligned}
\lambda \quad= & \text { arrival rate }(\text { demand })(\mathrm{vph}) \\
\mu \quad= & \text { departure rate }(\mathrm{vph}), \\
\mu_{R} \quad= & \text { reduced capacity rate under metering for ramps or under non-recurrent } \\
& \text { conditions for the mainline }(\mathrm{vph}), \\
t_{R}= & \text { event duration }(\mathrm{hr}), \text { and } \\
t_{Q} \quad= & \text { time in queue duration }(\mathrm{hr}) .
\end{aligned}
$$

An important input to the calculation of delay in the above equations is the reduction in the incident duration due to the reduction in the detection time resulting from applying the alternative detection technology. The incident detection time based on CV 
data and traffic detector data were derived based on simulation results and are presented in Chapter IV. The general format of the developed equations is shown below, with the derived equations presented in Chapter IV:

$$
M T T D_{C V}=f\left(M P, \frac{v}{c}\right)
$$

where,

$$
\begin{array}{ll}
\text { MTTD }_{C V} & =\text { mean time to detect using CV data }(\mathrm{min}), \\
\mathrm{MP} & =\mathrm{CV} \text { market penetration }(\%), \\
\mathrm{v} & =\text { volume }(\mathrm{vph}), \text { and } \\
\mathrm{c} & =\text { capacity }(\mathrm{vph}) . \\
& \\
&
\end{array}
$$

where,

$$
\begin{aligned}
\text { MTTD }_{\text {detector }}= & \text { mean time to detect using detector data }(\min ), \text { and } \\
= & \text { distance between the closest upstream point detector to the } \\
& \text { incident location }(\mathrm{ft})
\end{aligned}
$$

Equations 3-2 to 3-6 include several stochastic variables that result in uncertainty in the benefit analysis. The uncertainty in the incident rate, $\mathrm{CV}$ market penetration, traffic demand, incident location with respect to the point detectors, incident detection time without infrastructure detection, and the value of time were accounted for by varying these variables in the Monte Carlo analysis, specifically by expressing the variables as distributions rather than point estimates. The parameters of the distributions utilized in this study were borrowed from previous studies. The lane blockage incident rate was assumed to have a Poisson distribution, with a mean of 0.616 per million VMT per hour per lane, based on a previous study by the authors for the same location of the study area 
(Hadi et al. 2008). The variance of the Poisson distribution is equal to the mean. The utilized VOT stochastic distribution in the Monte Carlo simulation is calculated based on a distribution derived in a study by Hossan et al. (2016). The travel demand is assumed to have a fixed coefficient of variation calculated based on real-world data in Florida and with the mean demands changing according to a uniformly distributed random annual growth rate between $0.5 \%$ and $1.5 \%$. The location of the incident is assumed to vary according to a uniform distribution between $20 \mathrm{ft}$ and 2,250 $\mathrm{ft}$ from the upstream detector, with a detector spacing of half a mile.

The base case incident detection time (no detection technology) is assumed to follow a normal distribution with a mean of 6.856 minutes and a standard deviation of 1.782 minutes for detection based on the service patrol, a mean of 4.63 minutes, and a standard deviation of 3.273 minutes for detection using other methods (CCTV, FHP, and other manual methods), as estimated by Qiang et al. for the study area (Qiang et al. 2009). These distributions are used in the Monte Carlo simulation to determine the detection time with no detection technology. The connected vehicle market penetration is assumed to follow a lognormal distribution, as derived in a study by Iqbal et al. (2017).

The second part of the benefits is due to providing more accurate travel time information. The benefits of travel time accuracy in terms of the impact on diversion decisions made by travelers during incidents were also included in the return on investment analysis. The Standard Deviation of Percentage Error (SDPE) was used as a measure to estimate the reliability of the information since this measure was associated with the dollar value in a previous study. The SPDE with point traffic detection was calculated by assuming a random value between $10 \%$ and $20 \%$, based on a previous 
assessment of this parameter for estimating travel time during incident conditions (Xiao 2011). The SPDE of travel time estimated based on CV data was calculated as a function of the stochastic CV market penetration using the following equation (Hadi 2017):

$$
S P D E=25.15-19.81 \cos \left(\frac{v}{c}\right)-0.75 \log (M P)-11.56 \frac{v}{c}+0.02(M P)
$$

where,

$$
\begin{array}{ll}
S P D E & =\text { standard deviation of percentage error, } \\
\mathrm{v} & =\text { volume }(\mathrm{vph}), \\
\mathrm{c} & =\text { capacity }(\mathrm{vph}), \text { and } \\
\mathrm{MP} & =\mathrm{CV} \text { proportion. }
\end{array}
$$

To convert the travel time estimation error impact on traveler diversion decisions to dollar values, the relationship developed by Toppen et al. (2003) was used, which converts the SDPE measures to dollar values, as shown in the following equation:

$$
S=1.2-0.003918 \times S P D E_{i}^{2}
$$

where,

$\mathrm{S} \quad=$ monetary value of travel time accuracy per trip (\$), and $\mathrm{SPDE}_{\mathrm{i}}=\mathrm{i}^{\text {th }}$ year travel time standard deviation of percentage error.

The yearly benefits of travel time accuracy were then calculated by multiplying the dollar value obtained from Equation 3-8 by the yearly number of trips passing the incident location in the presence of queue and were willing to divert, as shown in the equation below:

$$
\text { TT Accuarcy Benefit }_{i}=\left(1.2-0.003918 \times S P D E_{i}^{2}\right) * t Q_{i} \times D_{i} \times I F_{i} \times D R_{i}
$$
where,

TT Accuarcy Benefit ${ }_{i} \quad \mathrm{i}^{\text {th }}$ year travel time accuracy benefit, 


$$
\begin{array}{ll}
\mathrm{SPDE}_{\mathrm{i}} & =\mathrm{i}^{\text {th }} \text { year travel time standard deviation of error, } \\
t Q_{i} & =\mathrm{i}^{\text {th }} \text { year queue duration calculated using the } \\
& \quad \text { queuing theory as presented in Equation 3-4, } \\
D_{i} & =\mathrm{i}^{\text {th }} \text { year travel demand, } \\
I F_{i} & =\mathrm{i}^{\text {th }} \text { year incident frequency, and } \\
D R_{i} & =\mathrm{i}^{\text {th }} \text { year diversion rate. }
\end{array}
$$

The diversion rate is assumed to be a random value between $20 \%$ and $40 \%$. It should be noted that as with the calculation of the incident detection benefits, as reported in the previous section, variables in the above equation are considered random variables in the Monte Carlo analysis. The user of the methodology can change the parameters of the variable distributions if information is available based on additional research or local conditions.

\subsubsection{Traffic Data Collection/ Monitoring Deployment Costs}

Based on the Florida Department of Transportation's (FDOT) District 6 cost database, the point detector cost at each location is estimated to be $\$ 21,800$. This cost includes capital, replacement, calibration, maintenance, design, and mobilization costs. It is assumed that these detectors are installed at a half-mile interval, resulting in a total capital cost of $\$ 665,200$ for the 15-mile segment of study. The connected vehicle deployment costs were extracted from "The Life Cycle Cost Model (LCCM)" developed by the Federal Highway Administration (FHWA) (2015). With this tool, the user is asked to specify the CV Vehicle-to-Infrastructure (V2I) application of interest, as well as other questions to determine the quantities of the components required for the application deployment. If necessary, other types of costs such as backhaul communication upgrades 
can be added by the user. The unit costs pertinent to the CV deployment are shown in Table 3-2. The segment length is assumed to be 1 mile; therefore, the study corridor includes 15 segments. The total cost of CV deployment for a 15-mile corridor was estimated to be $\$ 609,100$. Due to the uncertainty in the CV costs, it is assumed that the cost varies within $15 \%$ of these values, according to a uniform distribution.

\section{Table 3-2 CV Deployment Unit Costs}

\begin{tabular}{|l|l|c|}
\hline \multirow{4}{*}{ Roadside Equipment (RSEs) } & Unit Cost & $\$ 11,000$ \\
\cline { 2 - 3 } & Number of units per segment & 1 \\
\cline { 2 - 3 } & Installation Cost & $\$ 3550$ \\
\cline { 2 - 3 } & Operation and Maintenance Cost & $\$ 11,550$ \\
\cline { 2 - 3 } & System Engineering Cost & $\$ 16,500$ \\
\hline \multirow{3}{*}{ RSE Planning \& Design } & Unit Cost & $\$ 6,650$ \\
\cline { 2 - 3 } & Number of units per segment & 1 \\
\cline { 2 - 3 } & System Engineering Cost & $\$ 9,975$ \\
\hline
\end{tabular}

\subsubsection{Analytical Hierarchy Process Application}

As mentioned earlier, the AHP method was selected to perform the multi-criteria decision analysis of this study. The AHP method decomposes the decision criteria into a hierarchy by reducing the number of criteria for comparison at each level, thus simplifying the structure of the comparison of the relative importance of these criteria, along with considering the number of criteria that may still need to be examined. Both quantitative and qualitative criteria can be assessed using this method. The pairwise comparison by the decision makers facilitates the estimation of the weights of the criteria, and the consistency in the judgment between different comparisons can be checked. The method is also generally easy to apply using a spreadsheet or commercial off-the-shelve tools that have more advanced analysis and visualization capabilities of the decisionmaking elements and results. The AHP method has three steps: calculating the weights 
for each criteria (vector of criteria weights), calculating the rating for each alternative with respect to each criterion (matrix of alternative scores), and calculating the weighted average rating for each alternative and ranking them. These steps were described in Chapter II.

\subsection{SUMMARY}

In this chapter, data sources to calibrate, develop, and test the models and methods used in this research work were explained. Methods inspired by the literature were developed for incident/bottleneck detection and queue warning and estimation based on connected vehicle data. Finally, a novel MCDA framework which is a combination of a stochastic return on investment and AHP method was proposed as a part of this dissertation to support the ITS investment decisions. 


\section{CHAPTER IV}

\section{ANALYSIS RESULTS}

\subsection{INTRODUCTION}

As stated in the methodology chapter, microsimulation was used to evaluate the performance of the methods developed in this study. This chapter presents the results from applying the methodology. First, the performance of the incident/bottleneck detection was tested using simulated both $\mathrm{CV}$ and point-detector data. In the second part, the queue length resulting from the bottleneck is estimated using both simulated CV and point-detector data. Once the queue is detected by the developed algorithm, the queue warning system is assumed to be activated by delivering messages to the drivers ahead of the bottleneck. The safety impacts of the implemented queue warning system is then examined and presented. The third part shows the application of the developed AHP method to a bottleneck management case study utilizing the performance measures obtained from the first part. The results of the AHP application and the selection between CV deployment and legacy detection technology are presented in the third part.

\subsection{INCIDENT/BOTTLENECK DETECTION RESULTS}

The developed incident/bottleneck detection algorithm presented in Chapter III was tested using CV data and traffic detector data. The detection time based on the point detectors was derived in this study based on simulation results, as shown below:

$$
M T T D_{\text {detector }}=4.375-\left(6.427 \times \frac{v}{c}\right)+(0.003 \times X)
$$

where,

$$
M T T D_{\text {detector }}=\text { mean time to detect using detector data }(\mathrm{min}) \text {, }
$$




$$
\begin{aligned}
& \mathrm{X}=\text { distance between the closest upstream point detector to the } \\
& \quad \text { incident location }(\mathrm{ft}), \\
& = \\
& \mathrm{v} \\
& \mathrm{c}
\end{aligned}
$$

The detection time based on $\mathrm{CV}$ data in the Monte Carlo simulation was estimated as a function of the stochastic $\mathrm{CV}$ market penetration and volume levels, as shown in Table 4-2. The results in Table 4-1 are based on emulated CVs utilizing microscopic simulation combined with a Monte Carlo analysis with multiple runs that randomly assign connectivity to the vehicles since the position of the connected vehicles relative to the bottleneck location affects the results. One hundred runs were performed for each of the tested demand level and $\mathrm{CV}$ market penetration combinations. The investigated v/c ratios were $0.36,0.5,0.72,0.86$, and 1.01 , and the $\mathrm{CV}$ proportions were 1, 3, 6, 9 and 15 percent. The Monte Carlo run results are shown in Table 4-1. As can be seen, the median and different percentiles of the MTTD vary as a function of the market penetration and volume. It is interesting to note that the simulation shows that even at low market penetrations (1\%), the median and average MTTD are around 1.5 minutes. However, at such low market penetration, the 90th and 95th percentile MTTD can be between 3.0 minutes and 4.5 minutes, and between 4.5 and 6.75 minutes, respectively.

The results from the Monte Carlo runs were used to develop regression equations to allow the calculation of the MTTD at a certain CV proportion and volume level combination. Table 4-2 shows the equations derived for the $80^{\text {th }}$ and $95^{\text {th }}$ percentiles of the MTTD in minutes. The result shows that the MTTD decreases as the v/c ratio and CV market penetration (MP) increase. It should be noted that the equations in Table 4-2 are 
applicable to one-lane blockage incidents on four-lane freeways. The equations are also applicable when the v/c ratio is greater than 0.4 . This is because the incident is not detectable based on speed for v/c less than 0.4 with the utilized methodology, as there is no queue formed and no speed reduction, at least in the microscopic simulation model (queue may form in real world at this v/c ratio).

\subsection{QUEUE ESTIMATION AND WARNING RESUltS}

To test the queue estimation and warning methods presented in this study, a total of 40 scenarios with different CV penetrations and TCA seed numbers were evaluated (4 different CV penetrations and for each one, 10 TCA runs with different seed numbers were performed). The purpose of having multiple TCA runs is to randomly assign connectivity to the vehicles, since the position of the connected vehicles relative to the bottleneck location affects the accuracy of the results. To confirm that the 10 TCA runs are sufficient, the required numbers of runs at the $95 \%$ confidence level were estimated using the following equation:

$$
n=\frac{\sigma^{2 *} t^{2}}{e^{2}}
$$

where,

$$
\begin{aligned}
& \sigma \quad=\text { standard deviation of the measurements, } \\
& \mathrm{t} \quad=\text { associated } \mathrm{t} \text { value with the } 95 \% \text { confidence interval (T distribution), and } \\
& \mathrm{e} \quad=\text { the acceptable measurement error (assumed to be } 200 \mathrm{ft} \text { in this study). }
\end{aligned}
$$


Table 4-1 Mean Time to Detect (MTTD) for Different CV Market Penetrations and Different v/c Ratio

\begin{tabular}{|c|c|c|c|c|c|c|c|}
\hline $\mathbf{v} / \mathbf{c}$ & $\mathbf{M P} *(\%)$ & No. of TCA Runs & SD $^{* *}$ & Median (min) & $80 \%$ (min) & $90 \%(\min )$ & $95 \%$ (min) \\
\hline \multirow{5}{*}{0.43} & 1 & 130 & 1.56 & 2.25 & 3 & 4.5 & 5.25 \\
\hline & 3 & 30 & 0.68 & 1.5 & 1.5 & 2.25 & 3 \\
\hline & 6 & 30 & 0.42 & 0.75 & 1.5 & 1.5 & 1.5 \\
\hline & 9 & 20 & 0.43 & 0.75 & 1.5 & 1.5 & 1.5 \\
\hline & 15 & 10 & 0.32 & 0.75 & 0.75 & 1.5 & 1.5 \\
\hline \multirow{5}{*}{0.58} & 1 & 120 & 1.66 & 1.5 & 3 & 4.5 & 5.25 \\
\hline & 3 & 60 & 0.49 & 0.75 & 1.5 & 1.5 & 2.25 \\
\hline & 6 & 30 & 0.43 & 0.75 & 0.75 & 0.75 & 1.5 \\
\hline & 9 & 20 & 0.08 & 0.75 & 0.75 & 0.75 & 0.75 \\
\hline & 15 & 10 & 0 & 0.75 & 0.75 & 0.75 & 0.75 \\
\hline \multirow{5}{*}{0.61} & 1 & 100 & 1.8 & 1.5 & 3 & 3.75 & 6.75 \\
\hline & 3 & 20 & 0.51 & 0.75 & 1.5 & 1.575 & 2.25 \\
\hline & 6 & 10 & 0 & 0.75 & 0.75 & 0.75 & 0.75 \\
\hline & 9 & 10 & 0 & 0.75 & 0.75 & 0.75 & 0.75 \\
\hline & 15 & 10 & 0 & 0.75 & 0.75 & 0.75 & 0.75 \\
\hline \multirow{5}{*}{0.73} & 1 & 70 & 1.29 & 1.5 & 2.4 & 3 & 4.5 \\
\hline & 3 & 30 & 0.39 & 0.75 & 1.5 & 1.5 & 1.5 \\
\hline & 6 & 10 & 0.32 & 0.75 & 0.75 & 1.5 & 1.5 \\
\hline & 9 & 10 & 0 & 0.75 & 0.75 & 0.75 & 0.75 \\
\hline & 15 & 10 & 0 & 0.75 & 0.75 & 0.75 & 0.75 \\
\hline \multirow{5}{*}{0.86} & 1 & 130 & 1.61 & 1.5 & 3 & 4.5 & 5.7 \\
\hline & 3 & 30 & 0.45 & 0.75 & 1.5 & 1.5 & 2 \\
\hline & 6 & 20 & 0.27 & 0.75 & 0.75 & 1.5 & 1.5 \\
\hline & 9 & 10 & 0 & 0.75 & 0.75 & 0.75 & 0.75 \\
\hline & 15 & 10 & 0 & 0.75 & 0.75 & 0.75 & 0.75 \\
\hline
\end{tabular}

*MP: Market Penetration

**SD: Standard Deviation 
Table 4-2 Derived Equations for MTTD for Different CV Proportions and Different v/c Ratios

\begin{tabular}{|c|c|c|c|c|}
\hline & \multicolumn{4}{|c|}{ Mean Time to Detect (MTTD) $(80 \%)$} \\
\hline \multirow{2}{*}{ Equation } & \multirow{2}{*}{$M T T D=\{$} & 0.75 & $M P$ & \\
\hline & & $49+54.56$ & $M P \quad M P$ & $(4-2)$ \\
\hline \multirow{5}{*}{$\begin{array}{l}\text { Coefficients } \\
\text { Statistics }\end{array}$} & Coefficients & Std. Error & t value & $\operatorname{Pr}(>|t|)$ \\
\hline & $\beta_{0}$ & 7.447 & -6.936 & 0.000 \\
\hline & $\beta_{1}$ & 7.607 & 7.173 & 0.000 \\
\hline & \multicolumn{4}{|c|}{ Multiple R-squared: 0.798} \\
\hline & \multicolumn{4}{|c|}{ Adjusted R-squared: 0.783} \\
\hline & \multicolumn{4}{|c|}{ Mean Time to Detect (MTTD) (95\%) } \\
\hline \multirow{3}{*}{ Equation } & \multicolumn{4}{|c|}{$\begin{array}{ccc}0.75 & M P>6 \%\end{array}$} \\
\hline & \multirow{2}{*}{$\begin{aligned} M T T D & =\{-\end{aligned}$} & \multirow{2}{*}{\multicolumn{3}{|c|}{$\begin{array}{l}\left(-102.892+108.192 e^{-(v / c) \times M P} \quad M P \leq 6 \%\right. \\
\end{array}$}} \\
\hline & & & & \\
\hline \multirow{5}{*}{$\begin{array}{l}\text { Coefficients } \\
\text { Statistics }\end{array}$} & Coefficients & Std. Error & t value & $\operatorname{Pr}(>|t|)$ \\
\hline & $\beta_{0}$ & 20.864 & -4.931 & 0.000 \\
\hline & $\beta_{1}$ & 21.313 & 5.076 & 0.000 \\
\hline & \multicolumn{4}{|c|}{ Multiple R-squared: 0.665} \\
\hline & \multicolumn{4}{|c|}{ Adjusted R-squared: 0.639} \\
\hline
\end{tabular}

The calculated required numbers of runs for the 3\% market penetration was 9 runs, and 2 runs for $6 \%, 9 \%$ and $15 \%$, confirming that 10 runs were sufficient.

The generated BSMs were fed to the detection algorithms, and the bottleneck location and back of queue were determined each minute. The detected back-of-queue was compared with the ones detected by the VISSIM full trajectory, and the error percentage for each time step was calculated using the equation below.

$$
\operatorname{Error}(i, k)=100 \times \frac{\left(B O Q_{C_{i k}}\right)-\left(B O Q_{G T_{i}}\right)}{B O Q_{G T_{i}}}
$$

where,

$$
\begin{aligned}
\text { Error }(\mathrm{i}, \mathrm{k})= & \text { error percentage at time step } \mathrm{i} \text { for the } \mathrm{k}^{\text {th }} \text { TCA run, } \\
\text { BOQ_ } \mathrm{C}_{\mathrm{ik}} \quad= & \text { back-of-queue estimated by connected vehicle data at time step } \mathrm{i} \\
& \text { for the } \mathrm{k}^{\text {th }} \text { TCA run, and }
\end{aligned}
$$


BOQ_GT $\quad$ = back-of-queue estimated by full VISSIM trajectory at time step i.

The average error over different time steps for each run $\mathrm{k}$ was calculated using Equation 4-6, and is shown in Figure 4-1. As shown in this figure, the average error decreased with the increasing the market penetration.

$$
\text { Average_Error }(k)=\frac{\sum_{i=1}^{10} \operatorname{Error}(i, k)}{10}
$$

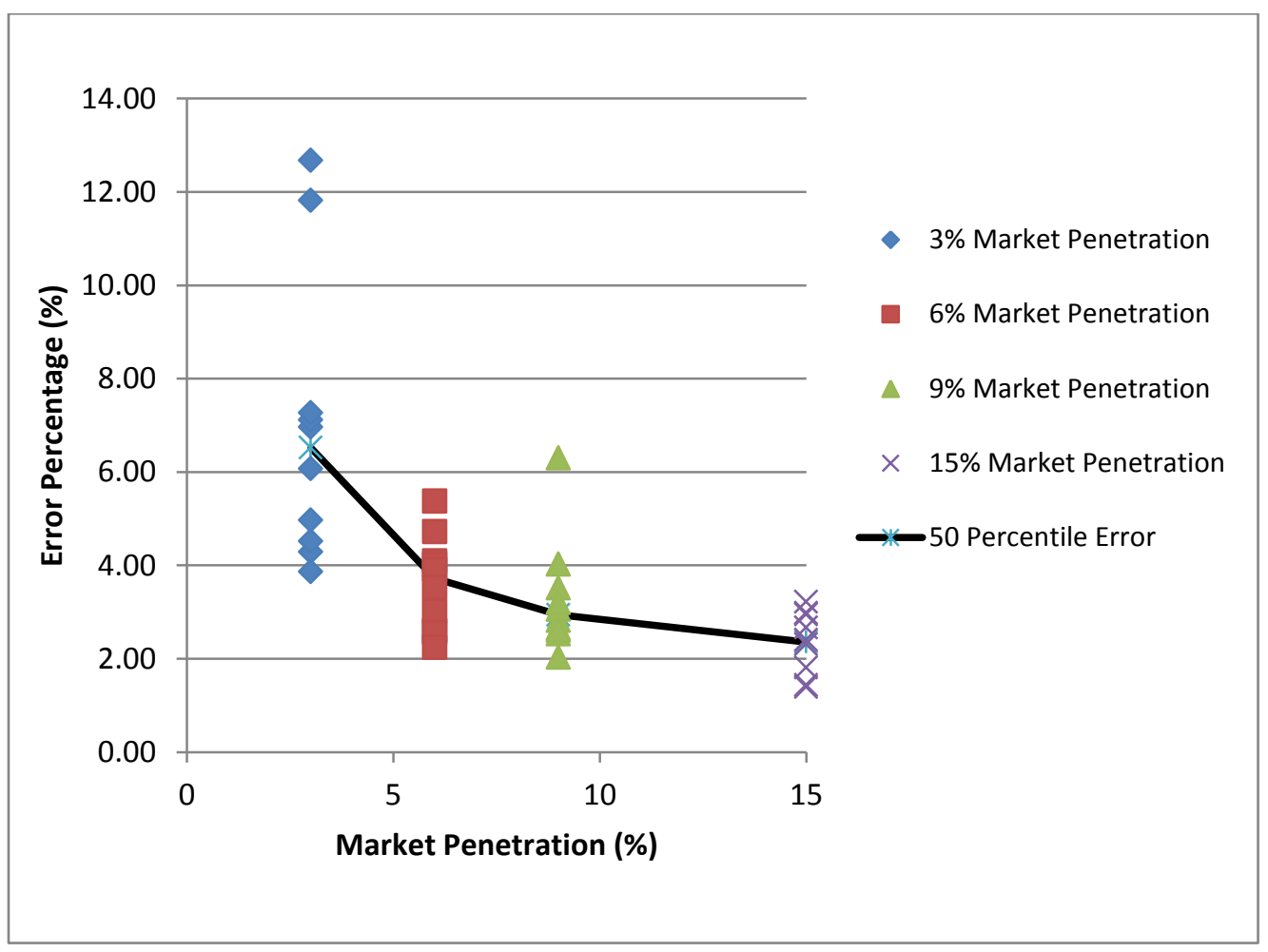

Figure 4-1 Average Error Percentages for Each Run

The median and error range for each market penetration is shown in Table 4-3. The median error for the $3 \%, 6 \%, 9 \%$ and $15 \% \mathrm{CV}$ penetrations were $6.52 \%, 3.72 \%$, $2.94 \%$ and $2.36 \%$ respectively. The detector-based error was calculated as $49.53 \%$, compared to the VISSIM simulation ground truth. 
Table 4-3 Error Percentage for Each Market Penetration Rate

\begin{tabular}{|c|c|c|}
\hline $\begin{array}{c}\text { Market Penetration Rate } \\
(\boldsymbol{\%})\end{array}$ & Error Range (\%) & Median Error (\%) \\
\hline 3 & 3.86 to 12.68 & 6.52 \\
\hline 6 & 2.25 to 5.37 & 3.72 \\
\hline 9 & 2.03 to 6.3 & 2.94 \\
\hline 15 & 1.36 to 3.22 & 2.4 \\
\hline
\end{tabular}

Figures 4-2(a) and 4-2(b) show the estimated queue lengths associated with results from the worst run (the run that produced the largest error among the 10 runs for a given scenario) and the median runs that produced the median error of the 10 TCA runs for the four different CV penetrations versus the ones estimated based on detector data and emulated $\mathrm{CV}$ vehicles for $100 \%$ market penetration based on simulation trajectories of all vehicles. As can be seen in Figure 4-2, even the worst estimated queue lengths of the ten TCA runs are better than the ones estimated by the point detectors, compared to ground truth. However, with a low market penetration (3\%), although the median of the runs produced accurate results at all the time intervals, the worst TCA runs produced errors at the beginning of the formation and dissipation of the queue, as shown for the $8^{\text {th }}$ and $23^{\text {rd }}$ minute in Figure 4-2 (a). This reflects the lower number of vehicles in shorter queues. It should be mentioned, however, that with the expected National Highway Transportation Safety Administration (NHTSA) mandating CV technologies on all new vehicles, it is forecasted that the $\mathrm{CV}$ market penetration will be around 5-7\% in the first year that this mandate becomes effective, considering the rate at which new vehicles are introduced in the traffic stream (Wright et al. 2014). The results from this study were also examined to determine how fast the bottleneck that starts the queue buildup is detected. It was found that the bottleneck was detected 4 minutes sooner with connected vehicle data, compared to point detectors at all the market penetration rates, as shown in Figure 4-2. 


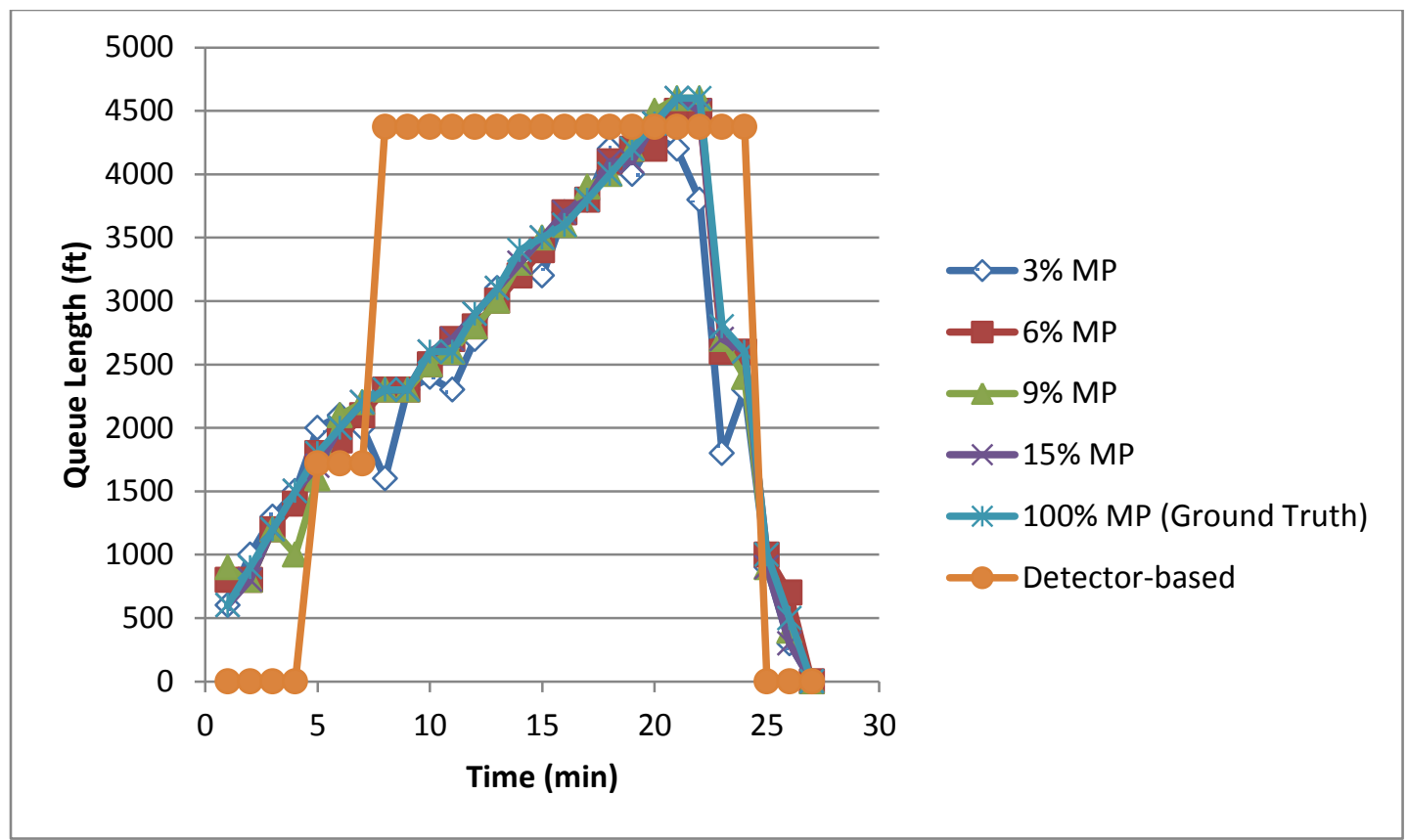

(a) Estimated queue lengths associated with the worst run vs. detector-based and ground truth

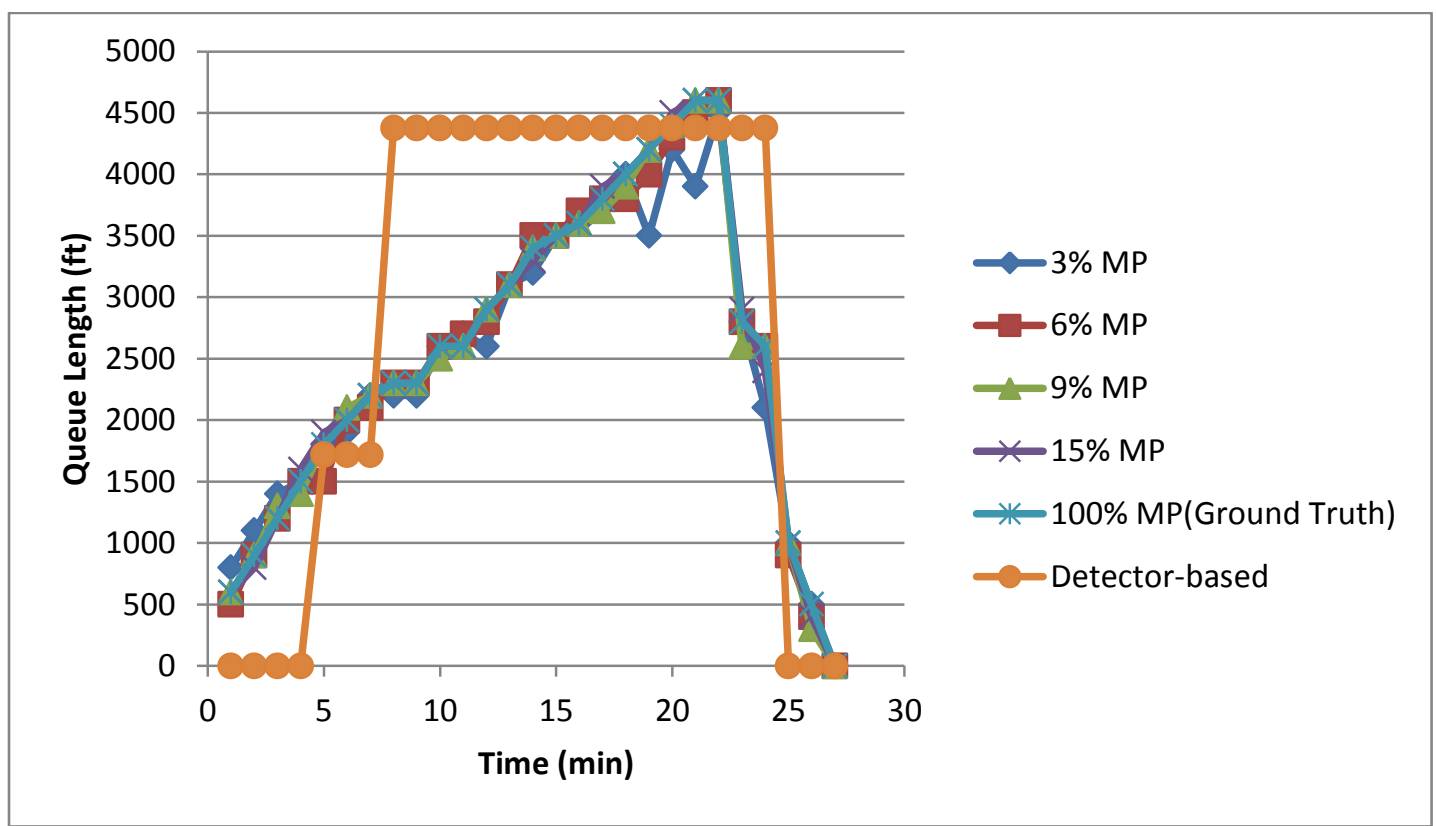

(b) Estimated queue lengths associated with the median run vs. detector-based and ground truth

MP: Market Penetration of connected vehicles in the traffic stream.

Figure 4-2 Estimated Queue Lengths by Connected Vehicle Data vs. Detector-Based and Ground Truth-Results Associated with (a) Worst TCA Run (b) Median TCA Run 
Once the queue is detected by the developed algorithm, the queue warning system is assumed to be activated by delivering messages to the drivers ahead of the bottleneck. In order to implement the queue warning system, a driver's response to the queue warning messages needs to be known or estimated. Li et al. (2010) conducted a study of the effectiveness of PCMS messages ("Road Work Ahead") on reducing vehicle speeds in rural highway work zones. The work zone was located on U.S.-36 and U.S.-73 in Kansas. The study concluded that the vehicle speeds decreased by $4.7 \mathrm{mph}$ over a distance of $500 \mathrm{ft}$ when the PCMS was turned on. Richards and Dudeck (1986) found, based on a field study, that when using DMS as a speed control device in work zones, vehicle speeds were reduced by $7 \mathrm{mph}$ on average. Zech et al. (2008) evaluated the effectiveness of three DMS messages on vehicle speed and variance reduction in highway work zones. The effective message decreased the speed by $3.3 \mathrm{mph}-6.7 \mathrm{mph}$. Dixon and Wang (2002) found a 6-7 mph reduction in vehicle speed in the immediate vicinity of DMS signs providing advanced warnings of DMS. Garber and Patel (1995) concluded that vehicle speeds decreased by $6 \mathrm{mph}$ due to a DMS posted ahead of work zones. A similar study by McCoy et al. (1995) reported that DMS activation resulted in a 4 to 5 mph reduction in vehicle speed, and the percentage of drivers exceeding the speed limit (45 mph) decreased by 20 to 40 percent. This study assumed that the messages are delivered using OBUs or DMS located about one mile ahead of the maximum queue length. The complying drivers were assumed to reduce their speed by $10 \mathrm{mph}$ and as a result, the average speed of the warning zone decreased by 3 to $10 \mathrm{mph}$, depending on the compliance rate with the QWS. 
The next step was to examine the safety impacts of the QWS. The trajectory file was imported into the SSAM tool to estimate the surrogate safety performance measures. In this study, the trajectories with and without queue warning were imported into the SSAM tool to investigate the effects of the implemented queue warning system on the number of rear-end conflicts. The tested compliance rates were 3\%, 5\%, 10\%, 15\%, 20\%, $30 \%, 50 \%$ and $70 \%$. The compliance rate with the QWS was assumed to be the combination of compliance with the DMS signs and the OBUs. One hundred SSAM runs were performed for each compliance rate, and a t-test with a significance level of 0.05 was conducted for each scenario. The results of the t-test are shown in Table 4-4. The mean number of rear-end conflicts over 100 SSAM runs for each compliance percentage scenario, as presented in the third column of the table, was compared with the mean conflicts of the base conditions, which is the no queue warning scenario or zero compliance (first cell of the third column). The significance of the reduction in the conflicts with different compliance rates was determined. The mean difference in the fifth column is the difference between the mean of each scenario (with a specific compliance rate) and the mean of no queue warning scenario. As shown in Table 4-4, the reduction in the number of rear-end conflicts becomes significant when the compliance with the queue warning messages is more than $15 \%$. Most of the expected safety benefits are expected to be achieved when reaching a $50 \%$ compliance rate, as the difference in the percentage reduction in rear-end conflicts between $50 \%$ and $70 \%$ compliance rates is very small.

\subsection{MCDA APPLICATION RESUlts}

This section illustrates the application of the MCDA methodology that combines the stochastic return on investment analysis and the AHP, as described earlier in a case 
study in southeast Florida. The case study addresses an investment decision for a 15-mile segment of a freeway corridor with two assumed volume demand levels: moderate and light traffic (v/c ratio $=0.8$ and $\mathrm{v} / \mathrm{c}$ ratio $=0.4)$. The different volume levels affect the number of $\mathrm{CV}$ vehicles available to provide vehicles in the traffic stream and thus the quality of travel time estimation, as shown in Equation 3-7.

Table 4-4 Statistical Analyses of the Impacts of QWS on the Number of Rear-End Conflicts Utilizing SSAM Model Results

\begin{tabular}{|c|c|c|c|c|c|c|c|}
\hline $\begin{array}{c}\text { SSAM } \\
\text { Measure }\end{array}$ & $\begin{array}{l}\text { Compliance } \\
\text { with the } \\
\text { queue } \\
\text { warning } \\
\text { System }\end{array}$ & $\begin{array}{c}\text { Mean } \\
\text { No. } \\
\text { of } \\
\text { Conflicts }\end{array}$ & Sig. & $\begin{array}{c}\text { Mean } \\
\text { difference } \\
\text { Relative } \\
\text { to No QWS }\end{array}$ & $\begin{array}{c}\text { Difference } \\
\text { Percentage } \\
\text { Relative } \\
\text { to } \\
\text { No QWS (\%) }\end{array}$ & \begin{tabular}{|c|} 
t-value of \\
the test to \\
determine \\
the \\
significance \\
of \\
the difference
\end{tabular} & t-critical \\
\hline \multirow{9}{*}{$\begin{array}{l}\text { Rear-end } \\
\text { Conflicts }\end{array}$} & $\begin{array}{c}0 \% \text { (No Queue } \\
\text { Warning) }\end{array}$ & 6589.16 & NA & NA & NA & NA & NA \\
\hline & $2 \%$ & 6589.16 & No & 6.492 & 0.10 & 0.039 & 1.66 \\
\hline & $5 \%$ & 6136.20 & No & 226.478 & 3.56 & 1.321 & 1.66 \\
\hline & $10 \%$ & 6332.94 & No & 256.22 & 3.89 & 1.472 & 1.66 \\
\hline & $15 \%$ & 6238.95 & Yes & 350.21 & 5.31 & 2.201 & 1.66 \\
\hline & $20 \%$ & 6235.65 & Yes & 353.512 & 5.37 & 2.212 & 1.66 \\
\hline & $30 \%$ & 6228.44 & Yes & 360.718 & 5.47 & 2.331 & 1.66 \\
\hline & $50 \%$ & 6097.12 & Yes & 492.164 & 7.47 & 2.359 & 1.66 \\
\hline & $70 \%$ & 6095.17 & Yes & 493.992 & 7.50 & 2.37 & 1.66 \\
\hline
\end{tabular}

NA: Not Applicable

In addition, the volume levels affect the MMTD for both $\mathrm{CV}$ and point detectors, as shown in Equations 4-1 and 4-2.

The results from the Monte Carlo analysis were used to generate the NPV distribution for each alternative. Next, the results from the Monte Carlo analysis are used as one of the inputs to the AHP analysis and the examined alternatives are ranked based on their final scores, as described below. 


\subsubsection{Monte Carlo Simulation Results}

One thousand Monte Carlo analysis runs were performed with the input variables generated randomly from the distributions specified for each stochastic variable in the return on investment analysis. The NPV estimated based on each run was saved, and the results from the 1,000 runs were used to generate the NPV distribution. The analysis was carried out for 6 hours of operation for the corridor with the moderate traffic (v/c ratio of 0.8 ) and 6 hours of operation with light traffic (v/c ratio of 0.4$)$. Table $4-5$ shows the generated performance measures from the Monte Carlo runs for each of the alternatives. As can be seen in this table, the quality of the CV data improves through the years due to the increase in the $\mathrm{CV}$ market penetration.

Table 4-5 Alternatives Performance Measures based on Monte Carlo Runs

\begin{tabular}{|c|c|c|c|c|c|c|c|}
\hline \multirow{12}{*}{$\mathrm{v} / \mathrm{c}=0.4$} & \multicolumn{7}{|c|}{$50^{\text {th }}$ Percentile (Median) Results } \\
\hline & & & Year 1 & Year 3 & Year 5 & Year 7 & Year 9 \\
\hline & \multirow{2}{*}{$\operatorname{SPDE}(\%)$} & CV-based & 10.76 & 8.38 & 7.05 & 6.02 & 5.12 \\
\hline & & Point Detector & 15.14 & 15.14 & 15.14 & 15.14 & 15.14 \\
\hline & \multirow{2}{*}{ MTTD (min) } & CV-based & 2.20 & 0.75 & 0.75 & 0.75 & 0.75 \\
\hline & & Point Detector & 5.03 & 4.96 & 4.90 & 4.84 & 4.76 \\
\hline & \multicolumn{7}{|c|}{$85^{\text {th }}$ Percentile Results } \\
\hline & & & Year 1 & Year 3 & Year 5 & Year 7 & Year 9 \\
\hline & \multirow{2}{*}{ SPDE $(\%)$} & CV-based & 11.59 & 8.92 & 7.48 & 6.40 & 5.48 \\
\hline & & Point Detector & 18.48 & 18.48 & 18.48 & 18.48 & 18.48 \\
\hline & \multirow{2}{*}{ MTTD (min) } & CV-based & 2.57 & 0.75 & 0.75 & 0.75 & 0.75 \\
\hline & & Point Detector & 7.70 & 7.66 & 7.61 & 7.50 & 7.47 \\
\hline \multirow{12}{*}{$\mathrm{v} / \mathrm{c}=0.8$} & \multicolumn{7}{|c|}{$50^{\text {th }}$ Percentile (Median) Results } \\
\hline & & & Year 1 & Year 3 & Year 5 & Year 7 & Year 9 \\
\hline & \multirow{2}{*}{$\operatorname{SPDE}(\%)$} & CV-based & 10.23 & 7.81 & 6.44 & 5.44 & 4.51 \\
\hline & & Point Detector & 14.91 & 14.91 & 14.91 & 14.91 & 14.91 \\
\hline & \multirow{2}{*}{ MTTD (min) } & CV-based & 1.66 & 0.75 & 0.75 & 0.75 & 0.75 \\
\hline & & Point Detector & 2.94 & 2.81 & 2.72 & 2.61 & 2.54 \\
\hline & \multicolumn{7}{|c|}{$85^{\text {th }}$ Percentile Results } \\
\hline & & & Year 1 & Year 3 & Year 5 & Year 7 & Year 9 \\
\hline & \multirow{2}{*}{ SPDE (\%) } & CV-based & 11.02 & 8.34 & 6.89 & 5.84 & 4.91 \\
\hline & & Point Detector & 18.30 & 18.30 & 18.30 & 18.30 & 18.30 \\
\hline & \multirow{2}{*}{ MTTD (min) } & CV-based & 2.24 & 0.75 & 0.75 & 0.75 & 0.75 \\
\hline & & Point Detector & 5.83 & 5.70 & 5.62 & 5.54 & 5.42 \\
\hline
\end{tabular}


The Incremental NPV of the CV utilization for traffic monitoring is defined as the difference in the NPV between the utilization of CV and traffic detectors for traffic monitoring, calculated as described in the Methodology section. The incremental NPV distribution utilizing Monte Carlo simulation outputs was generated for each year, starting with the first year of CV deployment, which is assumed to be the year when $\mathrm{CV}$ technology becomes mandatory for all new vehicles by the United States Department of Transportation. The results in Figure 4-3 indicate that utilizing CV data for freeway segments is significantly more cost-effective than point detectors in detecting incidents and providing travel time estimates about one year after the CV mandate for all new vehicles becomes effective, particularly for the corridor with moderate traffic. However, for the corridor or the time period with light traffic $(\mathrm{v} / \mathrm{c}=0.4)$, there is a probability of the $\mathrm{CV}$ deployment not being effective in its first few years due to low measurement reliability of travel time and high latency of incident detection.

\subsubsection{AHP Application Results}

In this study, the managers in two transportation system management agencies in Florida were asked to fill the rating tables required as inputs to the AHP methodology. The AHP analysis was done separately using each of the two inputs provided by managers, as their priorities are different. Table 4-6 shows the highest level of the ratings of the AHP process, which involves comparing the high-level objectives given by the first and second decision makers, referred to as Decision Maker 1 and Decision Maker 2, respectively. The colored cells are the only ones that needed to be filled, as the uncolored cells are the reciprocal of the colored ones. 


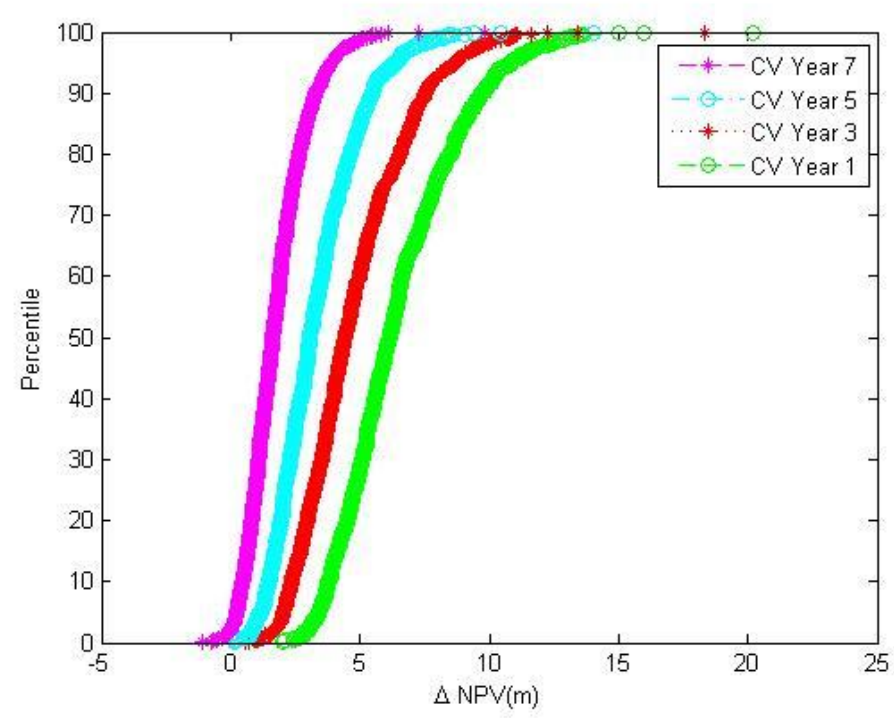

(a) Corridor with Moderate Traffic $(\mathrm{v} / \mathrm{c}=0.8)$

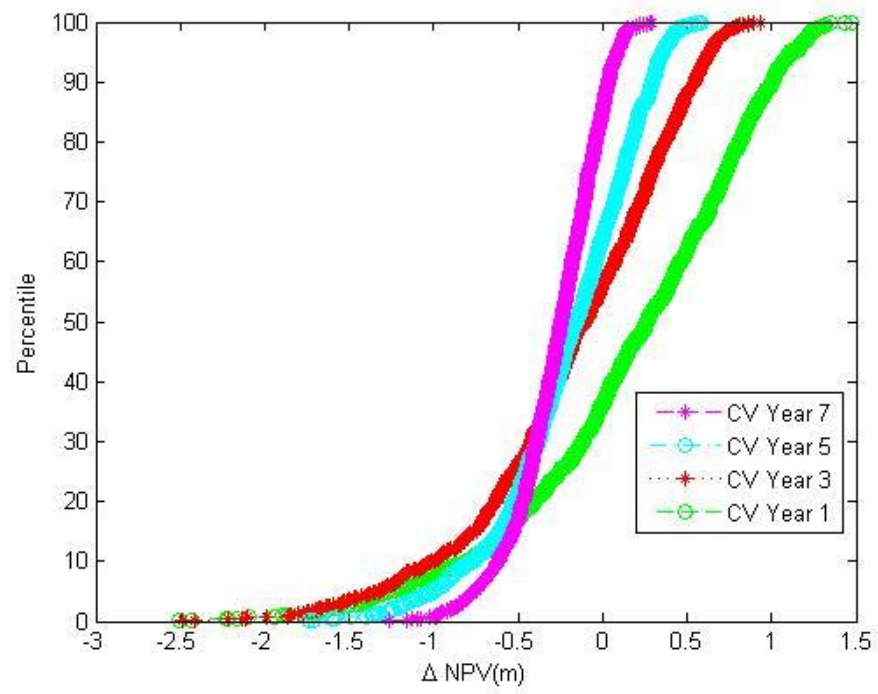

(b) Corridor with Light Traffic $(\mathrm{v} / \mathrm{c}=0.4)$

Figure 4-3 Incremental NPV Distributions Based on the CV Deployment vs. Point Detector for Each Year of Starting Utilizing CV Data after CV Technology Becomes Mandated

Decision Maker 1 put the highest emphasis on achieving the required functions and achieving the required performance and gave these two objectives twice the importance of minimizing the risk and constraints and maximizing the return on investment. This rating favors new technologies like utilizing CV data instead of other existing technologies. Unlike Decision Maker 1, minimizing the risks and constraints and 
maximizing the return on investment are the two most important factors to Decision Maker 2. This decision maker appears to be more conservative than Decision Maker 1 in accepting new technologies that provide additional functions and better performance, even if there are additional risks associated with the technology.

Table 4-6 Decision Objectives Pairwise Comparison by the Decision Makers

\begin{tabular}{|c|c|c|c|c|c|}
\hline $\begin{array}{c}\text { Decision } \\
\text { Maker }\end{array}$ & Objectives & $\begin{array}{l}\text { Provision of } \\
\text { the required } \\
\text { functions }\end{array}$ & $\begin{array}{c}\text { Achieving the } \\
\text { required } \\
\text { performance }\end{array}$ & $\begin{array}{c}\text { Minimizing } \\
\text { the risks and } \\
\text { constraints }\end{array}$ & $\begin{array}{l}\text { Maximizing } \\
\text { the return on } \\
\text { investment }\end{array}$ \\
\hline \multirow{4}{*}{$\begin{array}{c}\text { Decision Maker } \\
1\end{array}$} & $\begin{array}{l}\text { Provision of the } \\
\text { required functions }\end{array}$ & 1 & 1 & 2 & 2 \\
\hline & $\begin{array}{l}\text { Achieving the required } \\
\text { performance }\end{array}$ & 1 & 1 & 2 & 2 \\
\hline & $\begin{array}{l}\text { Minimizing the risk } \\
\text { and } \\
\text { constraints }\end{array}$ & 0.5 & 0.5 & 1 & 2 \\
\hline & $\begin{array}{l}\text { Maximizing the return } \\
\text { on investment }\end{array}$ & 0.5 & 0.5 & 0.5 & 1 \\
\hline \multirow{4}{*}{$\begin{array}{c}\text { Decision Maker } \\
2\end{array}$} & $\begin{array}{l}\begin{array}{l}\text { Provision of the } \\
\text { required functions }\end{array} \\
\end{array}$ & 1 & 1 & 0.5 & 0.5 \\
\hline & $\begin{array}{l}\text { Achieving the required } \\
\text { performance }\end{array}$ & 1 & 1 & 0.5 & 0.5 \\
\hline & $\begin{array}{l}\text { Minimizing the risks } \\
\text { and constraints }\end{array}$ & 2 & 2 & 1 & 1 \\
\hline & $\begin{array}{l}\text { Maximizing the return } \\
\text { on investment }\end{array}$ & 2 & 2 & 1 & 1 \\
\hline
\end{tabular}

The rating at the sub-criteria level by Decision Maker 1 is shown in Table 4-7. The following can be concluded based on the results in Table 4-7:

- With regard to the provided functions, Decision Maker 1 rated the measurement of travel time as important as measuring volume and density and twice as important as the ability to measure new measures that cannot be obtained using current detection technologies such as acceleration noise, stops, breaks, wiper on/off, light on/off, emission, potential for crashes, etc.

- With regard to achieving the required performance, the estimation accuracy, as measured by the mean absolute error, and the estimation reliability, as measured 
by the standard deviation of error, were ranked as equally important and two times more important than the timeliness of incident detection, and probably indicating the current use of the agency's detector data.

- With regard to the risks and constraints, Decision Maker 1 gave the highest rating to technology uncertainty, standard stability, and uncertainty in the business model. Data archiving and processing and the associated technical skill requirements, funding, data availability and sharing, and security and privacy concerns were not highly ranked, which indicates the current availability of good technical support and resources to the agency.

- With regard to the return on investment, Decision Maker 1 rated the 50 percentile NPV twice as important as the $15 \% \mathrm{NPV}$, indicating that the median value of the return on investment is more important than the uncertainty or stochasticity associated with the return on investment analysis.

The consistency index of the AHP was calculated for each of the tables to make sure that the decision maker rating of the criteria relative to each other was consistent. After confirming that the consistency index was acceptable, the AHP analysis was conducted for different demand levels and analysis years. Table 4-8 shows examples of the AHP analysis results. As shown in this table, in all of the cases, utilizing CV data has a higher final score than point detectors. This is because $\mathrm{CV}$ has a significantly better performance in incident detection and travel time estimation. The partial score for each of the criteria is also shown in the table. Utilizing CV data has lower scores in the third criterion, which minimizes the risk and constraints. However, the score improved in 
future years as the quality of data improved due to increased market penetration and the uncertainty and risks associated with the decrease in CV deployment.

Table 4-9 shows the AHP results based on the Decision Maker 2 ratings. In comparing Tables 4-8 and 4-9, it is clear that the CV data utilization alternative has a higher relative score based on the Decision Maker 1 inputs than on the Decision Maker 2 inputs, indicating the more conservative view of Decision Maker 2, although utilizing CV data is still the preferred alternative to collecting data for segments with moderate to heavy volumes for both decision makers.

\subsection{SUMMARY}

In this chapter, the performance of incident/bottleneck detection and queue estimation and warning system were assessed based on the utilization of $\mathrm{CV}$ and traffic detector technologies. Then, a stochastic return on investment analysis, combined with the AHP method, was applied to support the decision to select between CV-based deployments and legacy detection technology to support the freeway bottleneck management service, which includes incident detection and travel time estimation and disseminating back-of-queue information to travelers. Managers in two transportation system management agencies in Florida were asked to fill the AHP rating tables. Two separate AHP analyses were conducted based on the two different stakeholder priorities.

The results show that the CV-based incident detection and queue warning system outperform the traffic detector-based methods. Incidents/bottlenecks can be detected much faster with the use of CV data. It was also found that the CV-based estimation of 
back-of-queue identification is significantly more accurate than that based on detector measurements.

Table 4-7 Decision Sub-Criteria Pairwise Comparison by the First Decision Maker

\begin{tabular}{|c|c|c|c|c|c|c|c|}
\hline \multicolumn{8}{|c|}{ Provision of the required functions } \\
\hline & & \multicolumn{2}{|c|}{ Measuring travel time } & \multicolumn{2}{|c|}{$\begin{array}{l}\text { Measuring volume } \\
\text { and/or density }\end{array}$} & \multicolumn{2}{|c|}{$\begin{array}{l}\text { Measuring new } \\
\text { measures }\end{array}$} \\
\hline \multicolumn{2}{|c|}{ Measuring travel time } & \multicolumn{2}{|c|}{1} & \multicolumn{2}{|c|}{1} & \multicolumn{2}{|c|}{2} \\
\hline \multicolumn{2}{|c|}{$\begin{array}{l}\text { Measuring volume } \\
\text { and/or density }\end{array}$} & \multicolumn{2}{|c|}{1} & \multicolumn{2}{|c|}{1} & \multicolumn{2}{|c|}{2} \\
\hline \multicolumn{2}{|c|}{$\begin{array}{l}\text { Measuring new } \\
\text { measures }\end{array}$} & \multicolumn{2}{|c|}{0.5} & \multicolumn{2}{|c|}{0.5} & \multicolumn{2}{|c|}{1} \\
\hline \multicolumn{8}{|c|}{ Achieving the required performance } \\
\hline & & \multicolumn{2}{|c|}{ Mean absolute error } & \multicolumn{2}{|c|}{ Std. dev. of error } & \multicolumn{2}{|c|}{ Detection timelines } \\
\hline \multicolumn{2}{|c|}{ Mean absolute error } & \multicolumn{2}{|c|}{1} & \multicolumn{2}{|c|}{1} & \multicolumn{2}{|c|}{2} \\
\hline \multicolumn{2}{|c|}{ Std. dev. of error } & \multicolumn{2}{|c|}{1} & \multicolumn{2}{|c|}{1} & \multicolumn{2}{|c|}{2} \\
\hline \multicolumn{2}{|c|}{ Detection timelines } & \multicolumn{2}{|c|}{0.5} & \multicolumn{2}{|c|}{0.5} & \multicolumn{2}{|c|}{1} \\
\hline \multicolumn{8}{|c|}{ Minimizing the risks and constraints } \\
\hline Criteria no. & 1 & 2 & 3 & 4 & 5 & 6 & 7 \\
\hline 1 & 1 & 1 & 1 & 9 & 9 & 9 & 9 \\
\hline 2 & 1 & 1 & 0.5 & 9 & 9 & 9 & 9 \\
\hline 3 & 1 & 2 & 1 & 9 & 9 & 9 & 9 \\
\hline 4 & 0.11 & 0.11 & 0.11 & 1 & 1 & 1 & 1 \\
\hline 5 & 0.11 & 0.11 & 0.11 & 1 & 1 & 1 & 1 \\
\hline 6 & 0.11 & 0.11 & 0.11 & 1 & 1 & 1 & 1 \\
\hline 7 & 0.11 & 0.11 & 0.11 & 1 & 1 & 1 & 1 \\
\hline \multicolumn{8}{|c|}{ Maximizing the return on investment } \\
\hline & & & present & & & preser & \\
\hline Median pre & at worth & & 1 & & & 2 & \\
\hline $15 \%$ prese & worth & & 0.5 & & & 1 & \\
\hline
\end{tabular}


Table 4-8 AHP Results Based on Decision Maker 1 Ratings

\begin{tabular}{|c|c|c|c|c|c|c|}
\hline \multicolumn{7}{|c|}{ CV deployment start from year 1} \\
\hline Alternatives & $\mathrm{v} / \mathrm{c}$ & $\begin{array}{l}\text { Provision of } \\
\text { the required } \\
\text { functions }\end{array}$ & $\begin{array}{l}\text { Achieving the } \\
\text { required } \\
\text { performance }\end{array}$ & $\begin{array}{l}\text { Minimizing } \\
\text { the risks and } \\
\text { constraints }\end{array}$ & $\begin{array}{l}\text { Maximizing the } \\
\text { return on } \\
\text { investment based } \\
\text { on NPV }\end{array}$ & $\begin{array}{l}\text { Final } \\
\text { Score }\end{array}$ \\
\hline $\mathrm{CV}$ & \multirow[b]{2}{*}{0.8} & 0.58 & 0.66 & 0.21 & 0.84 & 0.56 \\
\hline $\begin{array}{c}\text { Point } \\
\text { Detector }\end{array}$ & & 0.42 & 0.34 & 0.79 & 0.16 & 0.44 \\
\hline $\mathrm{CV}$ & \multirow[b]{2}{*}{0.4} & 0.58 & 0.64 & 0.21 & 0.54 & 0.52 \\
\hline $\begin{array}{c}\text { Point } \\
\text { Detector }\end{array}$ & & 0.42 & 0.36 & 0.79 & 0.46 & 0.48 \\
\hline \multicolumn{7}{|c|}{ CV deployment start from year 5} \\
\hline Alternatives & $\mathrm{v} / \mathrm{c}$ & $\begin{array}{l}\text { Provision of } \\
\text { the required } \\
\text { functions }\end{array}$ & $\begin{array}{l}\text { Achieving the } \\
\text { required } \\
\text { performance }\end{array}$ & $\begin{array}{l}\text { Minimizing } \\
\text { the risks and } \\
\text { constraints }\end{array}$ & $\begin{array}{l}\text { Maximizing the } \\
\text { return on } \\
\text { investment based } \\
\text { on NPV }\end{array}$ & $\begin{array}{l}\text { Final } \\
\text { Score }\end{array}$ \\
\hline $\mathrm{CV}$ & \multirow[b]{2}{*}{0.8} & 0.58 & 0.76 & 0.34 & 0.74 & 0.60 \\
\hline $\begin{array}{c}\text { Point } \\
\text { Detector }\end{array}$ & & 0.42 & 0.24 & 0.66 & 0.26 & 0.40 \\
\hline $\mathrm{CV}$ & \multirow[b]{2}{*}{0.4} & 0.58 & 0.71 & 0.34 & 0.45 & 0.55 \\
\hline $\begin{array}{c}\text { Point } \\
\text { Detector }\end{array}$ & & 0.42 & 0.29 & 0.66 & 0.55 & 0.45 \\
\hline
\end{tabular}

Table 4-9 AHP Results Based on Decision Maker 2 Ratings

\begin{tabular}{|c|c|c|c|c|c|c|}
\hline \multicolumn{7}{|c|}{ CV deployment start from year 1} \\
\hline Alternatives & $\mathrm{v} / \mathrm{c}$ & $\begin{array}{l}\text { Provision of } \\
\text { the required } \\
\text { functions }\end{array}$ & $\begin{array}{l}\text { Achieving the } \\
\text { required } \\
\text { performance }\end{array}$ & $\begin{array}{l}\text { Minimizing } \\
\text { the risks and } \\
\text { constraints }\end{array}$ & $\begin{array}{l}\text { Maximizing the return } \\
\text { on investment based } \\
\text { on NPV }\end{array}$ & $\begin{array}{l}\text { Final } \\
\text { Score }\end{array}$ \\
\hline $\mathrm{CV}$ & \multirow[b]{2}{*}{0.8} & 0.58 & 0.60 & 0.23 & 0.85 & 0.56 \\
\hline $\begin{array}{c}\text { Point } \\
\text { Detector }\end{array}$ & & 0.42 & 0.40 & 0.86 & 0.15 & 0.47 \\
\hline $\mathrm{CV}$ & \multirow[b]{2}{*}{0.4} & 0.58 & 0.55 & 0.23 & 0.54 & 0.45 \\
\hline $\begin{array}{c}\text { Point } \\
\text { Detector }\end{array}$ & & 0.42 & 0.45 & 0.86 & 0.46 & 0.58 \\
\hline \multicolumn{7}{|c|}{ CV deployment start from year 5} \\
\hline Alternatives & $\mathrm{v} / \mathrm{c}$ & $\begin{array}{l}\text { Provision of } \\
\text { the required } \\
\text { functions }\end{array}$ & $\begin{array}{l}\text { Achieving the } \\
\text { required } \\
\text { performance }\end{array}$ & $\begin{array}{l}\text { Minimizing } \\
\text { the risks and } \\
\text { constraints }\end{array}$ & $\begin{array}{l}\text { Maximizing the return } \\
\text { on investment based } \\
\text { on NPV }\end{array}$ & $\begin{array}{l}\text { Final } \\
\text { Score }\end{array}$ \\
\hline $\mathrm{CV}$ & \multirow[b]{2}{*}{0.8} & 0.58 & 0.73 & 0.37 & 0.75 & 0.59 \\
\hline $\begin{array}{c}\text { Point } \\
\text { Detector }\end{array}$ & & 0.42 & 0.27 & 0.72 & 0.25 & 0.44 \\
\hline $\mathrm{CV}$ & \multirow[b]{2}{*}{0.4} & 0.58 & 0.64 & 0.37 & 0.45 & 0.48 \\
\hline $\begin{array}{c}\text { Point } \\
\text { Detector }\end{array}$ & & 0.42 & 0.36 & 0.72 & 0.55 & 0.55 \\
\hline
\end{tabular}

In addition, relatively low market penetrations are sufficient for timely incident/bottleneck detection and accurate and reliable estimation of the queue length. The results of the stochastic return on investment analysis indicates that utilizing $\mathrm{CV}$ data 
for freeway bottleneck management is significantly more cost-effective than using point detectors in detecting incidents and providing travel time estimates one year after $\mathrm{CV}$ technology becomes mandatory for all new vehicles and for corridors with moderate to heavy traffic. The AHP analysis results indicate that the scores of the evaluated alternatives vary depending on stakeholder priorities. 


\section{CHAPTER VI}

\section{CONCLUSIONS AND RECOMMENDATIONS FOR FUTURE STUDIES}

Bottleneck identification, which includes bottleneck occurrence detection, queue extent estimation and related information dissemination, is one of the crucial functions of traffic management centers. This study developed and assessed bottleneck and back-ofqueue identification methods utilizing $\mathrm{CV}$ data and compared the results to those obtained utilizing traffic detector data. The performance assessment of these emerging and existing technologies was input into a developed MCDA framework to support agencies in ITS investment decisions. A stochastic NPV analysis, combined with the AHP method, was applied to select between CV-based deployment and the legacy point detection technology. The methodology was demonstrated using a case study for bottleneck identification and management. The following subsections summarize the conclusions drawn from the results of this research and provide guidance for future works.

\subsection{Conclusions}

Connected and automated vehicle (CV/AV) technologies are expected to have significant impacts on agency investment decisions in Intelligent Transportation Systems (ITS) and need to be considered as part of the decision-making processes associated with agency investment in technology. This study demonstrates the need for developing a framework to support agencies in ITS investment decisions considering the emerging technologies. To provide the basis for the decision-making process, this study assessed the performance of alternative technologies using the developed evaluation methods. The 
focus of this study was on bottleneck identification, which involves incident/bottleneck detection and queue estimation and associated warning applications. The evaluation methods developed for the two applications were tested using $\mathrm{CV}$ and point detector data in the VISSIM microscopic simulation tool.

The incident/bottleneck detection time based on $\mathrm{CV}$ data was estimated as a function of the stochastic CV market penetration and demand level. It was found that even at a low market penetration (1\%), the median and average MTTD are around 1.5 minutes. A market penetration of just $3 \%$ produces acceptable results for bottleneck/incident detection on freeways. It was also shown that $\mathrm{CV}$ data allows for faster detection of bottleneck and queue formation. The connected vehicle-based algorithm can detect the start of queue 4 minutes sooner than the detector-based algorithm.

The study further investigated the impact of CV market penetration on the backof-queue estimation accuracy. It was concluded that a relatively low market penetration, around $3 \%$ to $6 \%$, is sufficient for accurate and reliable estimation of the queue length. It can also be concluded that having $6 \%$ connected vehicles in the traffic stream allows for the estimation of the back-of-queue location with less than a $4 \%$ error on average. Even at a 3\% market penetration, the CV-based estimation of back-of-queue identification is more accurate than that based on detector measurements. It was also found that $\mathrm{CV}$ data allows for faster detection of bottleneck and queue formation. In addition, the safety impacts of the implemented queue warning system (QWS) were investigated using the SSAM tool. It was shown that the QWS improved the safety conditions of the network by reducing the number of rear-end conflicts. The safety impacts become significant when 
compliance with the queue warning messages is more than $15 \%$. However, most of the expected safety benefits are expected to be achieved when reaching a 50\% compliance percentage and the improvements with increasing the compliance percentage above $50 \%$ are lower.

Finally, a multi-criteria decision-making methodology with consideration of uncertainties involved in the alternative assessment was presented. An AHP approach was used to select between utilizing CV-based alternatives versus legacy technology alternatives. The four objectives specified in the AHP analysis are providing the required functions, providing the required performance, minimizing the risks and constraints, and maximizing the return on investment. A stochastic return on investment analysis using the Monte Carlo simulation was used in combination with the AHP method. The method was applied to the selection between $\mathrm{CV}$ deployment and legacy detection technology to support the freeway bottleneck identification service, which includes incident/bottleneck detection and travel time estimation. However, the methodology can be applied to any other ITS service. Two alternatives were evaluated in the case study: utilizing CV data versus utilizing point detector data. The results of the stochastic return on investment analysis indicate that utilizing $\mathrm{CV}$ data for freeway segments is significantly more costeffective than using point detectors in detecting incidents and providing travel time estimates one year after CV technology becomes mandatory for all new vehicles, and for corridors with moderate to heavy traffic. However, for corridors with light traffic $(\mathrm{v} / \mathrm{c}=0.4)$, there is a probability of $\mathrm{CV}$ deployment not being effective in the first few years due to low measurement reliability of travel times and high latency of incident detection, associated with smaller sample sizes of the collected data. The AHP analysis 
results indicate that the scores of the evaluated alternatives vary depending on stakeholder priorities. When the provision of the required function and achieving the required performance are more important than minimizing the risk for an agency, the $\mathrm{CV}$ based alternative has a higher score than when minimizing the risk has a higher weight in the MCDA.

\subsection{RECOMMENDATIONS FOR FUTURE WORKS}

As mentioned earlier, this study aims to develop methods to assess the use of connected vehicle data, combined with new algorithms for use as part of a framework to support agencies in ITS investment decisions related to traffic and bottleneck management. This section presents a number of research opportunities to extend the scope of this study, as listed below:

- This study developed methods for bottleneck/incident and back-of-queue detection that were assessed using simulated connected vehicle data. It is recommended to evaluate the developed methods utilizing real-world connected vehicle data, when this data becomes available.

- To test the bottleneck/incident detection method of the study, a one-lane blockage incident was modeled in the VISSIM microscopic simulation tool. There is a need to investigate the effectiveness of the developed methods for other incident severities, such as two- and three-lane blockage incidents.

- Speed measurements transmitted from the simulated connected vehicles were used to detect the bottleneck/incident and the associated back-of-queue. Connected vehicles offer a variety of information that can be utilized for this 
purpose, such as vehicle acceleration and braking information that can be used; this should be assessed in future studies.

- The proposed MCDA methodology of this study is based on a certain number of assumptions. To consider uncertainties involved in the decision-making process, the analysis variables were assumed to follow a certain distribution rather than fixed values. These distributions can be changed by the user if better information is available and is based on additional research or local conditions.

- In this study, the AHP method was used to select between the alternatives of the study. Two experts were asked to fill the questionnaire and rate the criteria with regard to each alternative. There is a need to compare additional expert opinions in the decision-making process. 


\section{REFERENCES}

Adeli, H. and A. Samant (2000). An Adaptive Conjugate Gardiant Neural NetworkWavelet Model for Traffic Incident Detection. Computer Aided Civil and Infrastructure Engineering (4) :251-260.

Ahmed, M. S. and A.R. Cook (1977). Analysis of Freeway Traffic Time-Series Data Using Box- Jenkins Techniques.Transportation Research Record (722): 1-9.

Alexander, W. and M. Chamberlain (2002). ITS in Ontario: The COMPASS System. University of Toronto.

Annette, J.R., A. Banu and P.S., Chandran (2016). Comparison of Multi Criteria Decision Making Algorithms for Ranking Cloud Renderfarm Services. Indian Journal of Science and Technology (90): 1-5.

ARTBA Work Zone Safety Consortium (2015). Work Zone Safety Innovative End-of Queue Warning System Reduces Crashes Up to 45\%. Available: https://www.workzonesafety.org/publication/innovative-end-of-queue-warning-systemreduces-crashes-up-to-45/.

Asakura, Y. (2015). Incident Detection Methods Using Probe Vehicles with On-board GPS Equipment. Transportation Reaserach Procedia (6): 17-27.

Awasthi, A., S.S. Chauhan and H. Omrani (2011). Application of Fuzzy TOPSIS in Evaluating Sustainable Transportation Systems. Expert Systems with Applications (38): 12270-12280.

Balke, K., C.L. Dudek and C.E. Mountain (1996). Using Probe-Measured Travel Time to Detect Major Freeway Incidents in Houston, Texas. Transportation Research Record: Journal of the Transportation Research Board. (1554): 213-220.

Balke, K., H. Charara and S. Sunkari (2014). Report on Dynamic Speed Harmonization and Queue Warning Algorithm Design. College Station, Texas: Texas A\& M Transportation Institute, Texas A\&M University System.

Benayoun, R., B. Roy and N. Sussman (1966). Manual de Reference du Programme Electre, Mote de Synthese et Formaton. Proceedings of Direction Scientifique SEMA Conference, Paris, France.

Boyle, P. P. (1977). Options: a Monte Carlo approach. Journal of Financial Economics (4): 323-338. 
Brans, J., and P.A. Vincke (1985). Preference Ranking Organization Method (The PROMETHEE Method for Multiple Criteria Decision Making). Management Science (31): 647-656.

Chang, E. Ching-Ping (1994). Fuzzy Systems Based Automatic Freeway Incident Detection. Proceedings of the IEEE International Conference on Systems, Man, and Cybernetics: 1727-1733.

Chang, E. Chin-Ping, and Su- Hua Wang (1994). Improved Freeway Incident Detection Using Fuzzy Set Theory. Transportation Research Record: Journal of the Transportation Research Board (1453): 75-82.

Christenson, R. (1995). Evaluation of Cellular Call-in Programs for Incidnet Detection and Verification. College Station, Texas: Department of Civil Engineering, Texas A\&M University.

Chue, R., H. Qi and D.H. Lee (2002). Mobile Sensor and Sample-Basd Algorithm for Freeway Incident Detection. Transportation Research Record: Journal of the Transportation Research Board (1811): 12-20.

Cook, A. R. (1974). Management of Urban Freeway Traffic. Canadian Journal of Civil Engineering (1): 141-149.

Cook, A. R. and C.M. Cleveland (1974). Detection of Freeway Capacity-Reducing Incidents by Traffic Stream Measurements. Transportation Research Record: Journal of the Transportation Research Board (495): 1-11.

Cox, A.R., R. Fenton and P. Carlock (1999). Incorporating Contingency Risk into Project Cost and Benefit Baselines: A Way to Enhance Realism. Proceedings of the 9th Annual Symposium of the International Council of Systems Engineering (INCOSE), Brighton, England.

Crabtree, J.D., and N. Stamatiadis (2007). Dedicated Short-Range Communications Technology for Freeway Incident Detection. Transportation Research Record: Journal of the Transportation Research Board (2000): 59-69.

Dia, H., and R. Geoff (1997). Development and Evaluation of Neural Network Freeway Incident Detection Models Using Field Data. Transportation Research Part C (1): 203217.

Dixon, K., and C. Wang (2002). Development of Speed Reduction Strategies for Highway Work Zones. Final Report FHWA-GA-02-9810. FHWA, U.S. Department of Transportation.

Dowling, R. (2015). Impacts Assessment of Dynamic Speed Harmonization with Queue Warning. FHWA, U.S. Department of Transportation. 
Dudek, C. L., C.J. Messer and N.B. Nuckles (1974). Incident Detection on Urban Freeway. Transportation Research Record (495): 12-24.

Elfar, A., A. Talebpour and H. S. Mahmassani (2016). Analyzing Queue Warning in Connected Environment: A Micro Simulation Approach. Transportation Research Record, Journal of Transportation Research Board.

Engen, T., and T. Haugen (2001). Evaluation of Queue Detection in Oslo. Proceedings of the 8th ITS World Congress. Sydney, Australia.

Enterprise (2014). Queue Warning Systems in Work Zones. Available: enterprise.prog.org/Projects/2010.../QueueWarning_Summary_FINAL_June2014.pdf.

Fambro, D. B., and G. P. Ritch (1979). Automatic Detection of Freeway Incidents During Low Volume Conditions. College Station, TX: Texas Transportation Institute, Texas A\&M University System.

Fariello, B. (2002). TransGuide Update: After Model Deployment. TransGuide Home Page. Available: http://www.transguide.dot.state.tx.us/docs/transguide_update.html.

FHWA (2010). Federal Highway Administration Traffic Incident Management Handbook.

FHWA (1998). Queue Length Detector Reduces Risk of Rear-End Accidents in Work Zones. Available: http://www.tfhrc.gov/focus/archives/Fcs498/048chips.htm.

FHWA (2015). Near-Term V2I Transition and Ohasing Analysis, Life Cycle Cost Model, User Guide, Washington, D.C.

Fishburn, P. C. (1976). Additive Utilities with Incomplete Product Set: Applications to Priorities and Assignments. Baltimore : Operations Research Society of America.

FLIR (1998). E313 Antwerpen to Hasselt, Belgium Case Study. Available: http://www.traficon.com/inhoud_1_4_3_1.lasso?Case_ID=58.

Forbes, J.G., and F.L.Hall (1990). The Applicability of Catastrophe Theory in Modeling Freeway Traffic Operations. Transportation Research Part A (24): 335-334.

Gall, A.I., and F.L. Hall (1989). Distinguishing Between Incident Congestion and Recurrent Congestion: A Proposed Logic. Transportation Research Record: Journal of Transportation Research Board (1232): 1-8.

Garber, N. J. and S. T. Patel (1995). Control of Vehicle Speeds in Temporary Traffic Control Zones Using Changeable Message Signs with Radar. Transportation Research Record: Journal of Transportation Research Board (1509): 73-81. 
Gettman, D. (2008). Surrogate Safety Assessment Model and Validation: Final Report. FHWA-HRT-08-051, Federal Highway Administration, U.S. Department of Transportation, Washington, D.C.

Gettman, D., and L. Head (2003). Surrogate Safety Measures From Traffic Simulation Models Final Report. FHWA-RD-03-050, Federal Highway Administration, U.S. Department of Transportation, Washington, D.C.

Gomez, G., A. May and R. Horowitz (2004) .Calibration of VISSIM for a Congested Freeway Final Report. California PATH Program, Institute of Transportation Studies, University of California, Berkeley, California.

Gordon, S., and J. Trombly (2014). Deployment of Intelligent Transportation Systems: A Summary of the 2013 National Survey Results. Final Report. FHWA-JPO-14-146, Federal Highway Administration, U.S. Department of Transportation, Washington, D.C..

Hadi, M. (2008). Evaluation Tools to Support ITS Planning Process. Final Report Prepared for FDOT Research Center by Florida International University, Miami, FL.

Hadi, M. (2017). Framework to Support Transportation Agency ITS Infrastructure and ITS Legacy Decisions with Consideration of Connected Vehicle Deployment and Automated Vehicle Initiatives. Final Report Prepared for the National Cooperative Highway Research Program Transportation Research Board of the National Academies of Sciences, Engineering, and Medicine, washington, D.C.

Hall, F.L, Y. Shi and G. Atala (1993). Testing of the McMaster Incident Detection Algorithm Under Recurrent Congestion. Transportation Research Record: Journal of Transportation Research Board (1394): 1-7.

Hamilton, B. (2015). Safety Pilot Model Deployment-Sample Data Handbook Version 1.3. Prepared for US Department of Transportation Research and Technology Innovation Administration Intelligent Transportation Systems-Joint Program Office.

Hellinga, B., and G. Knapp (2000). Automatic Vehicle Identification Technology-Based Freeway Incident Detection. Transportation Research Record: Journal of Transportation Research Board 1727): 142-153.

Highway Capacity Manual (HCM) (2010). Transportation Research Board (TRB), National Research Council, Washington, D.C.

Hokkanen, J., and P. Salminen (1997). Choosing a Solid Waste Management System Using Multicriteria Decision Analysis. European Journal of Operational Research (98): 19-36. 
Hossan, S., H. Asgari and X. Jin (2016). Investigating preference heterogeneity in Value of Time (VOT) and Value of Reliability (VOR) Estimation for Managed Lanes. Transportation Research Part A (94): 638-649. Available:

https://www.iteris.com/cvria/html/applications/applications.html.

Hwang, C. L., and K. P. Yoon (1981). Multiple Attribute Decision Making: Methods and Applications. Springer.

Iqbal, Sh., M. Hadi and Y. Xiao (2017). Assessment of Link Level Variation of Connected Vehicle Market Penetration. Proceedings of the 96th Transportation Research Board Annual Meeting, Washington D.C.

Jato-Espino, D. (2014). A Review of Application of Multi-Criteria Decision Making Methods in Construction. Automation in Construction (45): 151-162.

Iowa State University Center for Transportation Research (2002). Potential Safety Benefits of Intelligent Transportation Systems (ITS) Technologies-Results of Previous Research. Available: http://www.ctre.iastate.edu/pubs/semisesq/session2/preston.

Karantanos, M. and A.H.F. Chow (2015). Incident Detection for Congested Motorways . Proceedings of the $94^{\text {th }}$ Transprtation Research Board 2015 Annual Meeting, Washington D.C.

Kay, S. (1998). Fundamentals of Statistical Signal Processing Volume II: Detection Theory.

Knoop, V. L., H. J. Van Zuylen and S. P. Hoogendoorn (2009). Microscopic Traffic Behavior Near Incidnets. Procceiding of Second Sino-Dutch Joint Workshop in Transportation and Traffic Study, Shanghai, China.

Levin, M. and G . Krause (1979). Incident-Detection Algorithms, Part1. Off-Line Evaluation. Transportation Research Record: Journal of Transportation Research Board (722): 49-64.

Levin, M. and G. M. Krause (1978). Incident Detection: A Bayesian Approach. Transportation Research Record: Journal of Transportation Research Board (682): 52-58.

Li, Y., Y. Bai and U. Firman (2010). Determining the Effectiveness of PCMS on Reducing Vehicle Speed in Rural Highway Work Zones. Proceedings of the $89^{\text {th }}$ Transportation Research Board Annual Meeting, Washington, D.C.

Lin, C. K., and G.L. Chang (1998). Developement of Fuzzy-Expert System for Incident Detection and Classification. Mathematical and Computer Modelling (9): 9-25. 
Macharis, C., and A. Bernardini (2015). Reviewing the Use of Multi-Criteria Decision Analysis for the Evaluation of Transport Projects: Time for A Multi-Actor Approach. Transport Policy (37): 177-186.

Mahmassani, H. S. and C. Hass (1998). Evaluation of Incident Detection Methodologies. Final Report. Center for Transportation Research, University of Texas at Austin, Austin, TX.

Martin, P.T. (2009). Incident Detection Algorithm Evaluation. Filal Report. Utah Department of Transportation.

May, A.D. (1990). Traffic Flow Fundamentals. Prentice Hall Inc., Englewood Cliffs: New Jersey.

McCoy, P. T., J. A.Bonneson and J. A. Kollbaum (1995). Speed Reduction Effects of Speed Monitoring Displays with Radar in Work Zones on Interstate Highways. Transportation Research Record: Journal of Transportation Research Board (1509): 6572.

Medina, J. C., E. G. Lo and R. F. Benekohal (2014). Multiattribute Decision-Making Methods for Optimal Selection of Traffic Signal Control Parameters in Multimodal Analysis. Transportation Research Record: Journal of the Transportation Research Board (2438): 64-71.

Mouskos, K. C. (1998). Evaluation of the TRANSMIT System. Final Report. Institute for Transportation, New Jersey Institute of Technology.

Mussa, R.N. (1997). Evaluation of Driver-Based Freeway Incident Detection. ITE Journal (67): 33-40.

Nam, D. H. and D. R. Drew (1999). Automatic Measurement of Traffic Variables for Intelligent Transportation Systems Applications. Transportation Research Part B (33): 437-457.

National Transportation Safety Board (2001). Safety Recommendation H-01-10 and H$01-11$.

National Transportation Safety Board (NTSB) (2001). Vehicle-and Infrastructure-Based Technology for the Prevention of Rear-End Collisions. Washington, D.C.

Nemsky, T. P. (2014). ITS Work Zone Experiences in Southern Illinois. Webinar Presentation on Work Zone Intelligent Transportation Systems. Sponsored by FHWA, U.S. Department of Transportation.Available: http://www.ops.fhwa.dot.gov/wz/webinars/itsoverview013014/nemsky/index.htm. 
Neufville, R.D. and S. Scholtes (2011). Flexibilty in Engineering Design. MIT Press, Cambridge, Massachusetts.

Parkany, E., and D. Bernstein (1995). Design of Incident Detection Algorithms Using Vehicle-to-Roadside Communication Sensors. Transportation Research Record: Journal of Transportation Research Board (1494): 67-74.

Parkany, E. and C. Xie (2005). A Complete Review of Incident Detection Algorithms \& Their Deployment: What Work and What Doesn't. Final Report. The New England Transportation Consortium, Amherst, MA.

Payne, H. J., and S. C. Tignor (1987). Freeway Incident-Detection Algorithms Based on Decision Trees with States. Transportation Research Record: Journal of Transportation Research Board (682): 30-37.

Payne, H.J., E.D. Helfenbein and H. C. Knobel (1976). Development and Testing of Incident Detection Algorithms, Volume 2 : Research Methodology and Detailed Results. Final Report. Report No. FHWA-RD-76-20, FHWA.

Pedrycz, W. (1994). Why Triangular Membership Functions?. Fuzzy Sets and Systems (64): 21-30.

Pesti, G. (2013). Simulation Based Evaluation of Dynamic Queue Warning System Performance. Proceedings of the $92^{\text {nd }}$ Transportation Research Board Annual Meeting, Washington, D.C.

Peterson, S., E. Minge and Ch. Iverson (2014). Queue Warning and Travel Time Estimation near a Work Zone. Proceedings of the $93^{\text {rd }}$ Transportation Research Board Annual Meeting, Washington, D.C.

Petty, K. F., A. Skabardonis and P.P. Varaiya (1997). Incident Detection with Probe Vehicles: Performance, Infrastructure Requirements and Feasibility. Transportation

Systems :A Proceedings Volume from the 8th IFAC/IFIP/IFORS Symposium (30): 125130.

Pulugurtha, S. S. (2002). Simulating and Analyzing Incidents Using CORSIM and VISSIM Traffic Simulation Software. Proceedings of the $7^{\text {th }}$ International Conference on Applications of Advanced Technologies in Transportation (AATT), Cambridge, Massachusetts.

Qiang H. (2009). Estimating Incident Detection Time Based on Incident Management and Traffic Detector Data. Proceedings of the $89^{\text {th }}$ Transportation Research Board Annual Meeting, Washington, D.C. 
Rahman, Z., and S. P.Mattingly (2014). Macroscopic Evaluation of Incident-Induction Deriver Behavior Changes. Proceedings of the Symposium Celebrating 50 Years of Traffic Flow Theory, Portland, Oregon.

Release Indiana Department of Transportation (2000). Press Clark County I-65 Exit 4 Solution Proves Successful. Availabele: http://www.state.in.us/dot/motoristinfo/trafficwise/wnew_otherindiana_news_04.html.

Release Pennsylvania Turnpike Commission (1999). Press Travel Advisory: Turnpike Starts 10-Mile Total Reconstruction in Franklin County. Available: http://www.paturnpike.com/pressrel/ta090399.htm.

Richards, S. A., R. C. Wunderlich and C. L.Dudek (1986). Field Evaluation of Work Zone Speed Control Techniques. Transportation Research Record: Journal of Transportation Research Board (1035): 66-78.

Ritchie, S. G., and R. L.Chue (1993). Simulation of Freeway Incident Detection Using Artificial Neural Networks. Trasportation Research Part C (1): 313-331.

Rompis, S. Y., F. G. Habtemichael and M. A. Cetin (2014). Methodology for Calibrating Microscopic Simulation for Modeling Traffic Flow under Incidents. Proceedings of IEEE 17th International Conference on Intelligent Transportation Systems (ITSC), Qingdoa, China.

Roy, B. (1968). Classement et Choix en Présence de Points de vue Multiples (la Méthode ELECTRE). La Revue d'Informatique et de Recherche Opérationelle (RIRO)(8): 57-75.

Saaty, T. L. (2010). The Analytic Hierarchy Process. McGraw-Hill, New York.

Sabra, Z. A. (2010). Balancing Safety and Capacity in an Adaptive Signal Control System-Phase 1. Final Report. FHWA-HRT-10-038, Federal Highway Administration, U.S. Department of Transportation, Washington, D.C.

SAE International (2009). Dedicated Short Range Communication (DSRC) Message Set Dictionary, SAE J2735.

San Cristobal, J. (2013). Critical Path Definition Using Multicriteria Decision Making: PROMETHEE Method. Journal of Construction Engineering and Management 0290: $158-163$.

Shue, J. B. (2013). Microscopic Traffic Behavior Modelling and Simulation for LaneBlocking Arterial Incidents. Transportmetrica A: Transport Science (9): 335-357.

Skabardonis, A., T. Chira-chavala and D. Rydzewski (1998). The I-880 Field Experiment: Effectiveness Of Incident Detection Using Cellular Phones. Final Report. PATH Program, University of California, Berkeley, California. 
Stephanedas, Y.J., and X. Liu (1995). Artifical Neural Networks for Freeway Incident Detection . Transportation Research Record: Journal of Transportation Research Board (1): 91-97.

Stephanedes, Y., J. Chassiakos and P. Athanasios (1991). Low Pass Filter For Incident Detection .Proceedings of the 2nd International Conference on Applications of Advanced Technologies in Transportation Engineering, ASCE : 378-382.

Stephanedes, Y. J., and A. P. Chassiakos (1993). Application of Filtering Techniques for Incident Detection. Journal of Transportation Engineering (119): 13-26.

Stephanedes, Y. J., and A. P. Chassiakos (1993). Freeway Incident Detection Through Filtering. Transportation Research Part C (1): 219-233.

Stephanedes, Y. J., and L. Xiao (1995). Artificial Neural Networks for Freeway Incident Detection. Transportation Research Record: Journal of Transportation Research Board (1494): 91-97.

Stephanedes, Y. J., A. P. Chassiakos and P. G. Michalopoulos (1992). Comparative Performance Evaluation of Incident Detection Algorithms. Transportation Research Record: Journal of Transportation Research Board (1360): 50-57.

Stephens, D. (2015). Intelligent Network Flow Optimization (INFLO) Prototype Seattle Small-Scale Demonstration Report. Final Report. ITS Joint Program Office, Research And Innovative Technology Administration (RITA), United States Department of Transportation, Washington, D.C.

Stevanovic, A., J. Stevanovic and C. Kergaye (2011). Optimizing Signal Timimg to Improve Safety of Signalized Arterials. Proceedings of 3rd International Conference on Road Safety and Simulation, Indianapolis, USA.

Sullivan, W., and S. LeClair (1985). Justification of Flexible Manufacturing Systems. Proceedings of Autofact '85 Conf., Society of Manufacturing Engineers.

Sullivan, W.G., and R.G. Orr (1982). Monte Carlo Simulation Analyzes Alternatives in Uncertain Economy. Industrial Engineering (14).

FHWA (1999). Team Study Tour Innovative Traffic Control Technology and Practice in Europe Final Report. Federal Highway Administration, International Technology Exchange Program.

Teng, H., and Y. Qi (2003). Application of Wavelet Technique to Freeway Incident Detection. Transportation Research Part C (11): 289-308. 
Toppen, A. and K. Wunderlich (2003). Travel Time Data Collection for Measurement of Advanced Traveler Information Systems Accuracy. Final Report. Federal Highway Administration, Project No. 0900610-D1.

Trajectory Conversion Algorithem (2014). VISSIM Software User Manual. Federal Highway Administration, U.S Department of Transportation.

Ullman, G. L., V. Iragavarapu and R. E. Brydia (2016). Safety Effects Of Portable EndOf-Queue Warning System Deployments At Texas Work Zones. Transportation Reseacrh Record, Journal of Transportation Research Board (2555): 46-52.

Vanajakshi, L. D., B. M. Williams and Rilett L. R.(2009). Improved Flow-Based Travel Time Estimation Method from Point Detector for Freeways. Journal of Transportation Engineering: 26-36.

Venkata Rao, R. (2006). Decision Making in the Manufacturing Environment. Springer, Gujarat State, India.

VISSIM 5.4 (2012). User Manual. Karlsruhe, Germany : PTV AG.

Viti, F. (2008). Speed and Acceleration Distributions at A Traffic Signal Analyzed from Microscopic Real and Simulated Data. Proceedings of the 11th International IEEE Conference on Intelligent Transportation Systems. Beijing, China.

Wiles Poonam, B. (2003). Advance Warning of Stopped Traffic on Freeways: Current Practices and Field Studies of Queue Propagation Speeds. Final Report. Texas Transportation Institute, The Texas A\&M University System, College Station, Texas.

Woody, T. (2006). Calibrating Freeway Simulation Models in VISSIM. Final Report. University of Washington, Seattle, WA.

Wright. J. (2014). National Connected Vehicle Field Infrastructure Footprint Analysis. Final Report. FHWA-JPO-14-125. Federal Highway Administration.

Wu, W., H. Wang and P. Alluri (2013). Automatic Incident Detection Using Real-Time Traffic Detector Data. Final Report. Department of Civil and Environmental Engineering, Florida International University, Miami, Florida.

Xiao, Y. (2011). Hybrid Approaches to Estimating Freeway Travel Times Using Point Traffic Detector Data. Florida International University, Miami, FL.

Yang, S., S. Luou and M. Hadi (2007). Risk Analysis to Account for Uncertainty in Benefit-Cost Evaluations of Intelligent Transportation Systems. Journal of the Transportation Research Board, Transportation Research Record, Transportation Research Board (2035): 187-194. 
Yeh, C. H., and H. A. Deng (2004). Practical Approach To Fuzzy Utilities Comparison In Fuzzy Multi-Criteria Analysis. International Journal of Approximate Reasoning (35): 179-174.

Yu, W. (2015). Arterial Road Incident Detection Based on Time-Moving Average Method in Bluetooth-Based Wireless Vehicle reidentification System. Journal of Transportation Engineering (141).

Zadeh, L. A. (1965). Fuzzy Set. Information and Control (8): 338-353.

Zech, W. C., S. B. Mohan and J.Dmochowski (2008). Evaluation of Messages on Changeable Message Signs as a Speed Control Measure in Highway Work Zones. Practical Periodical on Structural Design and Construction (13): 11-18.

Zhang, W. (2006). Freeway Travel Time Estimation Based on Spot Speed Measurements. Final Report. Virginia Polytechnic Institute and State University, Blacksburg, Virginia. 
VITA

\section{SAMANEH KHAZRAEIAN}

$2010 \quad$ B.Sc., Civil Engineering

Iran University of Science and Technology, Tehran, Iran

2012 M.Sc., Civil Engineering (Transportation Engineering)

Iran University of Science and Technology, Tehran, Iran

2017 Doctoral Candidate and Research Assistant, Transportation

Engineering

Florida International University, Miami, Florida

- 2017 Outstanding Graduate Student Runner-Up, FIU College of Engineering and Computing

- 2017 Outstanding Graduate Student, FIU Civil and Environmental Engineering Department

- 2017 Third Place, Poster Competition, FAV Summit

- 2017 Anne Brewer Scholarship, ITS Florida

- 2017 Leadership Legacy Scholarship, WTS International

- 2017 Leadership Legacy Award, WTS South Florida

- 2017 WTS International Chair Shadow, WTS International

- 2017 Eno Fellowship, Eno Foundation/ Eno Center for Transportation

- 2017 Graduate Leader of the Year Award, Florida International University

- 2017 Dissertation Year Fellowship, Florida International University

- 2016 Featured in the Transportation YOU Newsletter, WTS International

- 2016 Best Student Paper Award, TRB $15^{\text {th }}$ International Conference on Managed Lanes

- 2016 Featured in the STRIDE Newsletter, University of Florida

- 2016 Third Place, 3Minute Thesis Competition-Mobility Category, 2016 UTC Conference

- 2015 University-Wide Scholarship Award, Florida International University

- 2015 Helene M. Overly Memorial Scholarship, WTS South Florida

- 2015 Best Student Chapter Award, FIU Council of Student Organizations (CSO) 
- 2014 Student Government Association (SGA) Award, Florida International University

- 2011 Distinctive Student Award, Iran University of Science and Technology

- 2011 Ranked $\mathbf{1}^{\text {st }}$ among Transportation Engineering Students, Iran University of Science and Technology

\section{PUBLICATIONS}

- S. Khazraeian, M. Hadi, Monte Carlo Simulation-Based Benefit-Cost Analysis Combined with Analytical Hierarchy Process to Support ITS Investment with Consideration of Connected Vehicle. Accepted for Presentation at the 97th Annual Meeting of the Transportation Research Board and considered for publication at the Transportation Research Record: Journal of the Transportation Research Board, 2018.

- S. Iqbal, S. Khazraeian, M. Hadi, Effect of Demand Variation on the Performance Measurements Utilizing Connected Vehicle Data. Accepted for Presentation at the 97th Annual Meeting of the Transportation Research Board and considered for publication at the Transportation Research Record: Journal of the Transportation Research Board, 2018.

- S. Khazraeian, M. Hadi, Y. Xiao, Safety Impacts of Queue warning in a Connected Vehicle Environment. Transportation Research Record: Journal of the Transportation Research Board, No.2621, 2017, pp. 31-37.

- S. Khazraeian, F. Koohifar, N. Kalantari, A Nonlinear Optimal Static Controller for Ramp Control (NOSCO). Proceedings of the 96th Annual Meeting of the Transportation Research Board, 2017.

- B. Aghdashi, S. Khazraeian, J. Trask, M. Hadi, N. Rouphail, Incorporating Adaptive (Traffic Responsive) Ramp Metering in the Highway Capacity Manual Context. Proceedings of the 96th Annual Meeting of the Transportation Research Board, 2017.

- S. Khazraeian, M. Hadi, Y. Xiao, Detection of Freeway Incidents Based on Vehicle Acceleration Measurements Using Connected Vehicle Data. Proceedings of the 95th Annual Meeting of the Transportation Research Board, Washington, D.C., January 2016.

- S. Khazraeian, Y. Xiao, M. Hadi, Application of the Upcoming HCM Managed Lane Procedure to Pylon-Separated Managed Lane Analyses, Proceedings of the 94th Annual Meeting of the Transportation Research Board, Washington, D.C., January 2015. 